\title{
SISTEMAS DE PREPARO DO SOLO: EFEITOS NO SOLO E NA PRODUÇÃO DE MILHO (Zea mays L.)
}

\author{
EURIDICE SACCHI
}

Orientador: Prof. Dr. KLAUS REICHARDT

Tese apresentada à Escola Superior de Agricultura "Luiz de Queiroz", da Universidade de São Paulo, para obtenção do titulo de Doutor em Agronomia. Área de Concentração: Solos e Nutrição de Plantas.

P I R A C I C A B A

Estado de São Paulo - Brasil

Maio, 1982 
$\overline{\mathrm{A}}$

\author{
Selma, \\ Nanci, \\ Luiz Carlos, \\ Rodrigo e \\ Juliana
}

DEDICO 


\section{AGRADECIMENTOS}

Ao Professor Dr. Klaus Reichardt, pela orienta çao e participação na minha formação científica.

Aos Professores Dr. Paulo Cesar Corsini e Dr. Walter Politano, pelas participações na realização deste tra balho.

Aos Professores Dr. Euclides Alexandrino de Sou za, Dr. Vicente de Paula Pereira e Antonio Carlos Manduca Fer reira, pelo apoio oferecido.

Ao Professor Dr. Romisio Geraldo Bouhid André, pela colaboração prestada.

Ao Professor Dr. Sérgio do Nascimento Kronka, pe la colaboração na realização das análises estatísticas.

A Escola Superior de Agricultura "Luiz de Quei roz", Piracicaba e Faculdade de Ciências Agrárias e Veteriná rias, Campus de Jaboticabal, pelas oportunidades e facilida des oferecidas.

Ao Laudemir D'Aquila, pela participação na con dução do experimento.

A Izilda Maria de Carvalho, pelos serviços de desenho.

A Maria de Lourdes Moretto, pela participação na composição do texto:

E a todas as pessoas que, de uma forma ou de ou tra, tenham contribuido para a realização deste trabalho. 


\section{INDICE}

Pāgina

LISTA DE TABELAS...................... vi

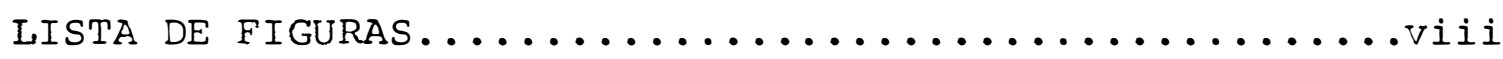

RESUMO $\ldots \ldots \ldots \ldots \ldots \ldots \ldots \ldots \ldots \ldots \ldots \ldots \ldots \ldots \ldots \ldots \ldots \ldots \ldots \ldots \ldots$

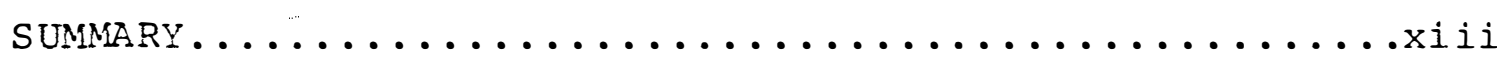

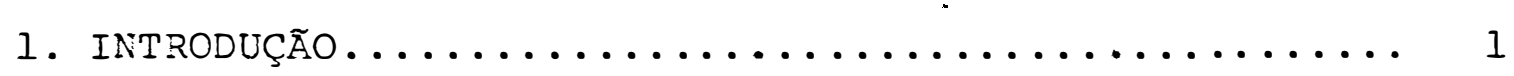

2. REvisÃo de LiteratURA....................... 3

3. MATERIAL E METOdO....................... 8

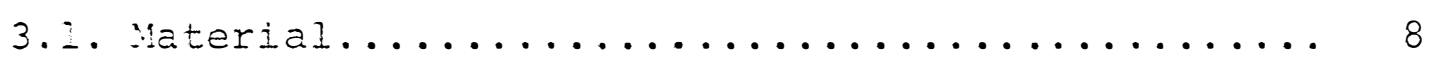

3.1.1. Area de estudo................ 8

3.1.2. Solos ..................... 9

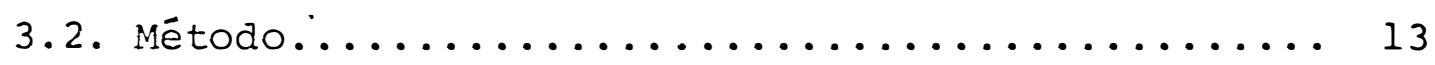

3.2.1. Estabelecimento dos tratamentos....... 13

3.2.2. Delineamento estatístico........... 13

3.2.3. Instalação e condução do experimento... 13

3.2.3.1. Preparo do solo............ 14

3.2.3.2. Semeadura e adubação......... 14

3.2.3.3. Tratos culturais........... 15

3.2.3.4. Colheita............... 15

3.2.3.5. Coleta das amostras de solo.... 15

3.2.3.6. Medida da umidade no campo.... 15

3.2.4. Análises de laboratório............ 16

3.2.4.1. Amostras com estrutura indefor mada.................. 17 
3.2.4.2. Amostras com estrutura deforma

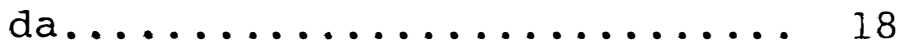

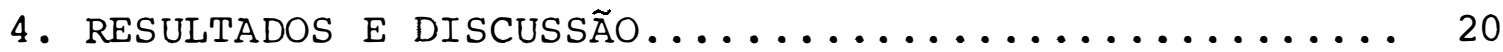

4.1. Características do solo determinadas antes da instalação dos experimentos.............. 20

4.2. Características dos solos com a realização do

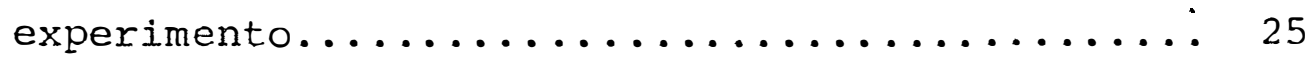

4.2.1. Latosol Vermelho Escuro - fase arenosa.. 25

4.2.2. Latosol Roxo...................... 37

4.2.3. Análise conjunta das características dos

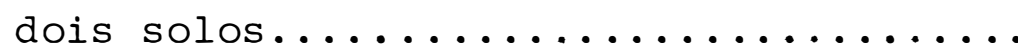

4.3. Algumas características hidricas do Latosol Ver melho Escuro - fase arenosa, determinadas nos tratamentos $\mathrm{T}_{1}$ (preparo convencional de aração e gradagem) e $\mathrm{T}_{5}$ (cultivo mínimo)...........4 48

4.4. Produção de grãos...................... 64

4.5. Análise do custo da modalidade de preparo do so lo em função de suas produções.............. 70

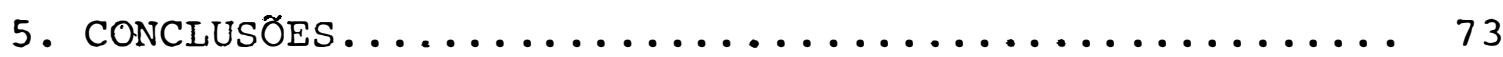

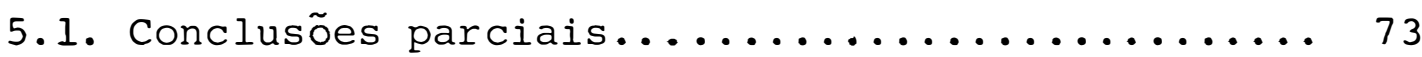

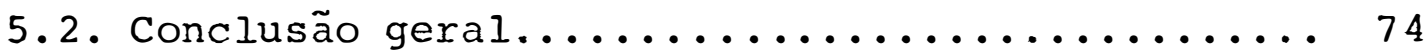

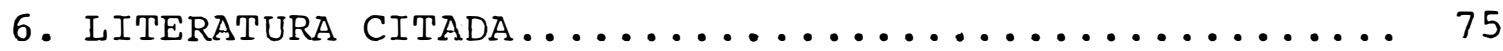

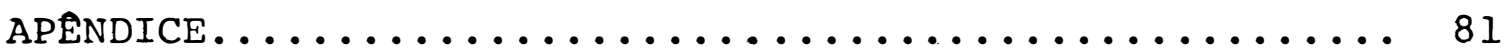




\section{LISTA DE TABELAS}

TABELA

Pāgina

1 - Dados climáticos e balanço hídrico mensal, segun do Thornthwaite e Matter (1955) da região de Jabo ticabal. (CAD.: $125 \mathrm{~mm}) \ldots \ldots \ldots \ldots \ldots \ldots$

2 - Separados do solo e classe textural do Latosol Vermelho Escuro - fase arenosa............... 21

3 - Separados do solo e classe textural do Latosol

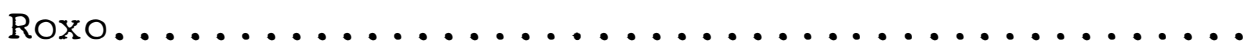

4 - Características físicas do Latosol Vermelho Escu ro - fase arenosa dos locais dos cinco tratamen

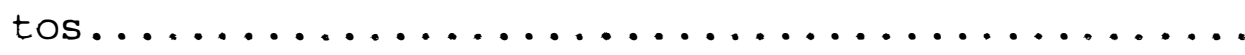

5 - Características físicas do Latosol Roxo dos lo

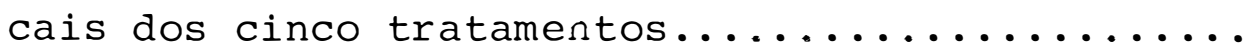

6 - Características físicas do Latosol Vermelho Escu ro - fase arenosa com a aplicação dos trạtamentos

7 - Características físicas do Latosol Roxo com a apli

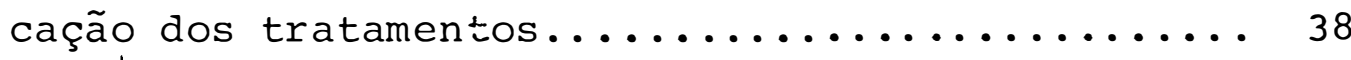

8 - Valores da umidade em volume $\left(\theta \mathrm{cm}^{3} \cdot \mathrm{cm}^{-3}\right)$ em fun ção da variação do potencial matricial para as di

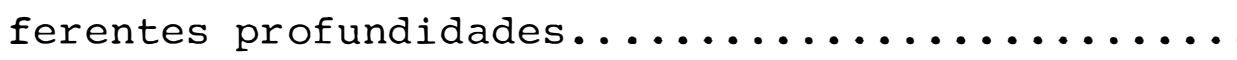

9 - Produção de milho em grãos no Latosol Vermelho Es curo - fase arenosa nos três anos agrícolas 1978/79, $1979 / 80$ e 1980/81, referentes aos tratamentos uti

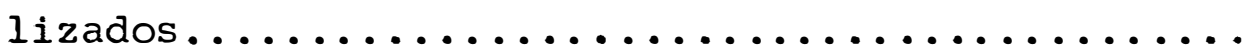

10 - Análise estatistica da produção de milho no Lato sol Vermelho Escuro - fase arenosa............ 
11 - produção de milho em grãos no Latosol Roxo nos três anos agrícolas 1978/79, 1979/80 e 1980/81, re ferentes aos tratamentos utilizados........... 68

12 - Análise estatística da produção de milho no Lato

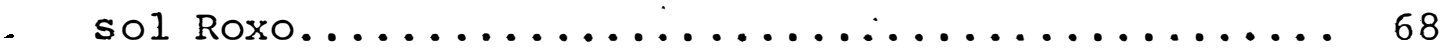

13 - Produção média de milho, custo da modalidade de preparo do solo e custo por quilograma de milho.. 71 


\section{LISTA DE FIGURAS}

FIGURA

Pāgina

1 - Balanço hídrico mensal da região de Jaboticabal,

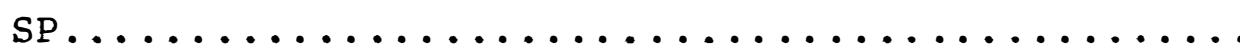

2 - Distribuição dos valores da densidade global em função da profundidade do Latosol Vermelho Escu ro - fase arenosa, para os anos de 1978 e 1979... 29

3 - Distribuição dos valores da densidade global em função da profundidade do Latosol Vermelho Escu ro - fase arenosa, para os anos de 1980 e 1981... 30

4 - Distribuição do espaço poroso e do material sóli * do do solo em função da profundidade para o trata mento $\mathrm{T}_{1}$ (preparo convencional, aração e graciagem) do Latosol Vermelho Escuro - fase arenosa.......

5 - Distribuição do esp̣aço poroso e do material sóli do do solo em função da profundidade para o trata mento $\mathrm{T}_{2}$ (subsolagem mais aração e gradagem) do Latosol Vermelho Escuro - fase arenosa......... 33

6 - Distribuição do espaço poroso e do material sóli do do solo em função da profundidade para o tratá mento $\mathrm{T}_{3}$ (duas gradagens) do Latosol Vermelho Es

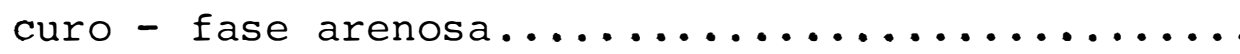

7 - Distribuição do espaço poroso e do material sólí do do solo em função da profundidade para o trata mento $\mathrm{T}_{4}$ (subsolagem mais duas gradagens) do Lato

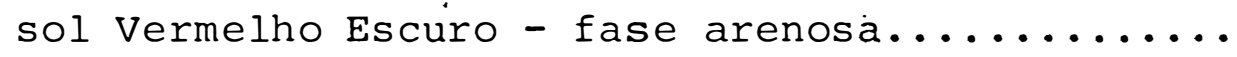


FIGURA

8 - Distribuição do espaço poroso e do material sóli do do solo em função da profundidade para o trata mento $\mathrm{T}_{5}$ (cultivo mínimo) do Latosol Vermelho Es

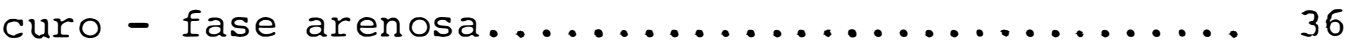

9 - Distribuição dos valores da densidade global em função da profundidade do Latosol Roxo, para os

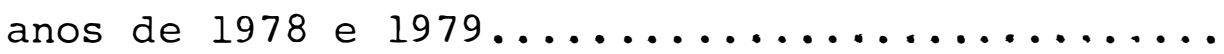

10 - Distribuição dos valores da densidade global em função da profundidade do Latosol Roxo, para os

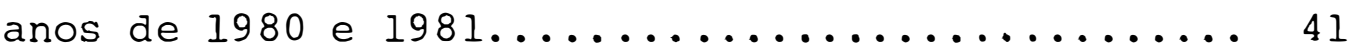

11 - Distribuição do espaço poroso e do material sóli do do solo em função da profundidade para o tratá mento $\mathrm{T}_{1}$ (preparo convencional, aração e gradagem)

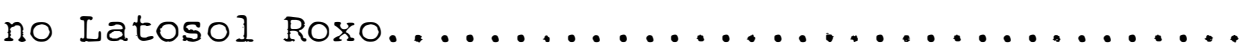

12 - Distribuição do espaço poroso e do material sóli do do solo em função da profundidade para o trata mentio $\mathrm{T}_{2}$ (subsolagem mais aração e gradagem) do

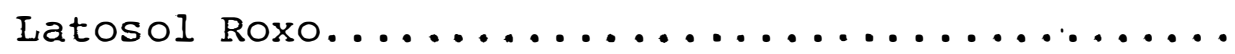

13 - Distribuição do espaço poroso e āo material sólí do do solo em função da profundidade para o trata mento $\mathrm{T}_{3}$ (duas gradagens) do Latosol Roxo....... 45

14 - Distribuição do espaço poroso e do material sóli do do solo em função da profundidade para o trata mento $\mathrm{T}_{4}$ (subsolagem mais duas gradagens) do Lato

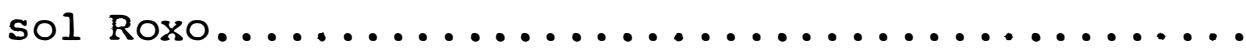

15 - Distribuição do espaço poroso e do material sóli do do solo em função da profundidade para o trata mento $\mathrm{T}_{5}$ (cultivo mínimo) do Latosol Roxo........ 
FIGURA

16 - Curvas de retenção de água - tratamento T $-1978 / 7951$

17 - Curvas de retenção de água - tratamento $T_{5}$ - 1978/79 51

18 - Curvas de retenção de água - tratamento $T_{1}$ - 1979/80 52

19 - Curvas de retenção de água - tratamento $T_{5}$ - 1979/80 52

20 - Curvas de retenção de água - tratamento $\mathrm{T}_{1}$ - 1980/81 53

21 - Curvas de retenção de água - tratamento $\mathrm{T}_{5}-1980 / 8153$

22 - Perfis de umidade do solo, em função da profundi dade e do tempo para o tratamento $\mathrm{T}_{1} \ldots . . . \ldots . .55$

23 - Perfis de umidade do solo, em função da profundi dade e do tempo para o tratamento $\mathbb{T}_{5} \ldots \ldots . \ldots . . .55$

24 - Perfis de umidade do solo, em função da profundi dade e do tempo para o tratamento $\mathrm{T}_{1} \ldots . . \ldots \ldots . .56$

25 - Perfis de umidade do solo, em função da profundí dade e do tempo para o tratamento $\mathrm{T}_{5} \ldots \ldots \ldots \ldots$

26 - Perfis de umidade do solo, em função da profundí dade e do tempo para o tratamento $T_{1} \ldots . . . . . .557$

27 - Perfis de umidade do solo, em função da profundi dade e do tempo para o tratamento $\mathrm{T}_{5} \ldots \ldots \ldots . . . .57$

28 - Variação do armazenamento de ãgua no solo em fun ção do tempo e da pluviosidade no período de de zembro de 1978 a março de $1979 \ldots \ldots \ldots \ldots \ldots \ldots \ldots \ldots$

29 - Variação do armazenamento de água no solo em fun ção do tempo e da pluviosidade no período de no vembro de 1979 a fevereiro de $1980 \ldots \ldots \ldots \ldots \ldots \ldots$ 
30 - Variação do armazenamento de água no solo em fun - ção do tempo e da pluviosidade no periodo de no vembro de 1980 a fevereiro de $1981 \ldots . . \ldots \ldots . . .63$

31 - Representação da produção de grãos do milho no lua tosol Vermelho Escuro - fase arenosa.......... 66

32 - Representação da produção de grãos do milho no La

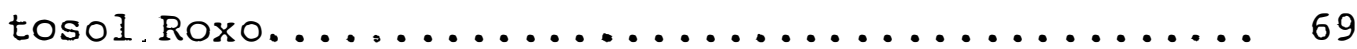




\section{SISTEMAS DE PREPARO DO SOLO: EFEITOS NO SOLO \\ E NA PRODUÇÃO DE MILHO (Zea mays L.)}

Autor: EURIDICE SACCHI

Orientador: Dr. KLAUS REICHARDT

RESUMO

Este trabalho foi desenvolvido para avaliar o efeito ce sistemas de preparo do solo sobre algumas proprieda des àc solo e sobre a produção de milho. Os tratamentos, apli cados com: seis repetições, durante três anos ao Latosol Verme Iho Escuro - fase arenosa e ao Latosol Roxo, foram os seguin tes: aração e gradagem, subsolagem seguida de aração e gradą. gem, duas gradagens, subsolagem seguida de duas gradagens e cultivo mínimo.

Os resultados obtidos não revelaram alterações nas propriedades do solo, nem na produção de milho, em conse qüência dos sistemas de preparo do solo; entretanto, as ten dências indicadas pelos dados concordam com as observações e com as conclusões contidas na bibliografia, que afirmam que o cultivo mínimo pode modificar favoravelmente as condições fí sicas do solo e a produção. A confirmação dessa hipótese fí cou, no entanto, dependente da repetição do experimento por períodos mais longos. 
SOIL MANAGEMENT SYSTEMS: EFFECTS ON THE SOIL AND CORN YIELD

Author: EURIDICE SACCHI

Adviser: Dr. KLAUS REICHARDT

SUMMARY

This work was carried out in two soil types ("Latosol Vermelho Escuro - fase arenosa" and "Latosol Roxo") with the objective of evaluating the effect of land preparation systems on some soil properties and on corn yield. The following treatments (with six replications), during a period of three years, were studied: plowing and cisc harrowing, subsoiling followed by plowing and disc harrowing, double disc harrowing, subsoiling followed by double disc harrowing; and minimum tillage system.

The results obtained did not show changes in the soil properties and corn yield as a consequence of the land preparation systems, however the tendency of data is in agreement with the observation and conclusions existing in the bibliography that the minimum tillage system can favourable modify the physical properties of the soil and the crop yield. The confirmation of this hypothesis, however, became dependent upon the repetition ot the experiment for longer periods. 


\section{INTRODUÇAO}

Solos intensivamente cultivados por longos pe ríodos, geralmente, apresentam modificações em suas proprieda des fisicas, as quais influem negativamente sobre a produção das culturas.

Esse fato sugerido pela observação está comprọ vado pela pesquisa, que tem demonstrado, também, que as alte rações das propriedades do solo variam em função da modalida de de preparo e da natureza do próprio solo.

Atualmente, a demanda de alimento e de matéria prima assume proporções preocupantes, em face da taxa de cres cimento populacional. Porisso, a escolha de sistemas conser vacionistas de manejo, que proporcionem altas produções a bai xo custo, constitui um sério objeto para a pesquisa agronômi ca.

Com base na afirmação de que o sistema de prepa ro do solo é de grande importância para a manutenção de suas condições físicas, assim como para a obtenção de altas produ 
ções (BAVER et alii, 1972), desenvolveu-se este trabalho com os seguintes objetivos especificos: estudar o efeito das mobi lizações sobre as propriedades físicas do solo e sobre a pró dução. Com os resultados obtidos, pretende-se contribuir pa ra a escolha do sistema de preparo mais adequado à cultura do milho, em solos de ocorrência freqüente no Município de Jabo ticabal. 


\section{REVISÃO DE LITERATURA}

As modificações do solo causadas pelo cultivo têm sido, há várias décadas, motivo de estudo porque a maio ria delas tem se revelado prejudicial à sua capacidade de pró dução. As pesquisas desenvolvidas nesse sentido têm normal mente objetivado identificar as diferenças nas alterações prô vocadas pelos distintos tipos de culturas e de seus sistemas de cultivo. E neste escopo que os efeitos das modalidades de preparo do solo para cultura do milho também tem sido investi gados.

Em 1946 experimentos comparando o sistema tradi cional de aração e gradagem com os de aração com arado espe cial para solos cobertos com grama, cultivador rotativo e cul tivador leve de superficie, executados por PAGE et alii (1946) revelaram a superioridade do sistema tradicional. Esta supe rioridade, mostrando sempre a existência da maior produção quando se empregava a aração e gradagem, também foi verifica da por diversos pesquisadores em experimentos realizados pos 
teriormente (ALOISI SOBRINHO e VAZ DE ARRUDA, 1960; MARQUES e BERTONI, 1961; PRIHAR e VAN DOREN, 1967; BENATTI et ali $i$, 1977) .

Resultados divergentes, onde não se observaram qualquer tipo de superioridade na produção de grãos quando se comparavam essas diferentes modalidades de preparo do solo, foram obtidos pelos pesquisadores JOHNSON e TAYLOR (1960), TRIPLETT et alii (1964), VAN DOREN et alii (1976), NELSON et alii (1977) e ORTOLANI (1977). Divergindo também destes últi mos pesquisadores citados, SWAMY et alii (1960), JONES et alii (1968), PASTANA (1972) e BENEZ (1980) obtiveram resultados mostrando a maior produção de milho com o emprego do cultivo minimo. Verifica-se portanto, a existência de grande diver gência entre os dados mostrados pela literatura, fato que tal vez possa ser atribuído às condições em que os experimentos foram realizados. As diferenças de altitude e longitude, de climas, de solos, de infestações por ervas daninhas, pragas e doenças podem muito provavelmente alterar substancialmente os resultados dos experimentos realizados.

Com respeito a aplicação da subsolagem, o seu emprego adicionado ao da aração e gradagem não produziu o de sejado aumento significativo de produção de milho, ocorrendo em certos casos até redução da produção (TARSON et alii, 1960). Ainda quanto ao comportamento da cultura devese registrar que as diferentes modalidades de preparo do solo provocam também distintas modificações no sistema radicular (PRIHAR e VAN DOREN, 1967). Na germinação e no crescimento 
das plantas (BOWERS e BATEMAN, 1960 e SWAMY et alii, 1960). Os experimentos de SWAMY et alii (1960) mostraram que o culti vo mínimo afetou negativamente a germinação e o crescimento das plantas em condições de solos argilosos, provocando a pre sença de planteis muito desiguais; contudo, nos solos de tex tura média e grossa, os resúltados mostraram maior adequação do cultivo mínimo.

Quanto aos efeitos das modalidades de preparo do solo para a cultura do milho, sobre as suas propriedades, a bibliografia disponível mostra a ocorrência de modifica ções, principalmente nas propriedades físicas. PAGE et alii (1946) e STEPHEN et alii (1967) identificaram diferenças nas alterações da porosidade, aeração e da infiltração da água.

Os experimentos de MACHADO (1976) e GOMES et alii (1978) mostraram que o aumento da intensidade da movimen tação do solo provoca redução na porosidade total e macroporo sidade e um aumento concomitante nos valores da densidade glo bal da camada superficial do solo.

Os efeitos das modalidades de preparo do solo que provocam maiores aumentos de densidade global estão liga dos a ocorrência de maior compactação do solo. Quando a compactação se torna acentuada ela provoca modificações no de senvolvimento do sistema radicular das plantas, por principal mente, reduzir os movimentos do ar e da água do solo, sendo que esta redução afeta também a disponibilidade de nutrien tes, (DAY e HOLMGREEN, 1952; TROUSE e HUMBERT, 1961; PHILLIPS e DON KIRKAN, 1962 e WITTSELL e HOBBS, 1965). Essa existēn 
cia de condições com reduzida aeração afeta substancialmente o desenvolvimento do milho, provocando diminuição drástica na produção de grãos (WILLIASON, 1964). Segundo este autor, os valores de difusão de oxigênio situado ao redor de $5 \times 10^{8}$ $\mathrm{g} / \mathrm{cm}^{2} \cdot \mathrm{min}$, provocaram redução na produção em cerca de $75 \%$. Considerando os efeitós sobre a capacidade de retenção da água no solo, os dados experimentais obtidos por BLEVINS et alii (1971) e LAL (1976) revelaram que o plantio direto, o qual provoca a menor mobilização do solo, proporcio nou as condições para maior retenção da água, principalmente na porção mais superficial do solo. Este fato, de acordo com BAEUMER e BAKERMANS (1973), está ligado ao maior acúmulo de matéria orgânica na superfície do solo, cuja presença foi con dicionada pela maior cobertura da superfície proporcionada pe lo plantio direto, principalmente para os solos arenosos.

A velocidade de infiltração e a desagregação são características do solo que também são afetadas pelas diferen tes modalidades de preparo do solo, sendo que a primeira é me nor quạdo' o sistema convencional de aração e gradagem é com parado ao de plantio direto (CANNEL e FINNEY, 1973 e MACEDO e BRAUM, 1978) e a segunda, aumenta com maior mobilização do solo (MARQUES e BERTONI, 1961; BENATTI et alii (1977) e ELTZ et alii, 1977), fato este associado tambén à ocorrência de maiores perdas pela erosão.

Finalmente, considerando que a maioria das alte rações do comportamento do solo provocadas pela sua mobiliza ção são decorrentes da modificação da estrutura, CORSINI (1974) 
desenvolveu experimentação no sentido de eleger uma caracte ristica que melhor indicasse as possiveis diferenças estrutu rais do solo, obtendo resultados que estabeleceram a conduti vidade hidráulica. 
3. MATERIAL E MÉTODO

\subsection{Material}

3.1.1. Área de estudo

A área escolhida para a instalação dos experí mentos está localizada na Faculdade de Ciências Agrárias e Ve terinárias - UNESP, no município de Jaboticabal - SP, que se situa entre $21^{\circ} 07^{\prime}$ e $21^{\circ} 20^{\prime}$ de latitude $s$ e $48^{\circ} 10^{\prime}$ e $48^{\circ} 30^{\prime}$ de longitude WGr.

O relevo regiona]. é suavemente ondulado, onde as latitudes máximas estão situadas ao redor de $620 \mathrm{~m}$ e as mí nimas, de $500 \mathrm{~m}$. A altitude dos locais do experimento é de aproximadamente $575 \mathrm{~m}$. As vertentes são muito longas e a de clividade pertence à classe B.

o clima é do tipo Cwa, segundo a classificação de Köppen, denominado mesotérmico de inverno seco. A tempe ratura do mês mais quente é superior a $22^{\circ} \mathrm{C}$ e a do mês frio é inferior a $18^{\circ} \mathrm{C}$. A precipitação média anual é de $1280 \mathrm{~mm}$, com 
distribuição monstrando maior concentração no periodo de outú bro a março e mais seco no período de abril a setembro. Os da dos climáticos da região de Jaboticabal estão apresentados na Tabela 1 e o gráfico do balanço hídrico, segundo THORNTHWAITE e MATTER (1955), está apresentado na Figura 1.

- Os dados mostram a existência de um período de excedentes de água com um valor de $317 \mathrm{~mm}$, que se inicja em de zembro e termina em março; um período de armazenamento, com valor de $108 \mathrm{~mm}$, que se inicia no final de outubro e termina em dezembro; um período de retirada de água do solo, com o va lor de $108 \mathrm{~mm}$, que começa em março e termina em setembro e um período de défice, apresentando um valor de $135 \mathrm{~mm}$, que se inicia em março e termina em setembro.

A vegetação originária é a floresta latifoliada tropical, de acordo com a COMISSÃO DE SOLOS (1960).

\subsubsection{Solos}

Os solos do local escolhido para a instalação foram classificados pela COMISSÃO DE SOLOS (1960) como Latosol Vermelho Escuro - fase arenosa e Latosol Roxo e segundo ALOISI e DEMATTE (1974), respectivamente, como Typic Haplortox e Typic Eutrorthox. Estes solos apresentam as seguintes ca racteristicas morfológicas: 


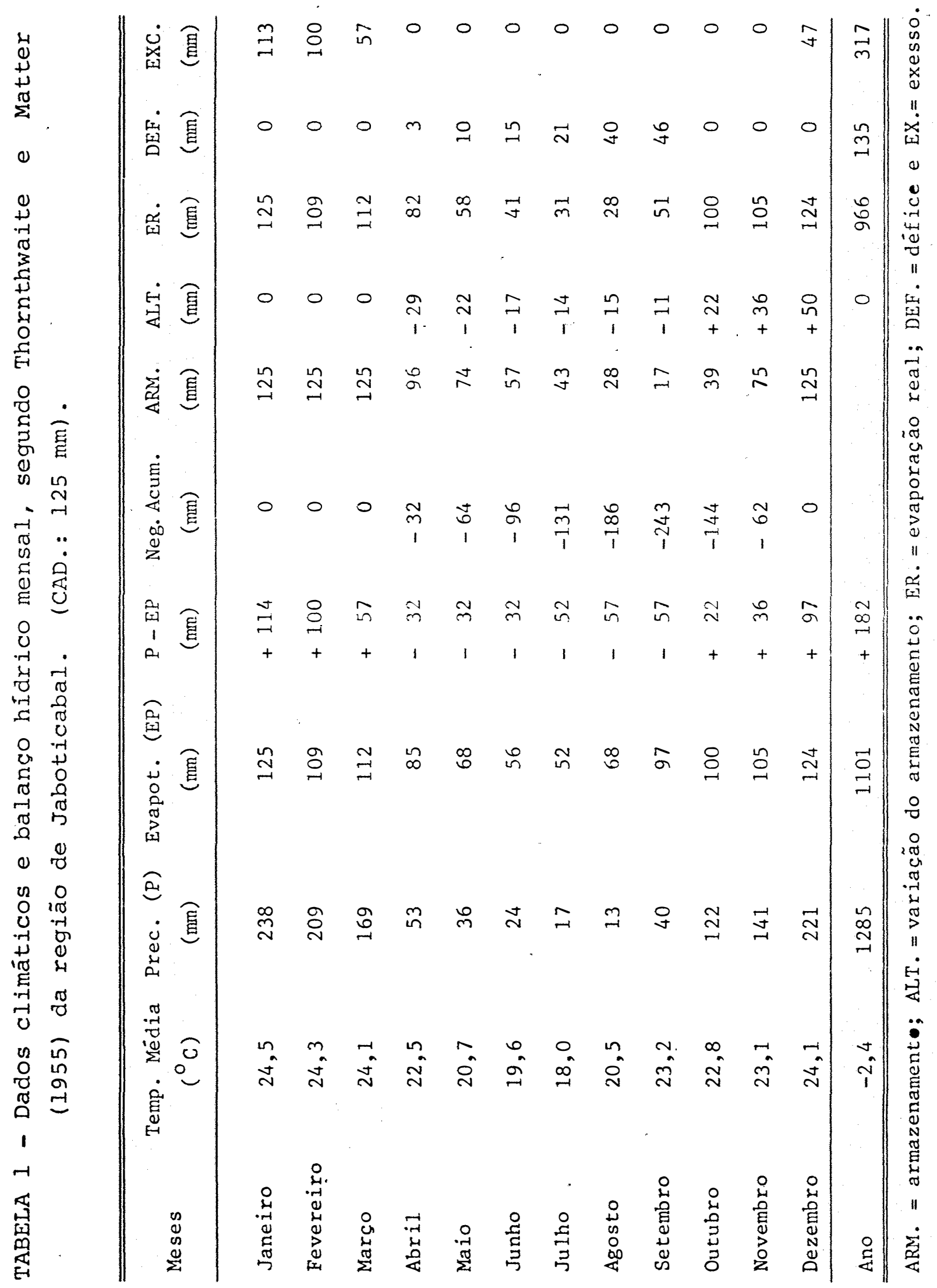




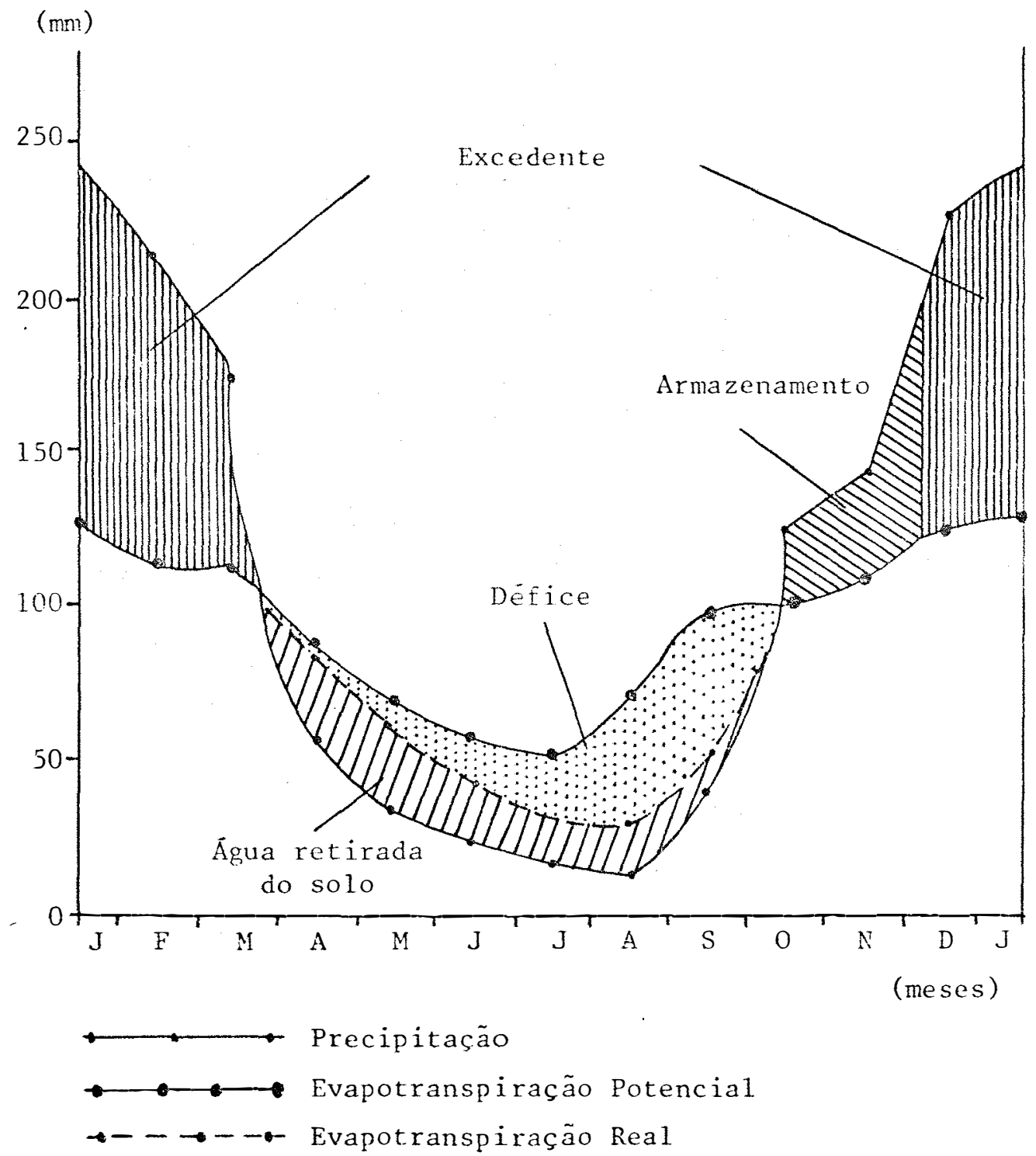

FIG. 1 - Balanço hídrico mensal da região de Jabotica bal, SP. 
Iatosol Vermelho Escuro - fase arenosa

Ap - 0-20 cm; vermelho amarelado (5YR 4/6); franco argilo arenoso; composta prismática e blocos, pequena a média fraca; ligeiramente duro, friável, ligeiramente plástí co, ligeiramente pegajoso; raizes abundantes e transi ção suave.

$\mathrm{B}_{21}$ - 20-55 cm; vermelho amarelado (5YR 4/4); franco argiio arenoso; composta prismática e blocos, pequena fraca; ligeiramente duro, friável, plástico e pegajoso; pou cas raízes e transição suave;

$\mathrm{B}_{22}$ - 55-120 cm +; vermelho (2,5 YR 3/6); franco argilo areno so; composta prismática e blocos, média fraca; ligeira mente pegajoso; ausēncia de raízes.

O perfil apresenta drenagem boa;

Latosol Roxo

$A_{p}$ - 0-30 cm; pardo avermelhado escuro (2,5 ÝR 3/4); argila; fraca, média, granular; macio, friável, plástico e pe gajoso; raízes abundantes; transição difusa.

$\mathrm{B}_{21}$ - 30-60 cm; pardo avermelhado escuro (2,5 YR 3/5); argila; fraca, muito pequena, granular; macio, friável, plásti co e pegajoso; transição difusa.

$\mathrm{B}_{22}$ - 60-120 cm +i vermelho escuro $(2,5 \mathrm{YR} 3 / 6)$; argila; maci ça porosa que se desfaz em fraca, muito pequena granu lar; muito friável, plástico e pegajoso.

o perfil apresenta drenagem boa. 
3.2. Método

3.2.1. Estabelecimento dos tratamentos

Foram estabelecidos cinco tratamentos, represen tando as modalidades de preparo do solo estudadas, a saber:

$\mathrm{T}_{1}$ - preparo convencional de aração e gradagem;

$\mathrm{T}_{2}$ - subsolagem, aração e gradagem;

$\mathrm{T}_{3}$ - duas gradagens;

$\mathrm{T}_{4}$ - subsolagem e duas gradagens;

$\mathrm{T}_{5}$ - "cultivo inínimo", sendo empregado o siste ma proposto por SHEAR (1968).

\subsubsection{Delineamento estatístico}

Foi empregado um delineamento experimental de bJocos casualizados, segundo PIMENTEL GOMES (1966), constando de cinco tratamentos com seis repetições.

Em cada parcela foram feitas oito linhas de $12 \mathrm{~m}$ de comprimento espaçadas entre si de $1 \mathrm{~m}$, perfazendo uma área de $96 \mathrm{~m}^{2}$. Foram consideradas como bordadura a primeira e a oitava linha e $1 \mathrm{~m}$ de cada extremidade das demais linhas.

3.2.3. Instalação e condução do experimento

As operações de cultivo efetuadas foram as de preparo do solo, semeadura e adubação, tratos culturais e co Iheita. 


\subsubsection{Preparo do solo}

O preparo do solo constou das operações de sub solagem, aração e gradagem, que foram realizadas de acordo com o estabelecido para cada tratamento. A subsolagem e a aração foram realizadas com a antecedência de um mês aproxima dámente da operação de semeadura. A gradagem foi efetuada na véspera da semeadura.

No tratamento $\mathrm{T}_{1}$ (preparo convencional de ara ção e gradagem) foram feitas a aração normal e a gradagem nor mal; no tratamento $\mathrm{T}_{2}$ (subsolagem mais aração e gradagem) fo ram realizadas a subsolagem e a aração e a gradagem normais; no tratamento $\mathrm{T}_{3}$ (duas gradagens) foram feitas duas gradagens normais; no tratamento $\mathrm{T}_{4}$ (subsolagem mais duas gradagens) fo ram realizadas a subsolagem e duas gradagens normais e no tra tamento $\mathrm{T}_{5}$ (cultivo mínimo) foi aplicada em pré-emergência uma mistura dos herbicidas Laço e Gesaprin-80, cujos princípios ativos são do grupo das triazinas, na dosagem correspondente a respectivamente $3,0 \mathrm{l} / \mathrm{ha}$ e $3,0 \mathrm{~kg} / \mathrm{ha}$.

\subsubsection{Semeadura e adubação}

Na operação de semeadura foram colocadas 5 a 6 sementes por metro linear. As linhas foram espaçadas entre si de $1 \mathrm{~m}$. A quantidade de sementes empregada foi a equiva lente a $25 \mathrm{~kg} / \mathrm{ha}$. A semeadura no ano agrícola 78/79 foi efe tuada na segunda quinzena do mês de novembro, no ano agrícola 79/80 na segunda quinzena de outubro e no ano agrícola 80/81 
na segunda quinzena de novembro. A adubação foi realizada concomitantemente com a semeadura, empregando-se a dose de 300 $\mathrm{kg} / \mathrm{ha}$ de fertilizante da fórmula 4-14-8 que corresponde a $12 \mathrm{~kg}$ de $\mathrm{N} / \mathrm{ha}, 42 \mathrm{~kg}$ de $\mathrm{P}_{2} \mathrm{O}_{5} / \mathrm{ha}$ e $24 \mathrm{~kg}$ de $\mathrm{K}_{2} \mathrm{O} / \mathrm{ha}$.

\subsubsection{Tratos culturais}

$\mathrm{Na}$ condução da cultura foram aplicadas as práti cas culturais recomendadas para a cultura do milho por VIEGAS (1978).

\subsubsection{Colheita}

A operação de colheita foi realizada manualmen te no final de abril e início de maio de cada ano.

Os valores da produção de grãos foram obtidos tendo-se como referēncia $13 \%$ de umidade. Os valores da pro dução foram convertidos para a unidade $\mathrm{kg} / \mathrm{ha}$.

\subsubsection{Coleta das amostras de solo}

As amostras de solo foram coletadas, com 3 repe tições, nas profundidades médias 5, 15, 30, 60, 90 e $120 \mathrm{~cm}$. A operação de amostragem foi feita por ocasião da colheita.

As amostras com estrutura indeformada foram co letadas empregando-se um amostrador especial baseado no mode lo descrito por LUTZ (1947).

3.2.3.6. Medida da umidade no campo

Para a medida da umidade no campo foram instala 
das quatro baterias de cinco tensiômetros com manōmetro de mercúrio nos tratamentos $\mathrm{T}_{1}$ (preparo convencional de aração e gradagem) e $\mathrm{T}_{5}$ (cultivo mínimo) do experimento da área do La tosol Vermelho Escuro - fase arenosa (LEa). Os tensiômetros foram instalados nas profundidades de 15, 30, 60, 90 e $120 \mathrm{~cm}$.

A determinação do potencial matricial foi feita determinando-se a altura da coluna de mercúrio do tensiômetro e aplicando-se na fórmula $\xi=-\left(13,6 \mathrm{~h}-\mathrm{h}-\mathrm{h}_{1}-\mathrm{h}_{2}\right)$ constante em REICHARDT (1975); onde: $\xi=$ potencial matricial, $\mathrm{h}=$ coluna de $\mathrm{H}_{\mathrm{g}}$ em $\mathrm{cm}, \mathrm{h}_{1}$ = altura do manômetro em relação a superfície do solo em $\mathrm{cm}, \mathrm{h}_{2}$ = profundidade da cápsula porosa do tensiô metro em relação a superfície do solo em $\mathrm{cm}$.

A umidade do solo foi determirada pela interpo lação dos valores do potencial da água do solo $\Psi$ (cm) na cur va de retenção de água.

Os valores de armazenamento da água de cada ca . mada foram obtidos pela multiplicação do valor da umidade do solo $\left(\theta \mathrm{cm}^{3} \cdot \mathrm{cm}^{-3}\right)$ pela espessura da respectiva camada. A un $\underline{i}$ dade do valor do armazenamento é dada em milímetros de água. O armazenamento total do perfil foi obtido pela somatória dos valores de cada camada.

\subsubsection{Análises de laboratório}

As análises realizadas no laboratório consistí ram na determinação de algumas características físicas do so lo com o emprego de amostras com estrutura indeformada e amos tras com estrutura deformada. 
3.2.4.1. Amostras com estrutura indeformada

\section{Determinação da umidade a diferentes tensões}

As amostras, após preparo prévio, foram satura das com água e pesadas, obtendo-se a massa do solo saturado $\left(m_{s a}\right)$.

As amostras saturadas foram colocadas em funis de placa porosa (funil de Buchner) e submetidas às tensões de $0,03,0,06,0,08$ atmosferas, sendo deixadas, em cada situação, drenando até que a água do solo estivesse em equilíbrio com a tensão aplicada. Atingido o equilíbrio as amostras foram pe sadas, obtendo-se os valores das massas de solo úmido referen tes a cada uma das tensões aplicadas $\left(\mathrm{m}_{0,03}, \mathrm{~m}_{0,06}, \mathrm{~m}_{0,08}\right)$.

Para determinação dos valores das massas de so lo úmido referentes as tensões de: $0,1,0,15,0,2,0,3,0,5$, 0,8 e 1,0 atmosfera $\left(m_{0,1}, m_{0,15}, m_{0,2}, m_{0,3}, m_{0,5}, m_{0,8}\right.$ e $\left.m_{1,0}\right)$ foi empregado a placa porosa de RICHARDS (1949).

Os valores das massas de solo seco $\left(m_{s}\right)$ foram obtidas mediante a colocação das amostras em estufa a $105^{\circ} \mathrm{C}$ $110^{\circ} \mathrm{C}$ e deixadas secar até peso constante.

\section{Densidade global}

Os valores da densidade global $\left(\rho \mathrm{g} g \cdot \mathrm{cm}^{-3}\right)$ foram determinadas empregando a relação massa de solo seco $\left(m_{s}\right)$ so bre volume total da amostra (Va).

Porosidade total calculada

A porosidade total calculada $\left(\alpha_{C}\right)$ foi determina da pela formula 


$$
\alpha_{c}=1-\frac{\rho_{g}}{\rho_{s}}
$$

onde: $\alpha_{C}=$ porosidade total calculada; $\rho_{S}=$ densidade das par tículas e $\rho_{g}=$ densidade global.

Porosidade total avaliada

A porosidade total avaliada $\left(\alpha_{a}\right)$ foi determina da em função da diferença da massa de solo saturada (msa) me nos massa de solo seca $\left(m_{s}\right)$.

Macroporosidade e microporosidade

Os valores da macroporosidade e microporosidade foram determinados tendo-se como referência a tensão de $60 \mathrm{~cm}$ de coluna de água, mediante o emprego do funil de placa poro sa de acordo com o método descrito por VOMOCIL (1965).

\subsubsection{Amostras com estrutura deformada}

Com o emprego das amostras preparadas foram rea lizadas a análise granulométrica para a determinação dos sepa rados dos solos e a densidade das partículas.

Análise granulométrica foi realizada utilizan do-se do método da pipeta de Kilmer e Alexander de 1949, modi ficado por DAY (1965).

Para a separação das subírações da areia foi empregado o conjunto de peneiras de malhas 1000, 500, 250, 100 e 50 micra, para obter-se respectivamente as subfrações areia muito grossa, areia grossa, areia média, areia fina e areia muito fina. 
Os valores da densidade das particulas ( $\left.\rho_{\mathrm{S}} \mathrm{g} \cdot \mathrm{cm}^{-3}\right)$ foram obtidos mediante o emprego do método do picnômetro des crito por BLAKE (1965). 
4. RESULtAdOS E DISCUSSÃO

4.1. Características do solo determinadas antes da instala ção dos experimentos

Os separados e as classes texturais dos solos dos locais da instalação dos cinco tratamentos são apresenta dos nas Tabelas 2 e 3 .

Os dados apresentados revelaram que em cada so 10 a área do experimento é homogênea. Em todos os pontos de amostragem são observadas a mesma classe textural e distribui ções dos separados do solo muito semelhante. As pequenas di ferenças existentes são provavelmente devidas aos erros do processo de determinação.

Nas Tabelas 4 e 5 são apresentados os valores da densidade global, densidade das partículas, porosidade to tal avaliada, porosidade total calculada, macroporosidade e microporosidade determinados para as diferentes camadas do La tosol Vermelho Escuro - fase arenosa e Latosol Roxo, dos lo cais de instalação dos cinco tratamentos. 
TABELA 2 - Separados do solo e classe textural do Lato sol Vermelho Escuro - fase arenosa.

\begin{tabular}{|c|c|c|c|c|c|c|c|c|c|c|c|c|}
\hline \multirow{2}{*}{ Trat. } & \multirow{2}{*}{$\begin{array}{c}\text { Prof. } \\
(\mathrm{cm})\end{array}$} & \multicolumn{8}{|c|}{ Classe de separados do sulo (r em peso) } & \multirow{2}{*}{\multicolumn{3}{|c|}{ Classe textural }} \\
\hline & & amg & $\mathrm{ag}$ & $a m$ & af & $a m \hat{~}$ & areia & silte & argila & & & \\
\hline \multirow{5}{*}{$T_{1}$} & 15 & 0,5 & 1,9 & 17,8 & 35,6 & 10,1 & 55,9 & 2,6 & 31,5 & \multirow[t]{5}{*}{ Franco } & \multirow{2}{*}{\multicolumn{2}{|c|}{ - arenoso }} \\
\hline & 30 & 0,6 & 1,8 & 15,2 & 32,4 & 9,3 & 59,3 & 3,2 & 37,5 & & & \\
\hline & 60 & 0,5 & 1,7 & 15,3 & 31,9 & 10,2 & 59,6 & 1,4 & 39,0 & & $"$ & \\
\hline & 90 & 0,4 & 1,6 & 15,1 & 31,4 & 10,1 & 58,6 & 2,4 . & 39,0 & & $"$ & \\
\hline & 120 & 0,3 & 1,5 & 15,4 & 31,4 & 9,8 & 58,4 & 4,0 & 37,6 & & $"$ & . \\
\hline \multirow{5}{*}{$\mathrm{T}_{2}$} & 15 & 0,6 & 1,8 & 16,8 & 37,6 & 9,7 & 66,5 & 4,0 & 29,5 & \multirow[t]{5}{*}{ Eranco } & argilo & arenoso \\
\hline & 30 & 0,5 & 1,8 & 14,5 & 34,4 & 10,2 & 61,4 & 3,6 & 35,0 & & $"$ & \\
\hline & 60 & 0,5 & 1,7 & 15,3 & 32,6 & 10,3 & 60,4 & 3,0 & 36,5 & & $"$ & \\
\hline & 90 & 0,4 & 1,7 & 15,1 & 33,1 & $10 ; 5$ & 60,8 & 1,7 & 37,5 & & $"$ & \\
\hline & 120 & 0,3 & 1,6 & 14,2 & 32,2 & 10,8 & 59,1 & 4,4 & 36,5 & & $"$ & \\
\hline \multirow{5}{*}{$\mathrm{T}_{3}$} & 15 & 0,5 & 1,9 & 17,2 & 37,5 & 9,5 & 66,6 & 3,4 & 30,0 & \multirow[t]{5}{*}{ Eranco } & argilo & arenoso \\
\hline & 30 & 0,5 & 1,8 & 16,5 & 32,7 & 9,8 & 61,3 & 4,7 & 34,0 & & $"$ & \\
\hline & 60 & 0,4 & 1,7 & 15,3 & 33,4 & 10,2 & 61,0 & 3,5 & 35,5 & & $"$ & \\
\hline & 90 & 0,3 & 1,7 & 15,8 & 31,7 & 10,4 & 59,9 & 5,1 & 35,0 & & $"$ & \\
\hline & 120 & 0,2 & 1,5 & 15,0 & 32,6 & 10,9 & 60,2 & 5,3 & 34,5 & & $"$ & \\
\hline \multirow{5}{*}{$T_{4}$} & 15 & 0,5 & 1,8 & 16,5 & 40,5 & 8,2 & 67,5 & 7,0 & 25,5 & \multirow[t]{5}{*}{ Franco } & argilo & arenoso \\
\hline & 30 & 0,4 & 1,6 & 14,8 & 36,0 & 9,8 & 62,6 & 6,9 & 30,5 & & $"$ & \\
\hline & 60 & 0,3 & 1,5 & 15,2 & 34,8 & 10,5 & 62,3 & 1,7 & 36,0 & & $"$ & \\
\hline & 90 & 0,2 & 1,4 & 14,7 & 32,0 & 10,8 & 59,1 & 3,9 & 37,0 & & $"$ & \\
\hline & 120 & 0,1 & 1,2 & 14,6 & 32,9 & 11,0 & 59,8 & 5,2 & 35,0 & & $"$ & \\
\hline \multirow{5}{*}{$\mathrm{T}_{5}$} & 15 & 0,6 & 1,6 & 18,5 & 36,9 & 8,5 & 66,1 & 5,6 & 28,3 & \\
\hline & 30 & 0,4 & 1,4 & 16,4 & 37,4 & 10,2 & 65,8 & 4,1 & 30,1 & & & \\
\hline & 60 & 0,4 & 1,3 & 15,8 & 34,7 & 11,2 & 63,4 & 5,6 & 31,0 & \multirow{3}{*}{\multicolumn{3}{|c|}{$\begin{array}{c}\text { Franco argilo arenoso } \\
" \\
\text { " } \\
\text { " }\end{array}$}} \\
\hline & 90 & 0,3 & 1,2 & 14,7 & 37,1 & 11,0 & 64,3 & 5,5 & 30,2 & & & \\
\hline & 120 & 0,2 & 1,1 & 14,5 & 38,1 & 11,3 & 65,2 & 4,0 & 30,8 & & & \\
\hline
\end{tabular}


TABELA 3 - Separados do solo e classe textural do Lato sol Roxo.

\begin{tabular}{|c|c|c|c|c|c|c|c|c|c|c|}
\hline \multirow{2}{*}{ Trat. } & \multirow{2}{*}{$\begin{array}{c}\text { Prof } \\
(\mathrm{cm})\end{array}$} & \multicolumn{8}{|c|}{ Classe de separados do solo (\% am peso) } & \multirow{2}{*}{ Classe textural } \\
\hline & & aing, & $\mathrm{ag}$ & $a m$ & af & $a m E$ & areia & silte & argila & \\
\hline \multirow{5}{*}{$T_{1}$} & 15 & 0,1 & 0,4 & 4,8 & 10,8 & 6,6 & 22,2 & 23,4 & 54,5 & Argila \\
\hline & 30 & 0,1 & 0,6 & 4,6 & 11,4 & 8,2 & 24,9 & 19,8 & 55,3 & $"$ \\
\hline & 60 & - & 0,2 & 4,2 & 10,3 & 7,5 & 22,2 & 21,7 & 56,1 & $"$ \\
\hline & 90 & - & - & 4,2 & 9,8 & 6,1 & 20,1 & 22,4 & 57,7 & $"$ \\
\hline & 120 & - & - & 4,0 & 9,3 & 5,7 & 19,0 & 22,9 & 58,1 & $"$ \\
\hline \multirow{5}{*}{$\mathrm{T}_{2}$} & 15 & 0,2 & 0,5 & 4,4 & 11,0 & 6,8 & 22,9 & 21,9 & 55,2 & Argila \\
\hline & 30 & 0,1 & 0,3 & 4,1 & 10,0 & 7,0 & 21,5 & 23,7 & 54,8 & $"$ \\
\hline & 60 & - & 0,3 & 3,9 & 9,3 & 6,7 & 20,1 & 26,0 & 53,9 & $"$ \\
\hline & 90 & - & 0,2 & 3,9 & 8,4 & 8,0 & 20,5 & 25,0 & 54,5 & $"$ \\
\hline & 120 & - & 0,1 & 3,8 & 8,1 & 6,5 & 18,5 & 27,5 & 54,0 & $"$ \\
\hline \multirow{5}{*}{$\mathrm{T}_{3}$} & 15 & 0,1 & 0,2 & 5,2 & 10,4 & 7,1 & 23,0 & 21,4 & 55,6 & Argila \\
\hline & 30 & - & 0,2 & 4,3 & 9,8 & 6,4 & 20,7 & 24,4 & 54,9 & $"$ \\
\hline & 60 & - & 0,1 & 4,2 & 9,6 & 7,0 & 20,9 & 24,5 & 54,6 & $"$ \\
\hline & 90 & - & - & 4,2 & 9,2 & 6,8 & 20,2 & 26,0 & 53,8 & $"$ \\
\hline & 120 & - & - & 4,0 & 8,1 & 6,1 & 18,2 & 25,0 & $\begin{array}{c}56,8 \\
.\end{array}$ & $"$ \\
\hline \multirow{5}{*}{$T_{4}$} & 15 & 0,1 & 0,4 & 5,0 & 10,8 & 6,8 & 23,1 & 21,1 & 55,8 & Argila \\
\hline & 30 & - & 0,2 & 5,1 & 9,5 & 6,4 & 21,2 & 22,6 & 56,2 & $"$ \\
\hline & 60 & - & 0,1 & 5,2 & 9,3 & 6,2 & 20,8 & 22,1 & 52,1 & $"$ \\
\hline & 90 & - & - & 4,8 & 8,6 & 6,5 & 19,1 & 24,8 & $55,3^{\circ}$ & $"$ \\
\hline & 120 & - & - & 4,8 & 8,2 & 6,4 & 19,2 & 24,0 & 56,8 & $"$ \\
\hline \multirow{5}{*}{$\mathrm{T}_{5}$} & 15 & 0,3 & 0,3 & 5,0 & 11,2 & 7,1 & 23,9 & 21,2 & 54,9 & Argila \\
\hline & 30 & 0,2 & 0,3 & 5,1 & 10,1 & 6,8 & 22,5 & 22,2 & 55,3 & $"$ \\
\hline & 60 & - & 0,4 & 4,8 & 9,0 & 6,4 & 20,6 & $2 \cdot 3,3$ & 56,1 & $"$ \\
\hline & 90 & - & 0,2 & 4,8 & 8,2 & 6,3 & 19,5 & 23,7 . & 56,8 & $"$ \\
\hline & 120 & - & 0,2 & 4,5 & 8,0 & 5,8 & 18,5 & 24,0 & 57,5 & $"$ \\
\hline
\end{tabular}


TABELA 4 - Características físicas do Latosol Vermelho Escu ro - fase arenosa dos locais dos cinco tratamen tos.

\begin{tabular}{|c|c|c|c|c|c|c|c|}
\hline Trat. & $\begin{array}{l}\text { Prof. } \\
\text { (cml) }\end{array}$ & $\rho_{g} g \cdot \mathrm{cm}^{-3}$ & $\rho_{s} 8 \cdot \mathrm{cm}^{-3}$ & $\alpha_{\mathrm{d}} \mathrm{cm}^{3} \cdot \mathrm{cm}^{-3}$ & $\alpha_{c} \mathrm{~cm}^{3} \cdot \mathrm{cm}^{-3}$ & $\begin{array}{l}\text { Macropososidac'e } \\
\mathrm{cm}^{3} \cdot \mathrm{cm}^{-3}\end{array}$ & $\begin{array}{l}\text { Microporosidado } \\
\mathrm{cm}^{3} \cdot \mathrm{cm}^{-3}\end{array}$ \\
\hline \multirow{6}{*}{$\mathrm{T}_{1}$} & $0-7$ & 1,50 & 2,52 & 0,39 & 0,40 & 0,14 & 0,26 \\
\hline & $7-15$ & 1,51 & 2,50 & 0,38 & 0,40 & 0,12 & 0,28 \\
\hline & $23-30$ & 1,48 & 2,50 & 0,39 & 0,41 & 0,11 & 0,30 \\
\hline & $53-60$ & 1,35 & 2,50 & 0,43 & $0,46^{\circ}$ & 0,16 & 0,30 \\
\hline & $83-90$ & 1,30 & 2,52 & 0,44 & 0,48 & 0,18 & 0,30 \\
\hline & $113-120$ & 1,28 & 2,51 & 0,45 & 0,49 & 0,18 & 0,31 \\
\hline \multirow{6}{*}{$\mathrm{T}_{2}$} & $0-7$ & 1,50 & $2,53 \cdots$ & 0,39 & 0,41 & 0,13 . & 0,28 \\
\hline & $7-15$ & 1,48 & 2,54 & 0,38 & 0,42 & 0,12 & 0,30 \\
\hline & $23-30$ & 1,50 & 2,56 & 0,40 & 0,41 & 0,12 & 0,29 \\
\hline & $53-60$ & 1,38 & 2,55 & 0,42 & 0,46 & 0,15 & 0,31 \\
\hline & $83-90$ & 1,28 & 2,55 & 0,45 & 0,50 & 0,17 & 0,33 \\
\hline & $113-120$ & 1,20 & 2,52 & 0,46 & 0,52 & 0,19 & 0,33 \\
\hline \multirow{5}{*}{$\mathrm{T}_{3}$} & $0-7$ & 1,52 & 2,60 & 0,40 & 0,42 & 0,12 & 0,30 \\
\hline & $7-15$ & 1,50 & 2,58 & 0,40 & 0,42 & 0,11 & 0,31 \\
\hline & $23-30$ & 1,50 & 2,60 & 0,39 & 0,42 & 0,12 & 0,30 \\
\hline & $53-60$ & 1,36 & 2,58 & 0,42 & 0,47 & 0,14 & 0,33 \\
\hline & $83-90$ & 1,28 & 2,56 & 0,45 & 0,50 & 0,18 & 0,32 \\
\hline- & $113-120$ & 1,25 & 2,55 & 0,48 & 0,51 & 0,18 & 0,33 \\
\hline \multirow{6}{*}{$T_{4}$} & $0-7$ & 1,54 & 2,61 & 0,38 & 0,41 & 0,14 & 0,27 \\
\hline & $7-15$ & 1,50 & 2,59 & 0,39 & 0,42 & 0,12 & 0,30 \\
\hline & $23-30$ & 1,52 & 2,59 & 0,38 & 0,41 & 0,11 & 0,30 \\
\hline & $53-60$ & 1,40 & 2,60 & 0,42 & 0,46 & 0,15 & 0,31 \\
\hline & $83-90$ & 1,30 & 2,60 & 0,45 & 0,50 & 0,18 & 0,32 \\
\hline & $113-120$ & 1,25 & 2,58 & 0,45 & 0,52 & 0,18 & 0,34 \\
\hline \multirow{6}{*}{$\mathrm{T}_{5}$} & $0-7$ & 1,53 & 2,54 & 0,39 & 0,40 & 0,13 & 0,27 \\
\hline & $7-15$ & 1,50 & 2,56 & 0,38 & 0,41 & 0,12 & 0,29 \\
\hline & $23-30$ & 1,48 & 2,59 & 0,40 & 0,43 & 0,13 & 2,30 \\
\hline & $53-60$ & 1,36 & 2,59 & 0,42 & 0,47 & 0,18 & 0,29 \\
\hline & $83-90$ & 1,28 & 2,58 & 0,43 & 0,50 & 0,19 & 0,31 \\
\hline & $113-120$ & 1,24 & 2,58 & 0,43 & 0,52 & 0,19 & 0,33 \\
\hline
\end{tabular}


TABELA 5 - Características físicas do Latosol Roxo dos 1 으 cais dos cinco tratamentos.

\begin{tabular}{|c|c|c|c|c|c|c|c|}
\hline Trat. & $\begin{array}{l}\text { Prof. } \\
\text { (cm) }\end{array}$ & $o_{g} g \cdot \mathrm{cm}^{-3}$ & $p_{s} g \cdot \mathrm{cm}^{-3}$ & $a_{a} \mathrm{~cm}^{3} \cdot \mathrm{cm}^{-3}$ & $a_{c} \mathrm{cnl}^{3} \cdot \mathrm{cm}^{-3}$ & $\begin{array}{c}\text { Macroporosidade } \\
\mathrm{cm}^{3} . \mathrm{cni}^{-3}\end{array}$ & $\begin{array}{l}\text { Microporosidade } \\
\mathrm{cm}^{3} \cdot \mathrm{cm}^{-3}\end{array}$ \\
\hline \multirow{6}{*}{$\mathrm{T}_{1}$} & $0-7$ & 1,34 & 2,75 & 0,49 & 0,51 & 0,21 & 0,30 \\
\hline & $7-15$ & 1,38 & 2,80 & 0,46 & 0,51 & 0,19 & 0,32 \\
\hline & $23-30$ & 1,35 & 2,83 & 0,47 & 0,52 & 0,20 & 0,32 \\
\hline & $53-60$ & 1,10 & 2,80 & 0,55 & 0,61 & 0,25 & 0,36 \\
\hline & $83-90$ & 1,16 & 2,85 & 0,54 & 0,59 & 0,29 & 0,30 \\
\hline & $113-120$ & 1,15 & 2,85 & 0,54 & 0,60 & 0,28 & 0,32 \\
\hline \multirow{6}{*}{$\mathrm{T}_{2}$} & $0-7$ & 1,43 & 2,76 & 0,48 & $0,5 !$ & 0,19 & 0,32 \\
\hline & $7-15$ & 1,40 & 2,80 & 0,47 & 0,50 & 0,18 & 0,32 \\
\hline & $23-30$ & 1,38 & 2,81 & 0,49 & 0,51 & 0,20 & 0,31 \\
\hline & $53-60$ & $1,1 \overline{1}^{-}$ & 2,82 & 0,58 & 0,61 & 0,25 & 0,36 \\
\hline & $83-90$ & 1,20 & 2,82 & 0,55 & 0,51 & 0,27 & 0,30 \\
\hline & $113-120$ & 1,18 & 2,82 & 0,53 & 0,58 & 0,27 & 0,31 \\
\hline \multirow{6}{*}{$\mathrm{T}_{3}$} & $0-7$ & 1,31 & 2,80 & 0,50 & 0,53 & 0,18 & 0,35 \\
\hline & $7-15$ & 1,42 & 2,83 & 0,47 & 0,50 & 0,19 & 0,31 \\
\hline & $23-30$ & 1,40 & 2,83 & 0,48 & 0,51 & 0,18 & $0 ; 33$ \\
\hline & $53-60$ & 1,16 & 2,85 & 0,53 & 0,59 & 0,24 & 0,35 \\
\hline & $83-90$ & 1,12 & 2,85 & 0,54 & 0,61 & 0,26 & 0,35 \\
\hline & $113-120$ & 1,10 & 2,83 & 0,54 & 0,61 & 0,28 & 0,33 \\
\hline \multirow{6}{*}{$\mathrm{T}_{4}$} & $0-7$ & 1,32 & 2,81 & 0,50 & 0,53 & 0,20 & 0,33 \\
\hline & $7-15$ & 1,38 & 2,85 & 0,46 & 0,52 & 0,19 & 0,33 \\
\hline & $23-30$ & 1,36 & 2,88 & 0,48 & 0,53 & 0,20 & 0,33 \\
\hline & $53-60$ & 1,08 & 2,89 & 0,55 & 0,63 & 0,25 & 0,38 \\
\hline & $83-90$ & 1,13 & 2,90 & 0,58 & 0,61 & 0,27 & 0,34 \\
\hline & $113-120$ & 1,13 & 2,90 & 0,57 & 0,61 & 0,29 & 0,32 \\
\hline \multirow{6}{*}{$T_{5}$} & $0-7$ & 1,38 & 2,80 & 0,49 & 0,53 & 0,21 & 0,32 \\
\hline & $7-15$ & 1,42 & 2,83 & 0,47 & 0,50 & 0,20 & 0,30 \\
\hline & $23-30$ & 1,40 & 2,84 & 0,46 & 0,51 & 0,20 & 0,31 \\
\hline & $53-60$ & 1,18 & 2,85 & 0,54 & 0,59 & 0,24 & 0,35 \\
\hline & $83-90$ & 1,08 & 2,85 & 0,54 & 0,62 & 0,24 & 0,38 \\
\hline & $113-120$ & 1,08 & 2,85 & 0,56 & 0,62 & 0,25 & 0,37 \\
\hline
\end{tabular}


Este novo conjunto de dados forneceram novos elementos que possibilitaram enfatizar a condição de similari dade dos diferentes locais de amostragem para cada solo. A densidade global ( $\left.\mathrm{g}_{\mathrm{g}} \mathrm{g} \cdot \mathrm{cm}^{-3}\right)$ nos dois solos apresentou valores mais altos nas camadas superiores e menores nas camadas subja centes, as quais correspondem ao horìzonte B latossólico des tes solos que se caracterizam por serem fofos. Os dados obti dos da porosidade total confirmam essa característica.

Os valores da porosidade total avaliada e os da porosidade total calculada dos dois solos se apresentaram bas tante próximos entre si, sendo levemente superiores na calcu lada, revelando dessa maneira condições de grande uniformida de da distribuição da porosidade e facilidade para absorção e remoção da água e do ar do solo, que segundo MARCOS (1971) é devido à geometria dos poros.

4.2. Características dos solos com a realizạão do experi mento

As características dos solos com a realização do experimento apresentam diferenças muito pequenas entre tra tamentos. Em nenhum caso a análise estatística dos dados for neceu valores de F significativos.

\subsubsection{Latosol Vermelho Escuro - fase arenosa}

As características densidade global, densidade das partículas, porosidade total avaliada, porosidade total calculada, macroporosidade e microporosidade do Latosol Verme 
Iho Escuro - fase arenosa determinadas logo após completar o ciclo da cultura do milho em cada ano de experimentação são apresentados na Tabela 6 .

Densidade global

Os valores da densidade global na parte supe rior do solo, até a profundidade de $30 \mathrm{~cm}$, não apresentaram modificações dentre os tratamentos, excetuando no tratamento $\mathrm{T}_{5}$ (cultivo mínimo). Os valores das camadas situadas abaixo de $30^{\circ} \mathrm{cm}$ de profundidade não mostraram qualquer tipo de alte ração diferencial. No tratamento $\mathrm{T}_{5}$ (cultivo mínimo) os valo res da densidade global foram um pouco inferiores aos dos de mais tratamentos, na porção superficial do solo, sendo essas diferenças aproximadamente 0,1 , não possibilitando, desse mo do, caracterizar efetivamente a alteração do solo com os dạ dos disponiveis. Contudo, os dados da bibliografia consulta da revelam que os valores da densidade global se apresentam menores com o emprego do "cultivo minimo". De maneira geral, os dados determinados após a instalação dos experimentos fo ram semelhantes aos anteriormente obtidos, sendo identificado somente um pequeno decrescimo dos valores da densidade global da parte mais superficial do solo, numa camada com expessura de $7,0 \mathrm{~cm}$. No decorrer dos três anos de experimentação não se identificaram diferenças sensiveis dos valores da densida de global em quaisquer dos tratamentos.

Deve-se ressaltar que não se observou altera ções da característica típica dos latossois de apresentar, de 


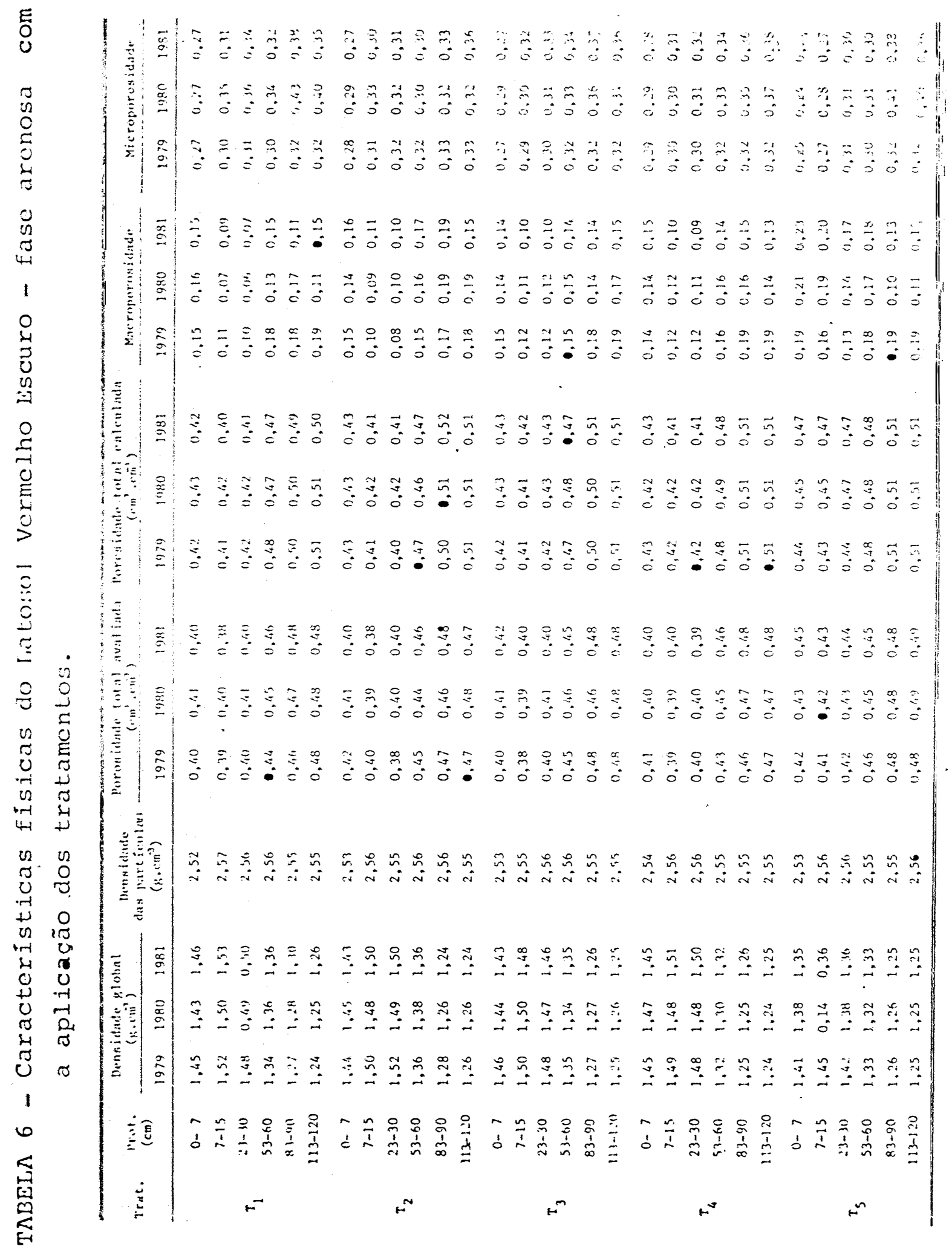


vido ao horizonte B latossólico bastante fofo, valores maio res nas camadas superiores e valores menores nas camadas, cor respondentes ao horizonte B. As Figuras 2 e 3 representam a distribuição dos valores da densidade global em função da prô fundidade do solo, por ocasião de cada amostragem. Essa re presentação ilustra e possibilita uma melhor compreensão dos aspectos apresentados e discutidos.

\section{Densidade das particulas}

Os valores da densidade das partículas determí nados para todos os tratamentos e diferentes amostragens fo ram sempre praticamente iguais, não revelando qualquer tipo de àteração.

Porosidade total

Os valores da porosidade total avaliada e da po rosicacie total' calculada, semelhantemente à densidade glo bal, se apresentaram somente com diferenças muito pequenas no tratamento $\mathrm{T}_{5}$ (cultivo mínimo), na porção superior do solo, numa espessura de $30 \mathrm{~cm}$. Nesta camada os valores foram lige ramente superiores aos mostrados pelas camadas da mesma posi ção no solo dos demais tratamentos. Os valores nesta camada tenderam aumentar com a sucessão dos ciclos culturais.

Ao analisar a distribuição dos valores em fun ção da profundidade do solo, constatou-se de maneira geral, que estes valores foram maiores nas camadas abaixo de $30 \mathrm{~cm}$, revelando um comportamento inverso ao da densidade global.

Confrontando os valores das porosidades avalia 


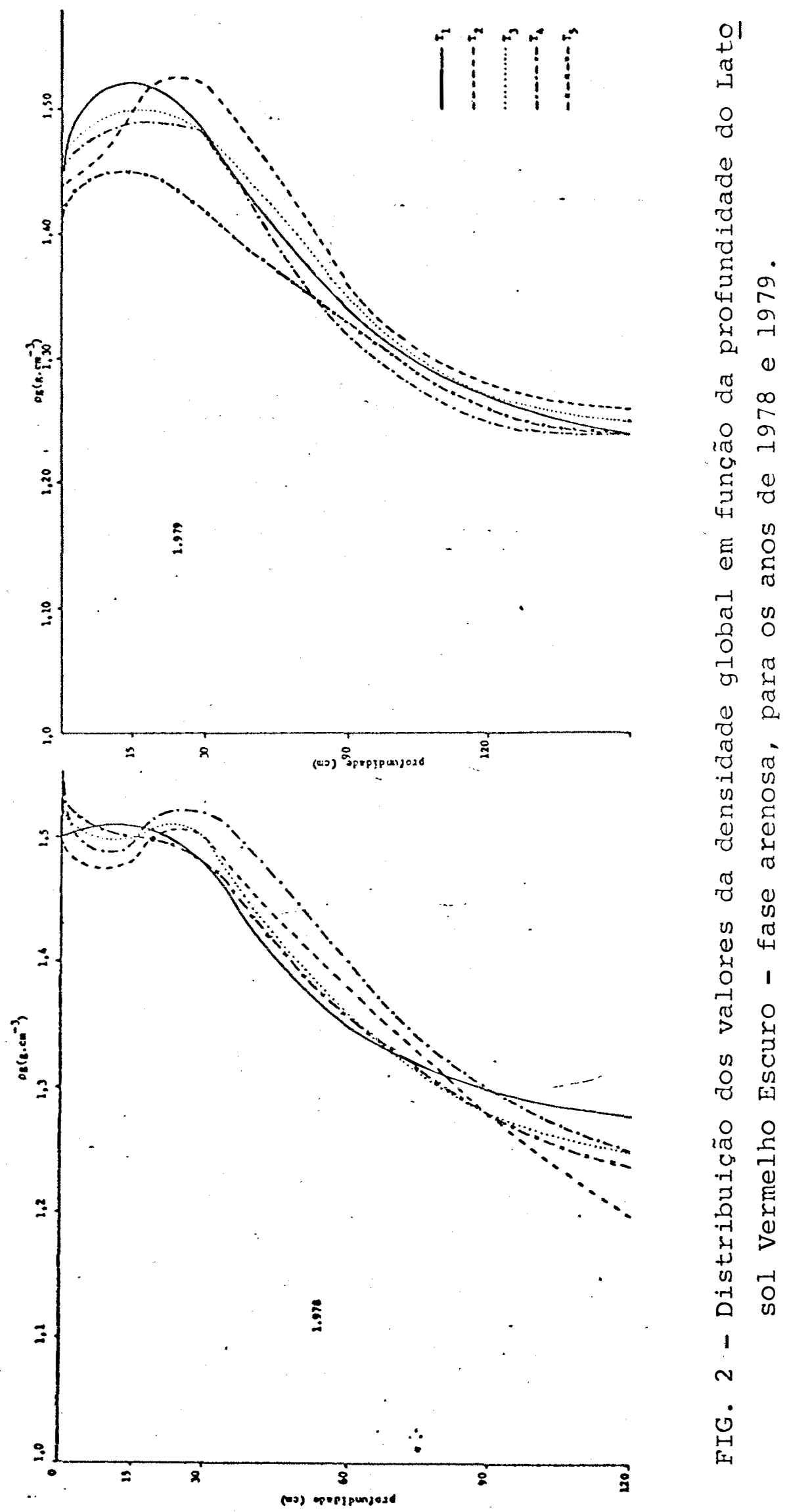



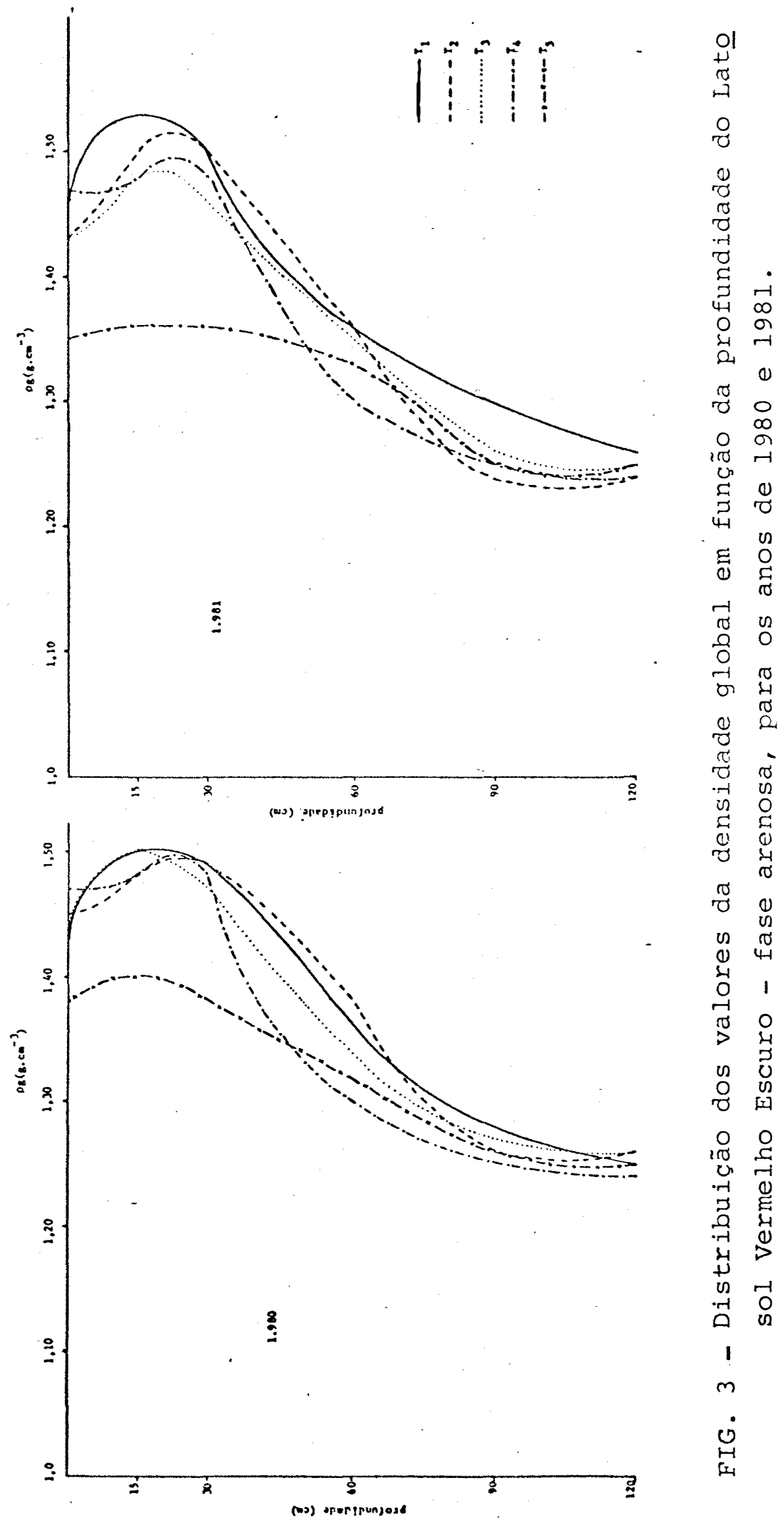
da e calculada, verificou-se que os valores da calculada fo ram um pouco mais altos do que os da avaliada, fato também verificado por SCARDUA (1972) para um Latosol - fase arenosa da região de Piracicaba. Por serem muito pequenas as diferen ças entre os valores dessas duas porosidades, pode-se obser var que a uniformidade da distribuição da porosidade não foi alterada pelo efeito de qualquer uma das modalidades de prepa ro do solo. As Figuras 4 a 8 apresentam a distribuição do es paço poroso e do material sólido do solo, em função da profun didade do solo, para os cinco tratamentos e três ocasiões de amostragem.

Macroporosidade

A macroporosidade do solo não revelou comportą mento diferente ca comportamento da porosidade total. Não di ferindo entre os tratamentos $\mathrm{T}_{1}$ (preparo convencional de ara ção e gradagem), $\mathrm{T}_{2}$ (subsolagem mais aração e gradagem), $\mathrm{T}_{3}$ (duas gradagens) e $\mathrm{T}_{4}$ (subsolagem mais duas gradagens) e, apresentando valores ligeiramente mais altos, no tratamento $\mathrm{T}_{5}$ (cultivo mínimo) na porção superficial do solo. Nesta por ção observou-se inclusive a tendência dos valores aumentarem un pouco com a sucessão dos ciclos culturais.

\section{Microporosidade}

A microporosidade do solo revelou-se semelhante à macroporosidade, com diferenças somente na porção superfí cial do solo no tratamento $\mathrm{T}_{5}$ (cultivo minimo). Os valores da microporosidade, ao contrário da macroporosidade, foram um 


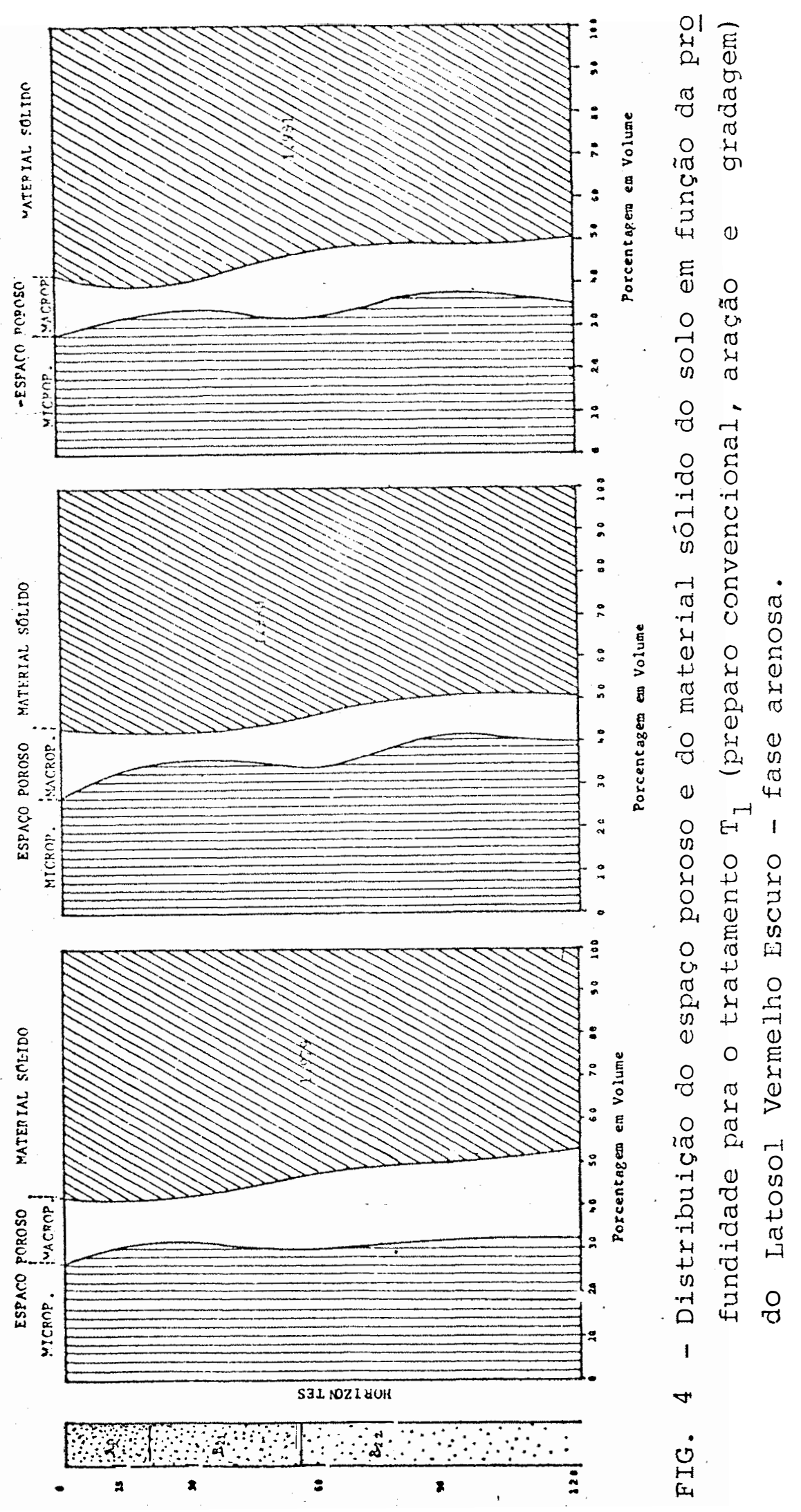



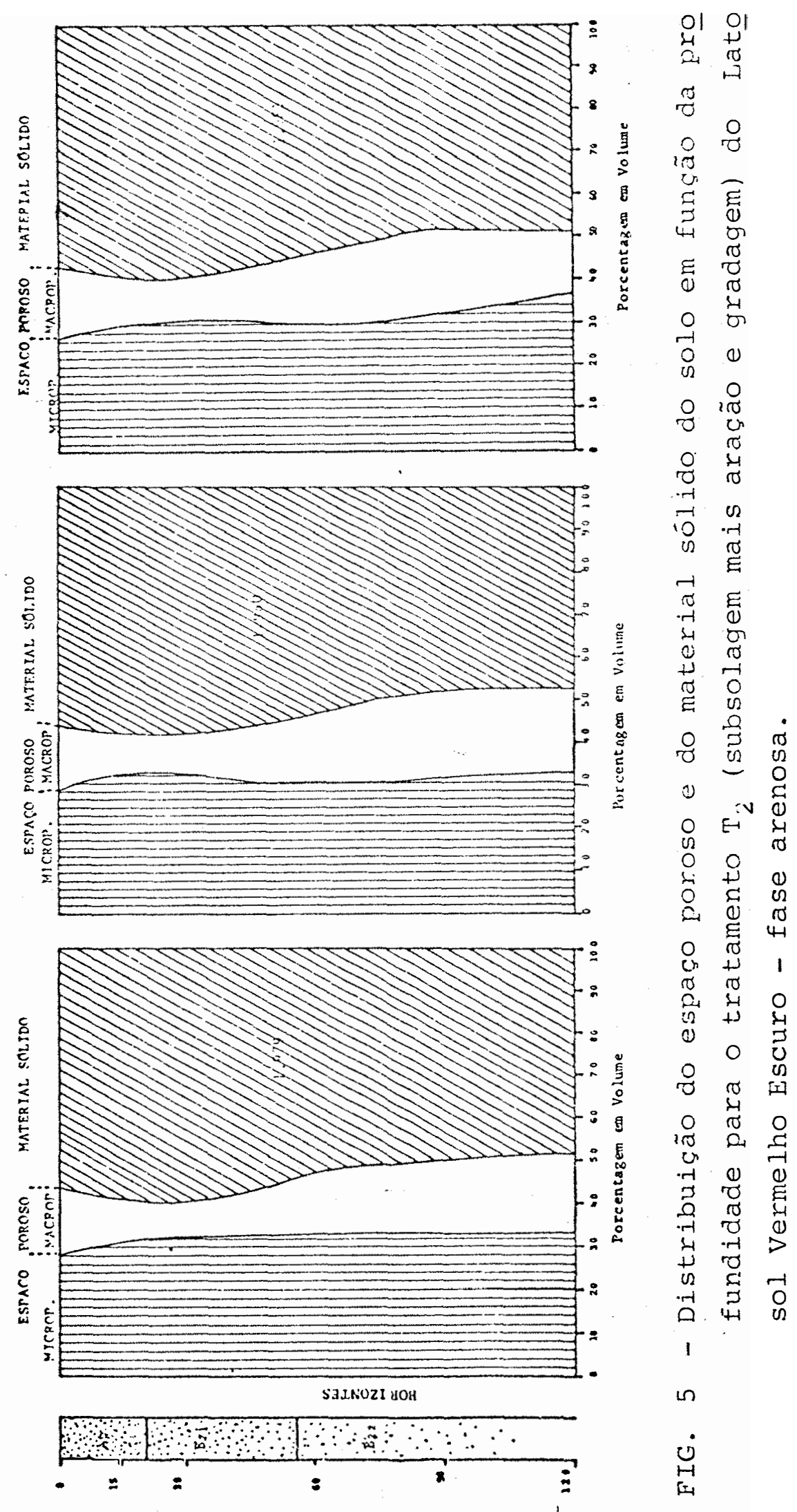


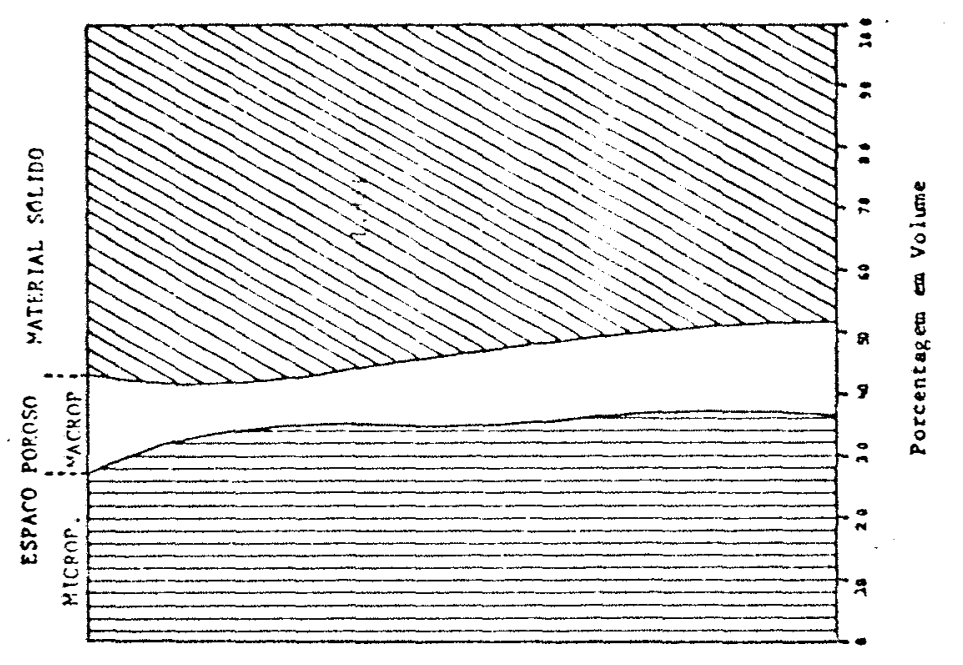

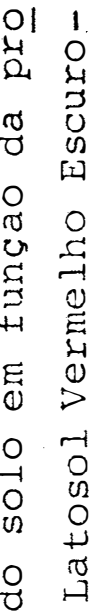

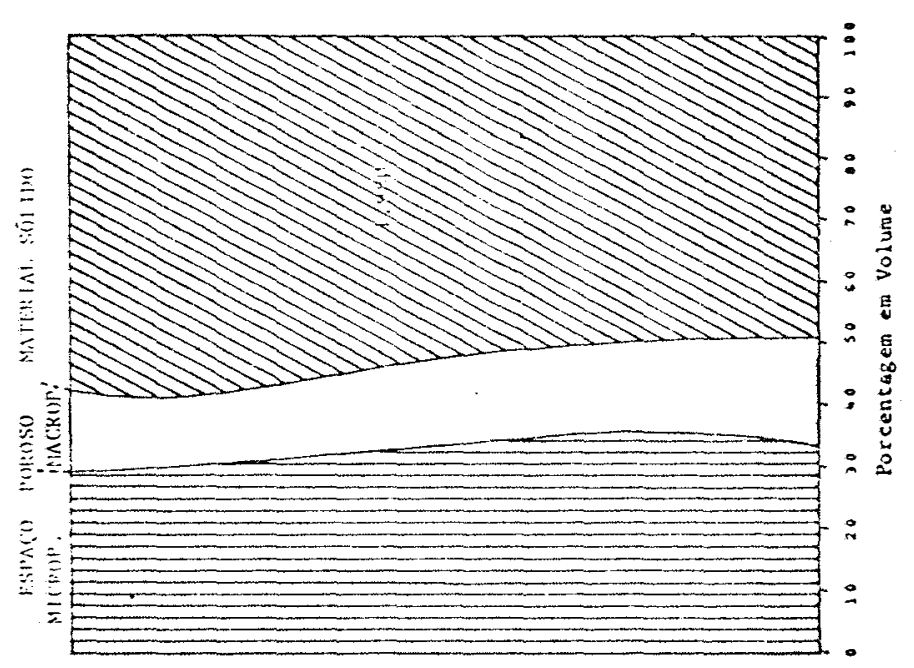

음

त)

U

다

- 4

(1)

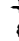

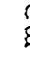

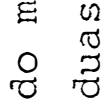

0

o $E^{m}$

O

मी

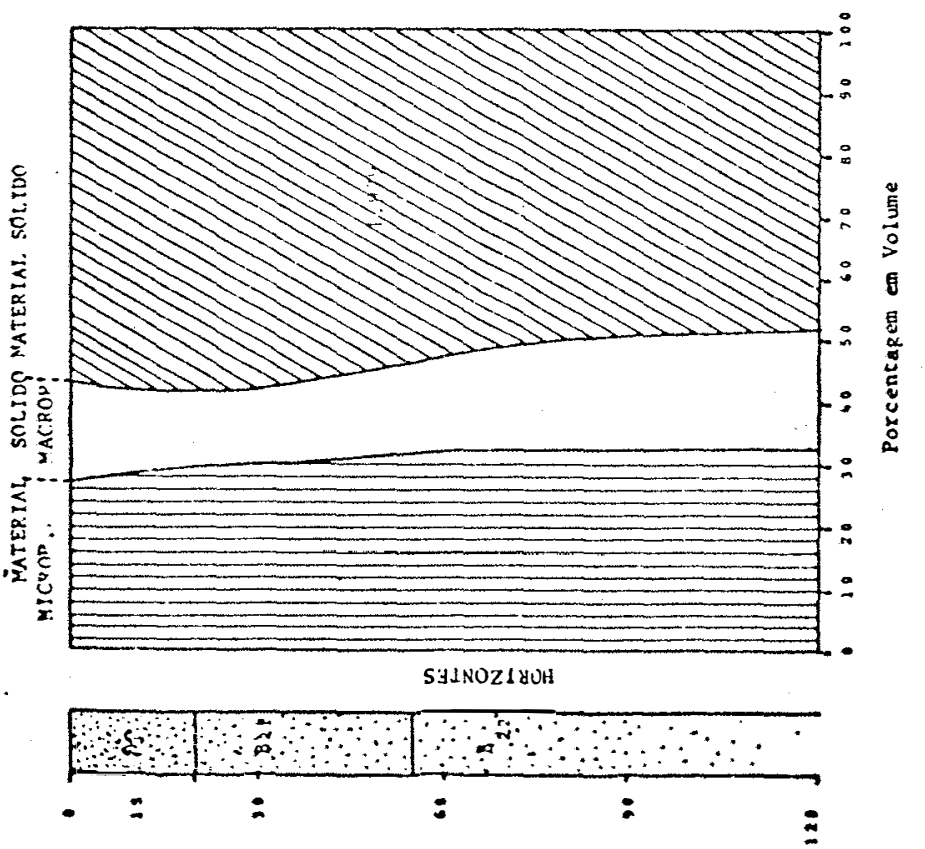

o

$\pi$

in 4

응

0

in $\pi$

$\begin{array}{ccc}0 & 1 & 0 \\ -1 & 0 & 0 \\ 3 & 0 & 0 \\ 3 & 0 & 4\end{array}$

त्र

留究

$\begin{array}{ccc}n & 5 & 0 \\ -1 & 5 & \pi \\ 0 & 4 & 4\end{array}$

1

6

$\dot{0}$

I 


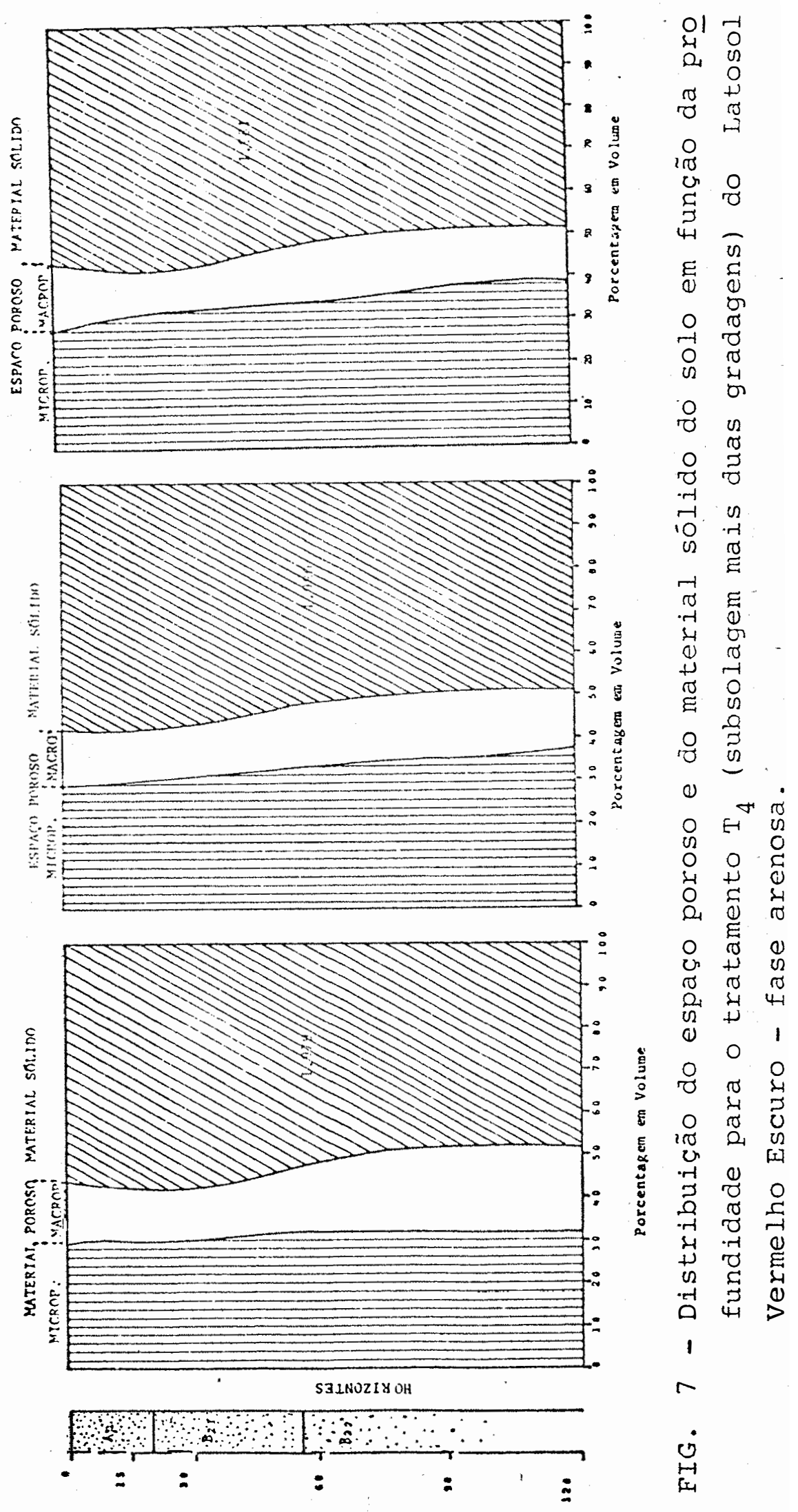




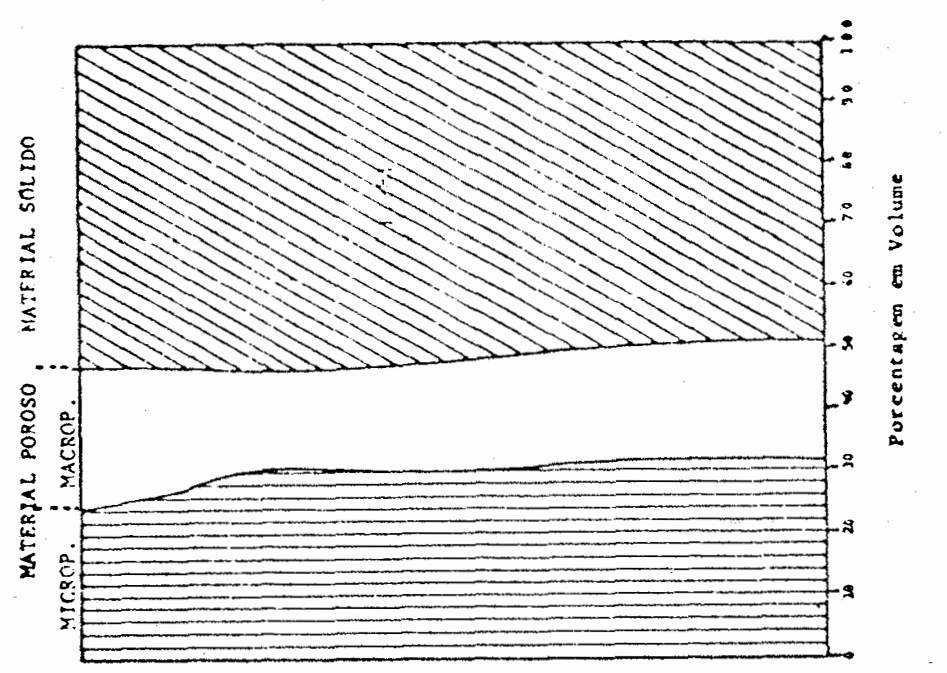

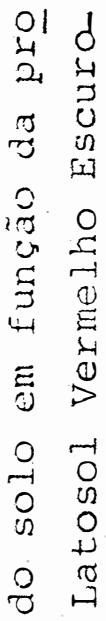

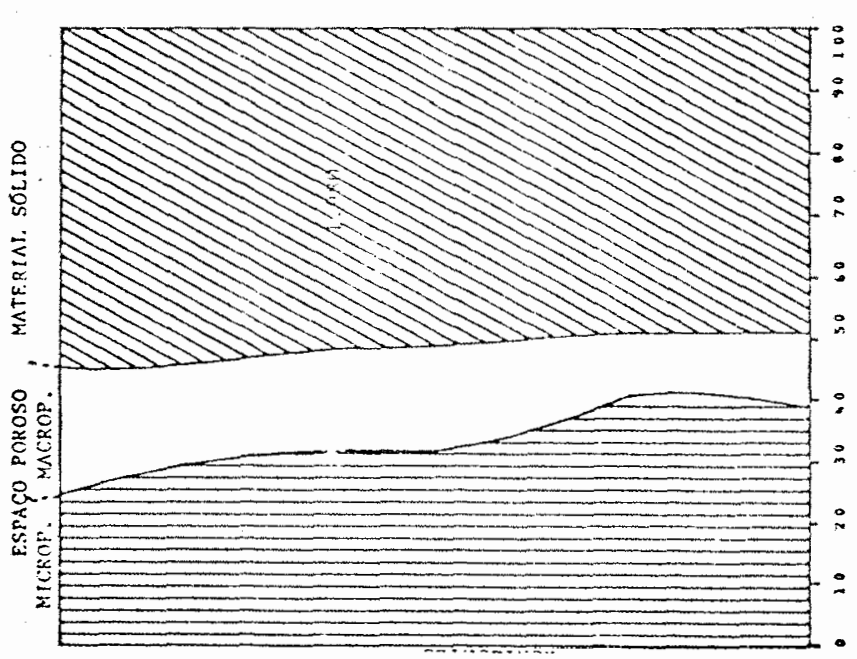

○

.

10

os

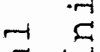

.

प

E

$\circ)$

0

$0 \Leftrightarrow$

0
0
0
0
0
0

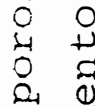

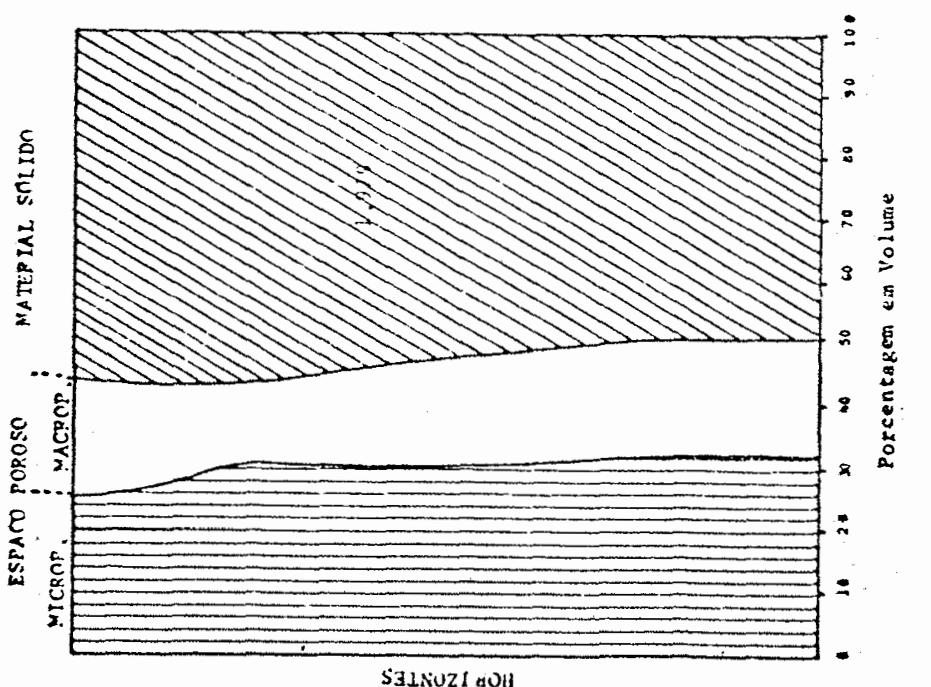

0 ह

थ

is

i)

0
0
0

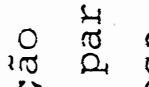

er

न

तु

艾赦

$\begin{array}{ccc}n & 5 & 0 \\ -1 & 5 & 0 \\ 0 & 4 & 4\end{array}$

1

$\infty$

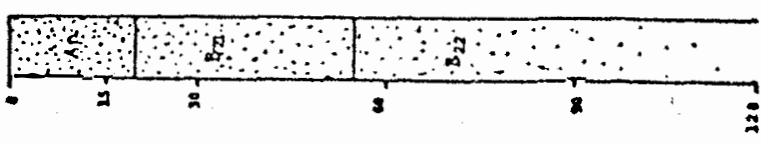

$\stackrel{0}{H}$ 
pouco menores nesta parte do solo no tratamento $\mathrm{T}_{5}$. Contudo, não foi observada qualquer tendência de alteração com o decor rer do tempo, conforme se verificaram na porosidade total e macroporosidade.

A macroporosidade e a microporosidade apresenta ram o comportamento revelado pela porosidade total, no que diz respeito à distribuição dos seus valores em função dä prô fundidade do solo.

Ao considerar-se a relação macroporosidade/micro porosidade se constatou que esta relação esteve sempre próxí ma de 0,5 em todas as camadas do solo e tratamentos, excetuan do a porção superficial do solo no tratamento $\mathrm{T}_{5}$, onde os va lores desta relação se apresentaram próximo de 0,8. Ocorreu inclusive um pequeno aumento com a sucessão dos ciclos cultú rais. A alteração desta relação, aumentando o seu valor, in dica um aumento da macroporosidade em relação a microporosidade, o que sugere maior formação de agregados na porção superior do solo no tratamento $\mathrm{T}_{5}$. Isto pode ser entendido como decor rente do máior acúmulo de material orgânico, deixado pelos restos culturais.

\subsubsection{Latosol Roxo}

As características determinadas no Latosol Roxo para cinco modalidades de preparo do solo e três épocas de amostragem são apresentadas na Tabela 7 . 

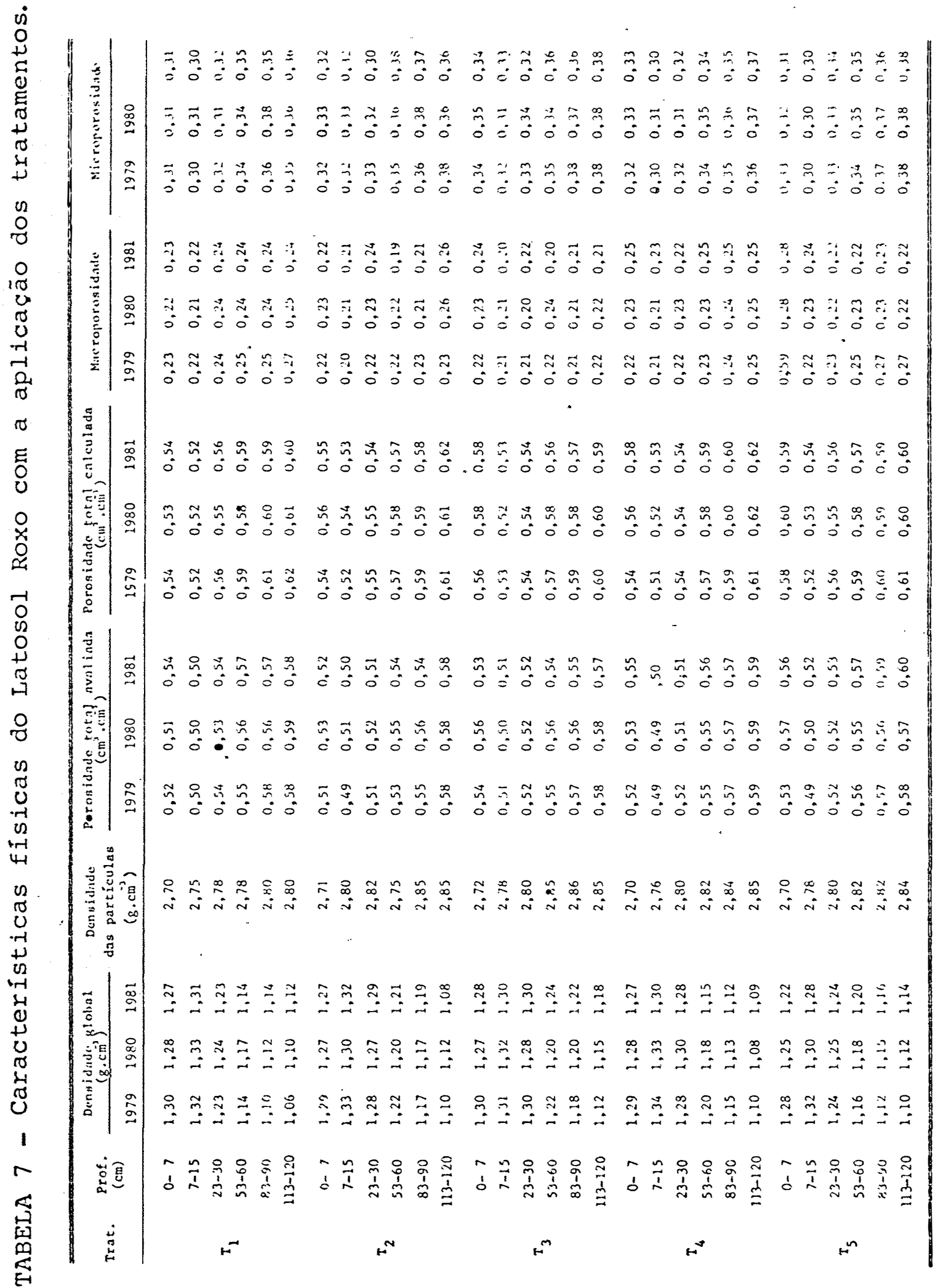
Densidade global

Não se observaram efeitos diferenciais das moda lidades de preparo do solo nos valores da densidade, exceto na porção superior do solo no tratamento $T_{5}$. Nesta camada do solo não se observaram, no primeiro ano de experimento, alte rações nos valores da densidade global, sendo estas mostradas somente a partir do segundo ano. Contudo, as diferenças fo ram pequenas, sendo mais evidentes somente nos primeiros 7,0 cm de espessura da camada superficial. Neste solo, também não foi alterada a caracteristica típica dos latossois de apresentar valores menores no horizonte B latossólico. As Fi guras 9 e 10 representam a distribuição dos valores da densi dade global em função da profundidade, possibilitando desta maneira uma melhor visualização dos aspectos considerados.

Densidade das partículas

Os valores da densidade das partículas não reve laram qualquer tipo de diferenças nas condições analisadas.

\section{Porusidade total}

A porosidade total avaliada e a porosidade to tal calculada não mostraram qualquer distinção entre os trata mentos e também, os seus valores não foram diferentes com o decorrer do tempo.

Os valores da porosidade total calculada foram pouco superiores aos da porosidade avaliada, mas com diferen ças pequenas, revelando deste modo a existēncia de uniformida de na distribuição da porosidade do solo, favorecendo assim a 


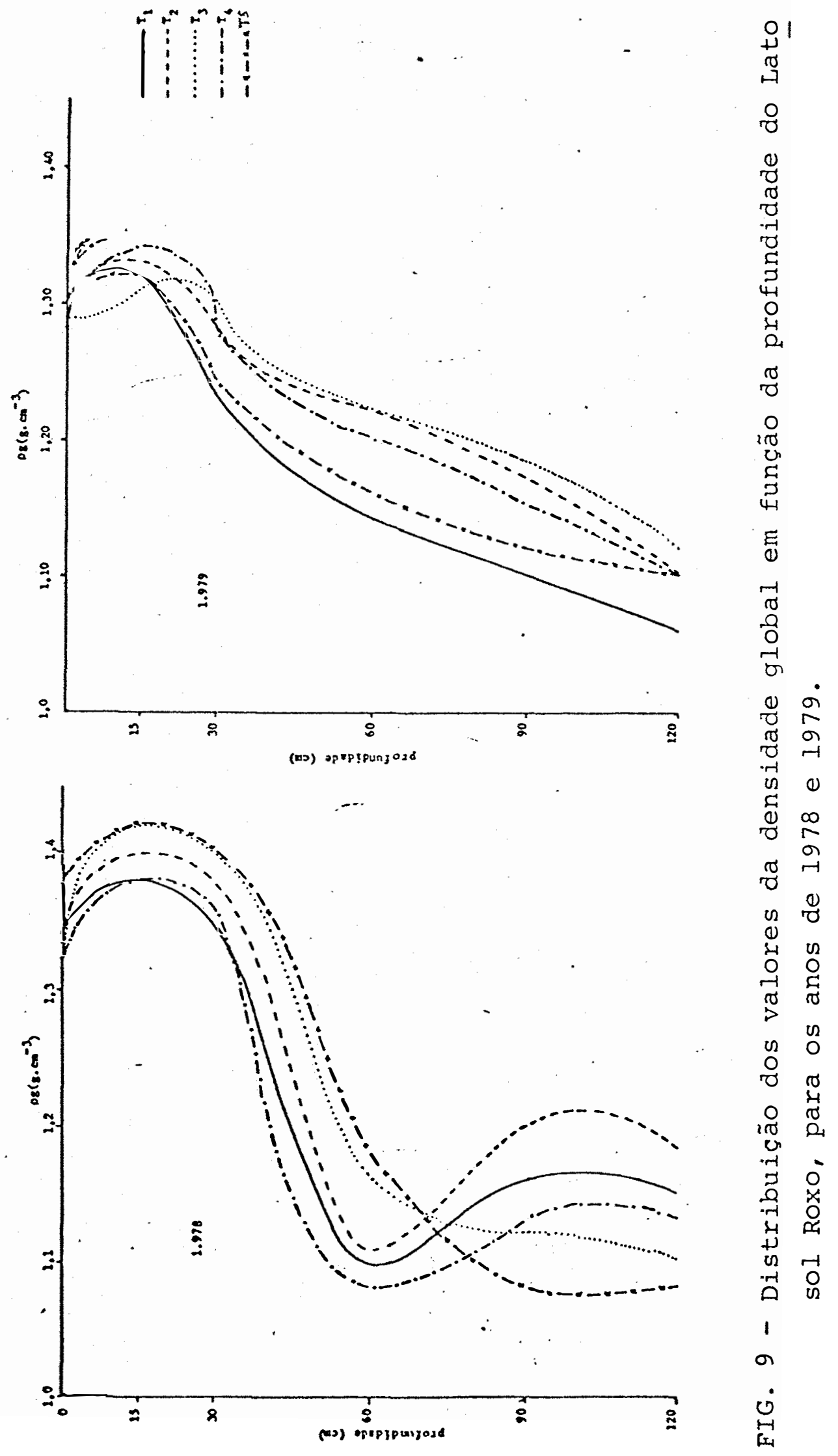




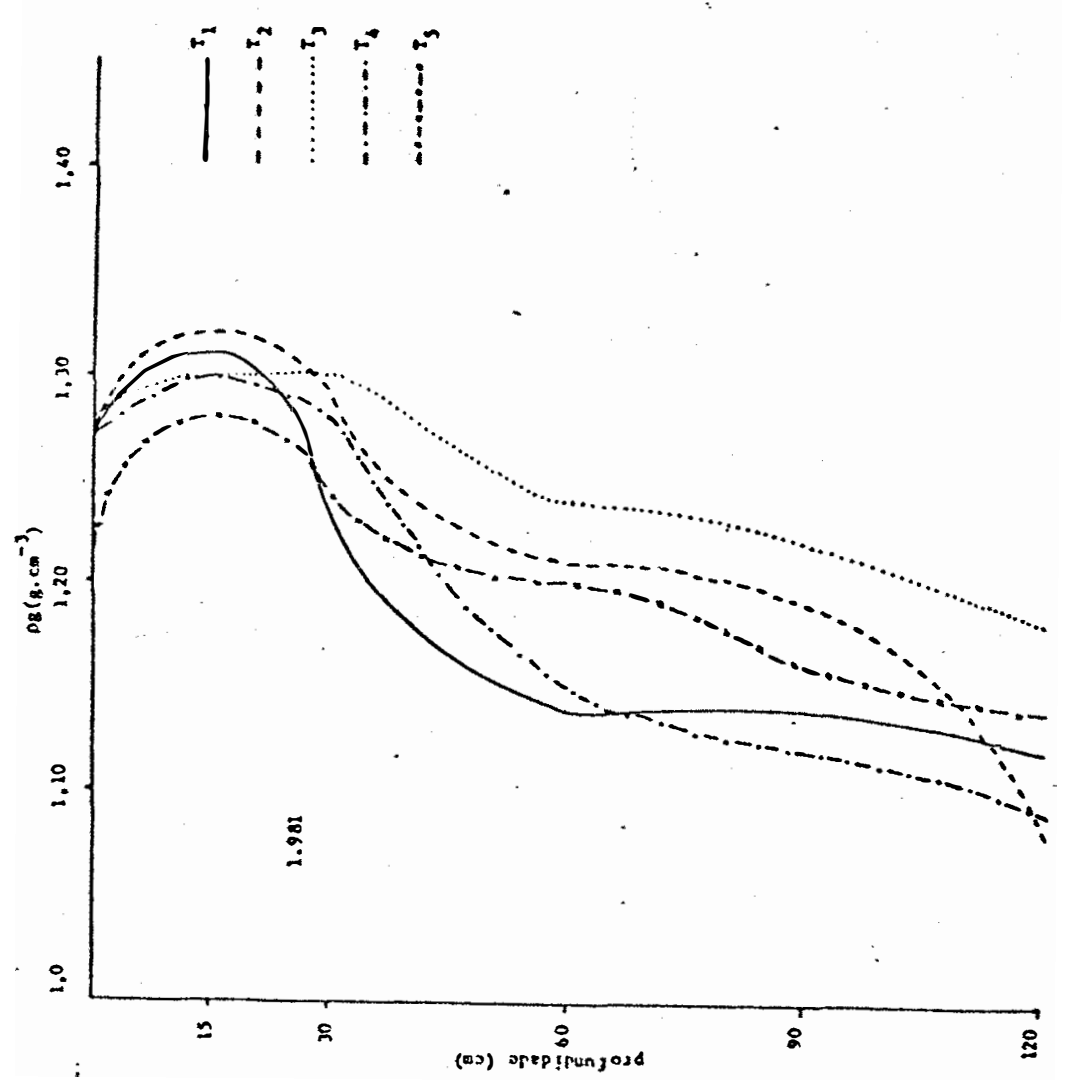

인

요

0
0
0
0
-1
0
0
5
4
0
4
4
0

శ్ర

范

E्ञ

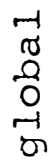

$\begin{array}{cc}0 & -1 \\ 0 & 0 \\ 0 & 0 \\ 0 & -1\end{array}$

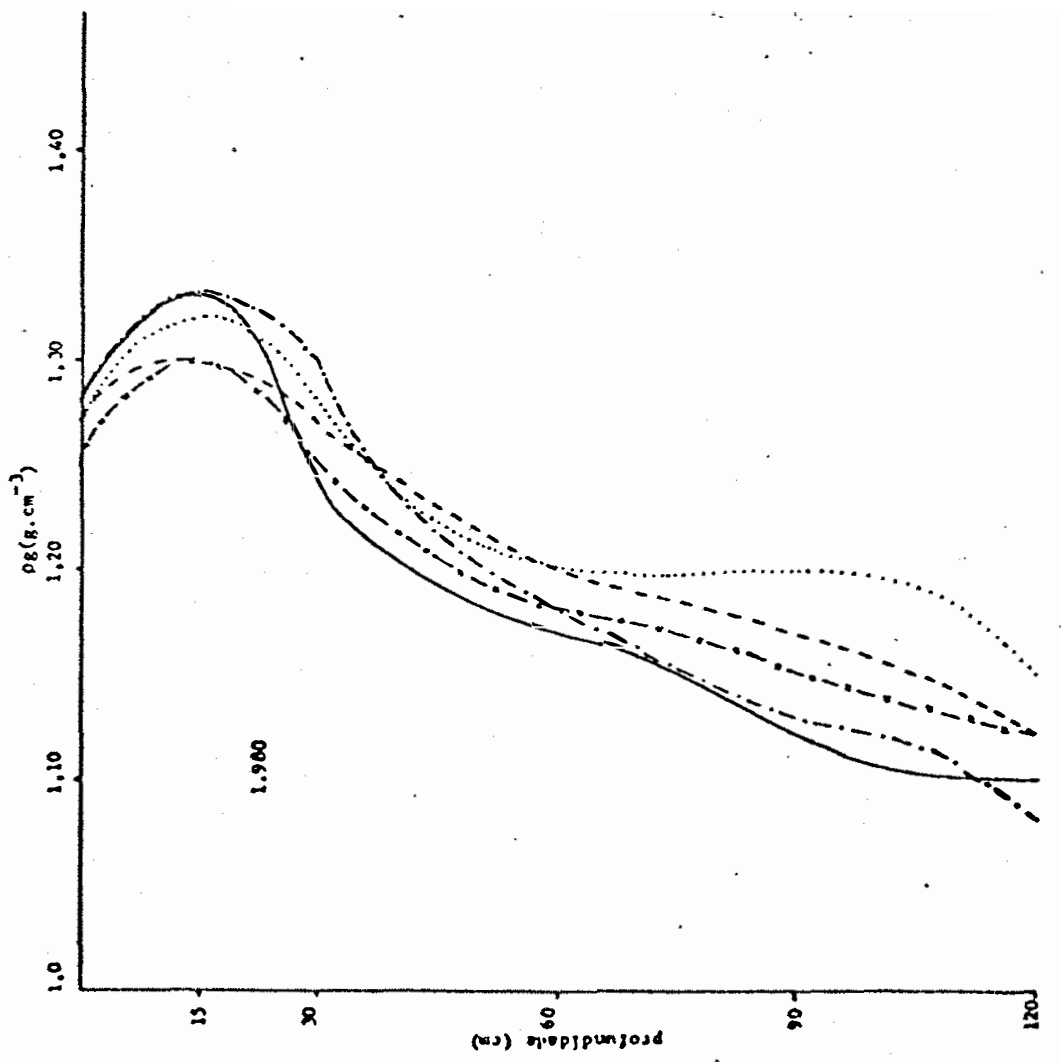

or 0

范

r

थ

0

$\begin{array}{cc}4 & 0 \\ 0 & 0 \\ -1 & 5\end{array}$

3

u 0

ชิ

- मै

in

on

กิ

4 م

in
-1
0

1

它 
entrada e a saída de água e de ar do solo. As Figuras 11 a 15 representam o espaço poroso do solo dos cinco tratamentos e três amostragens. Por apresentarem-se semelhantes quanto a distribuição e conformação, essas figuras foram eficientes pa ra melhor visualização das similaridades verificadas.

Mácroporosidade e microporosidade

A macroporosidade e a microporosidade não apre sentaram alterações diferenciais, provocadas pelas modalida des de preparo do solo com o decorrer da sucessão dos ciclos culturais, sendo semelhante, ao comportamento apresentado pe la porosidade total. Não foram observadas alterações na rela ção macroporosidade/microporusidade.

4.2.3. Análise conjunta das características dos dois solos

Pela análise conjunta das caracteristicas deter minadas nos dois solos, pode-se estabelecer, confirmando as análises individuais de cada solo, que as alterações diferen ciais determinadas pelas modalidades de preparo do solo foram muito pequenas nos dois solos. Constatou-se que em texturas bem diferentes os efeitos pouco diferenciados nas condições do presente estudo.

Nos dois solos, somente o tratamento $\mathrm{T}_{5}$ lculti vo minimol apresentou efeitos um pouco mais diferenciados e isto, restrito à porção superior dos solos. Analisando a den sidade global da porção superior dos solos, no tratamento $\mathrm{T}_{5}$ ' 


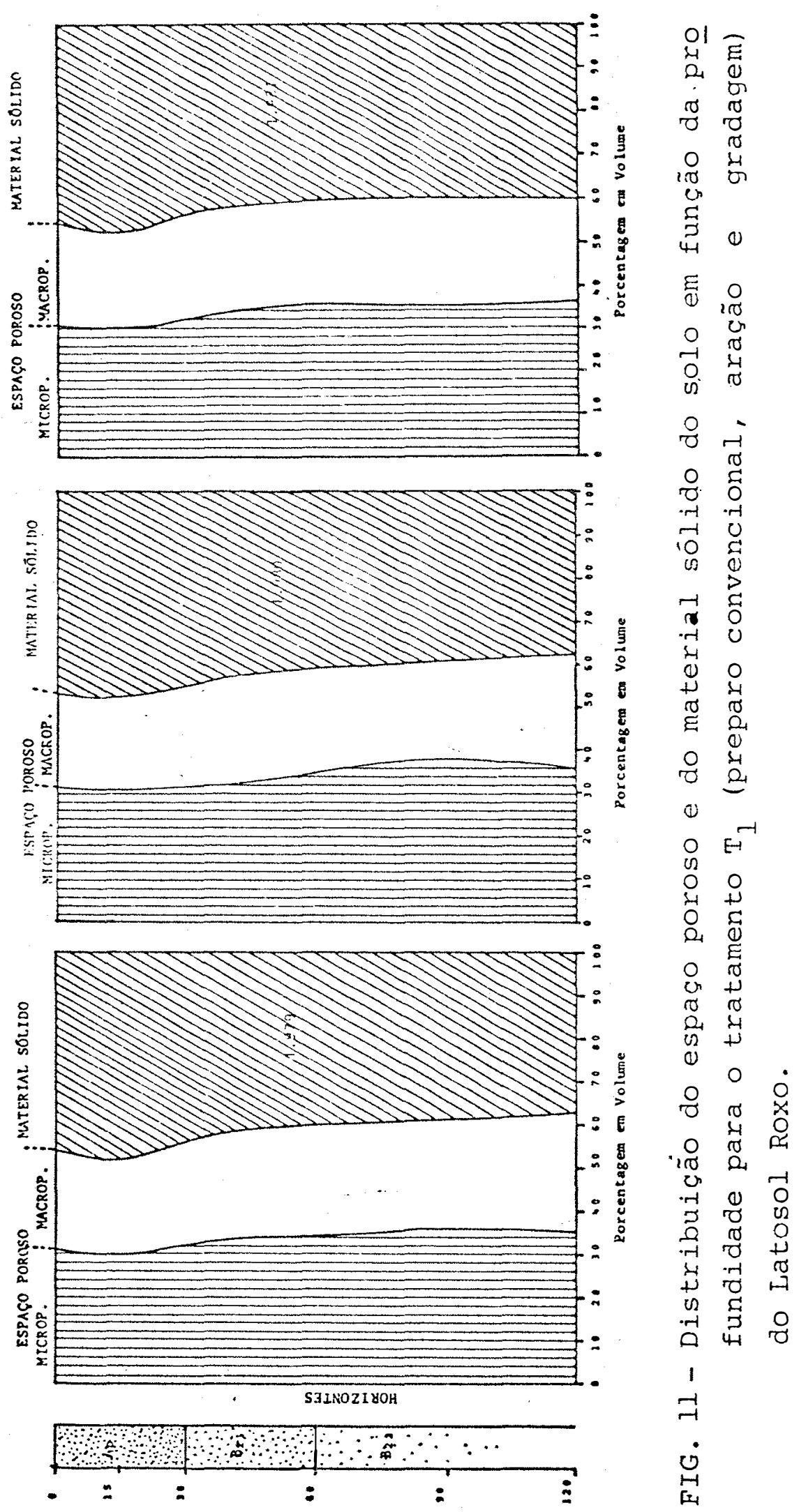



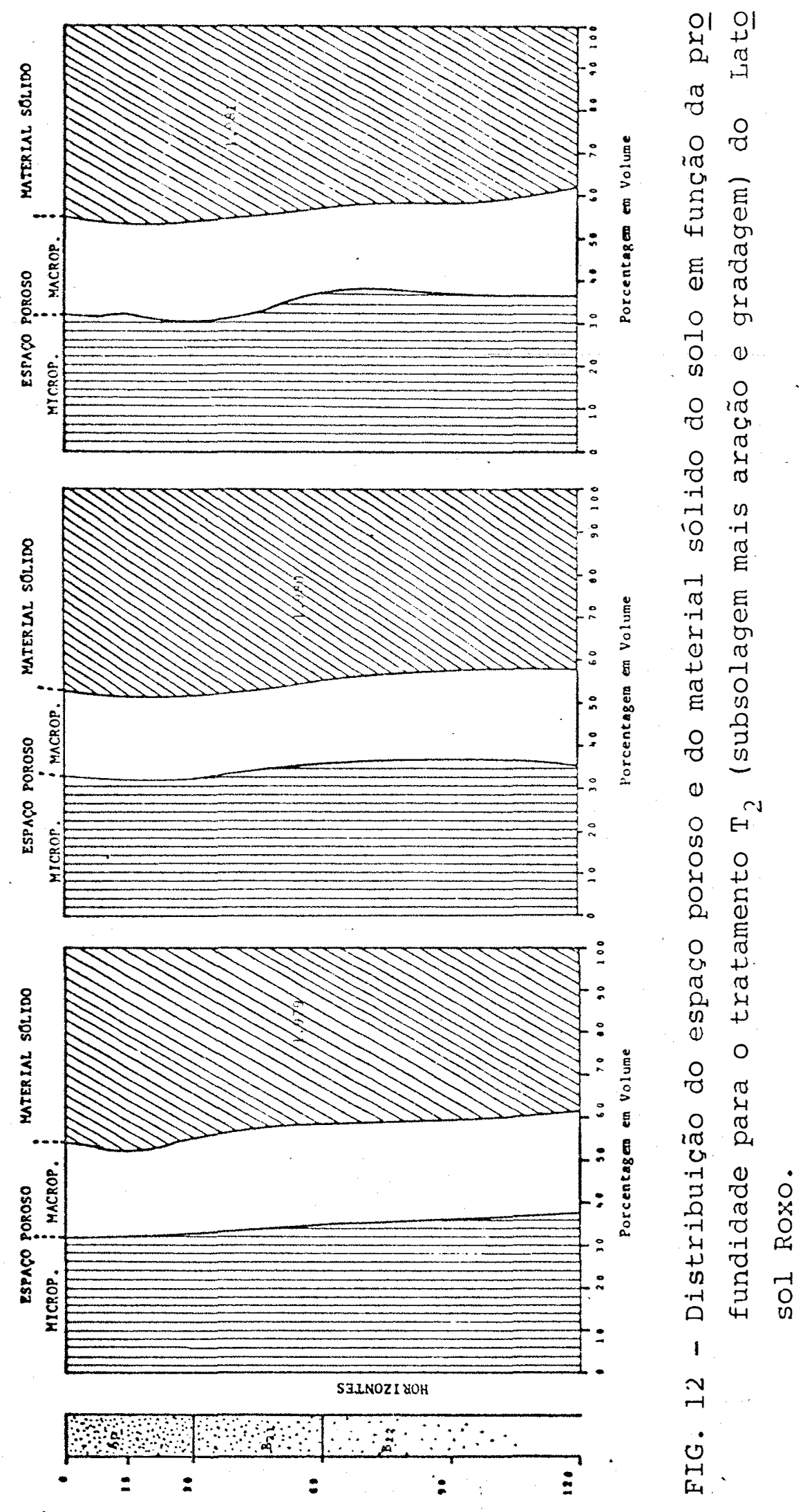


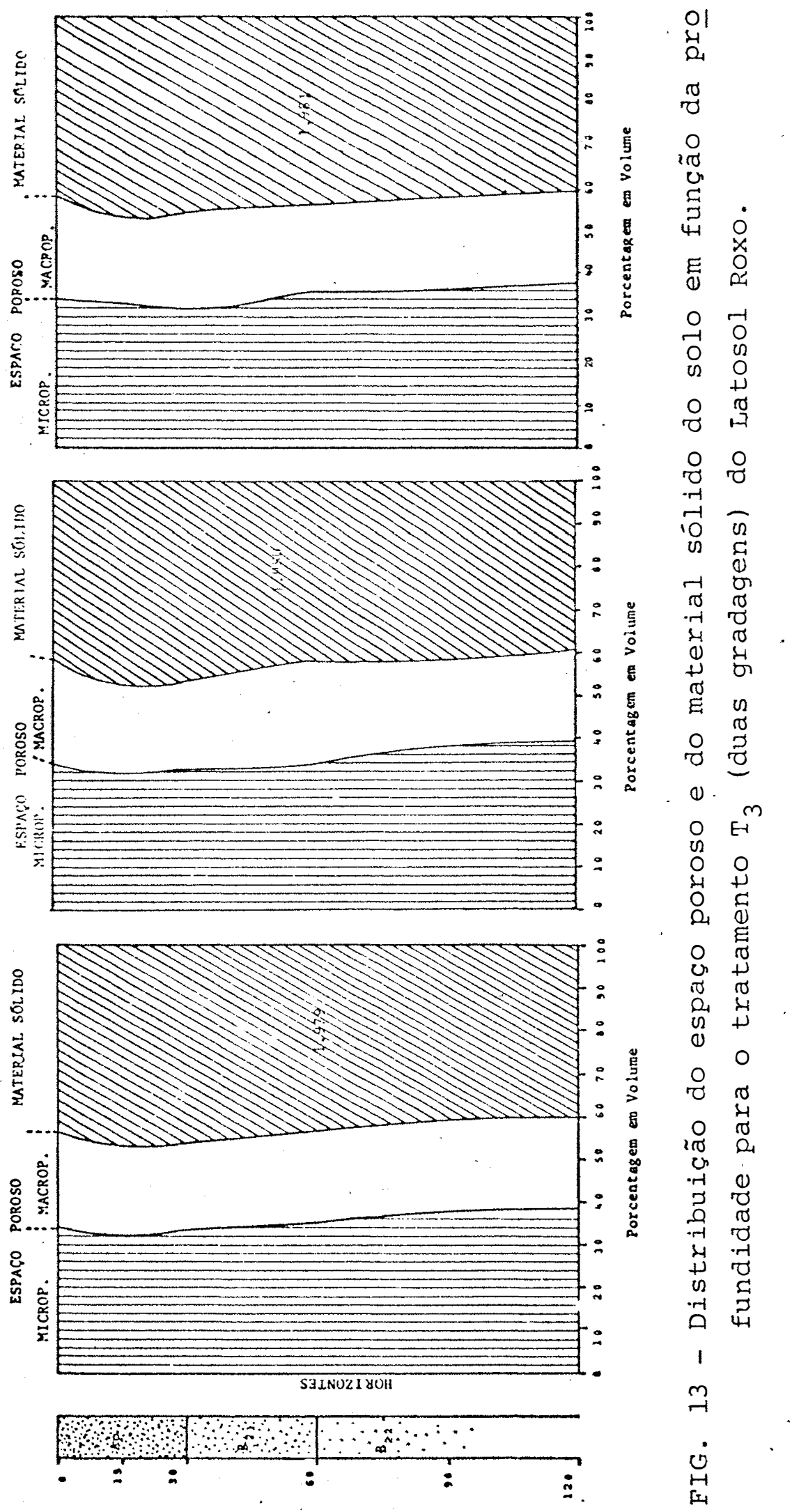




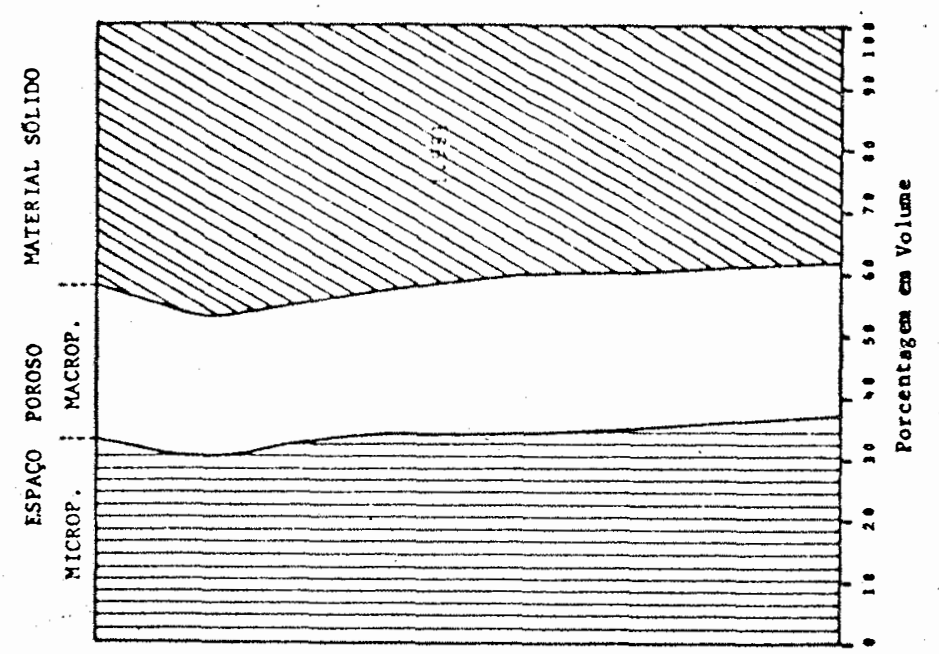

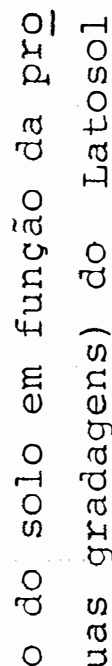
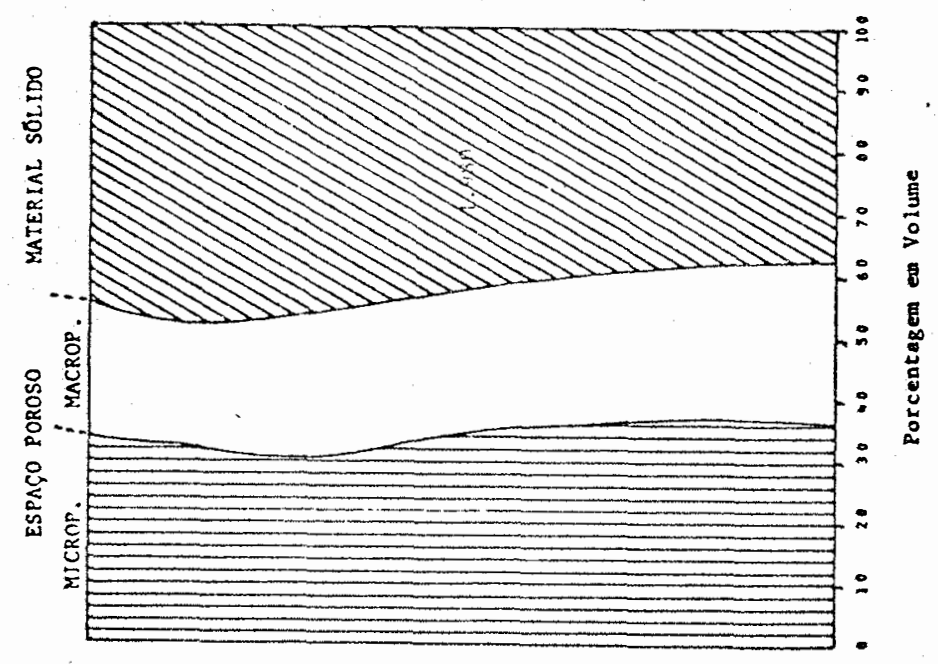

चु

- 2

$\because \begin{array}{ll}\sigma \\ 0 \\ 0\end{array}$

息

- $\begin{array}{ll}1 & 0 \\ 0 & 0\end{array}$

$+1$

正

응

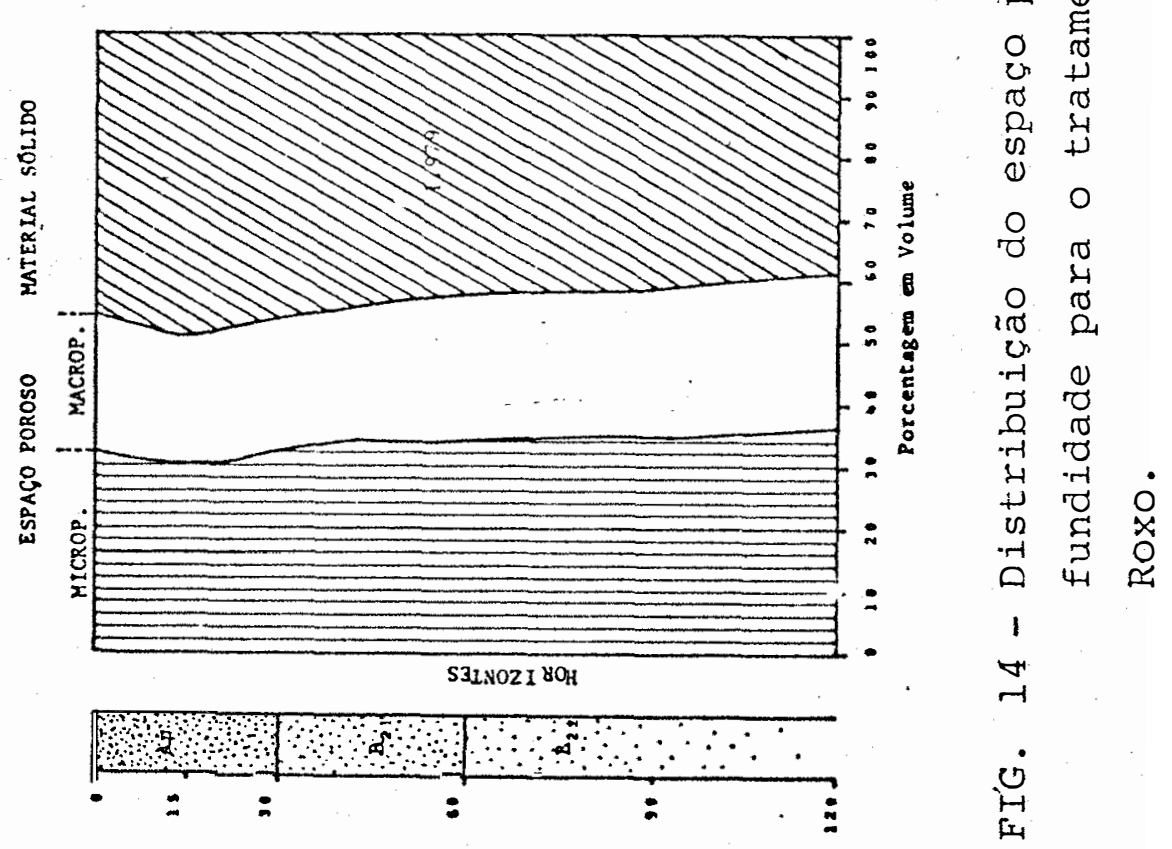



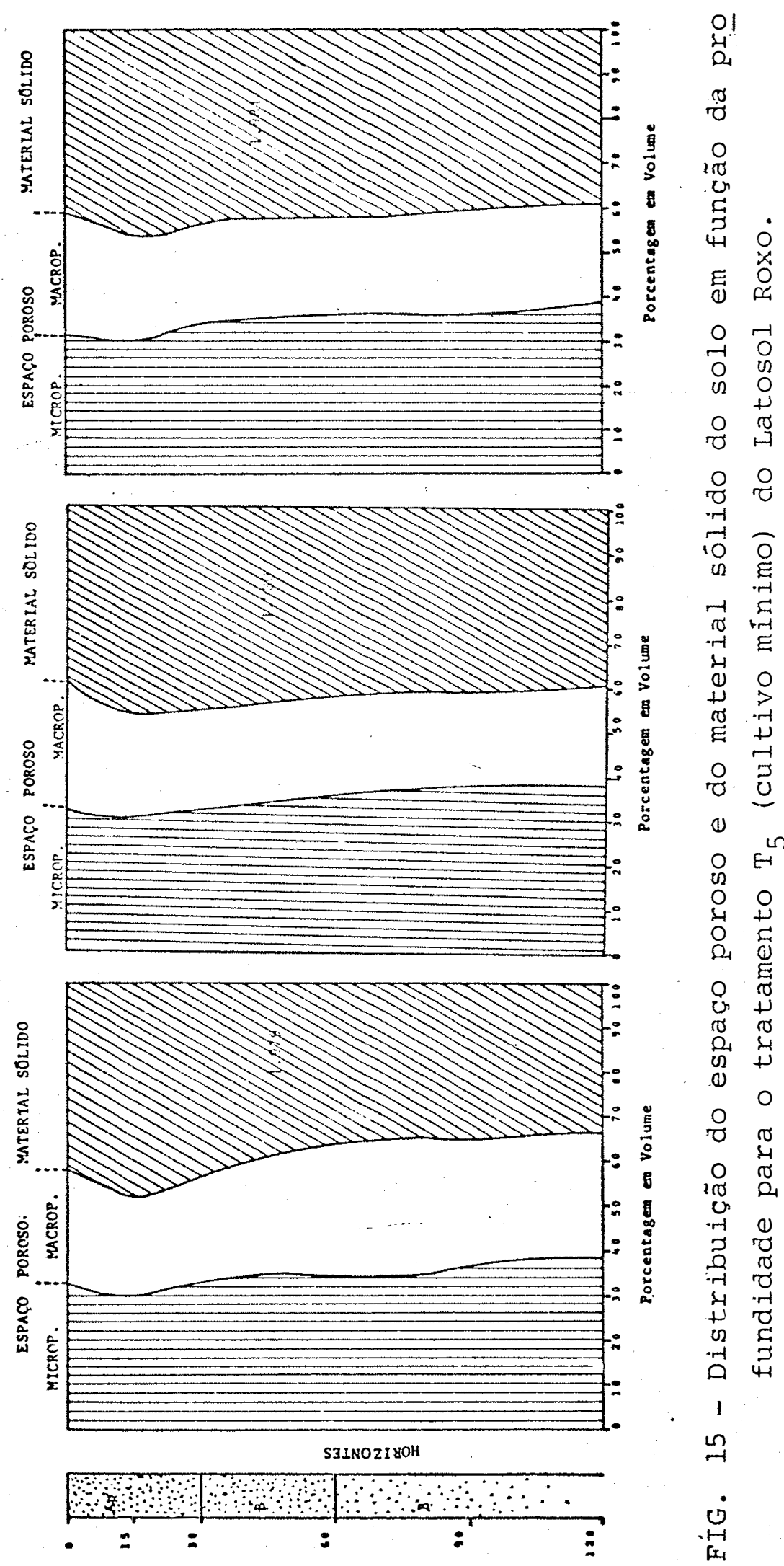
constatou-se diferenças entre solos, embora pequenas. No La tosol Vermelho Escuro - fase arenosa no primeiro ano de expe rimentação já foram observadas diferenciações dos valores da densidade global e no Latosol Roxo, as diferenças começaram a ser observadas somente a partir do segundo ano. As caracte risticas porosidade total, macroporosidade e microporosidade revelaram alterações provocadas pelo cultivo minimo somente no Latosol Vermelho Escuro - fase arenosa. Os resultados ob tidos corroboraram com dados bibliográficos, particularmente com os de BAEUMER e BAKERMANS (1971), por sugerirem, que em condições de textura mais grosseira, os efeitos da ação da mo bilização do solo deverão ser mais intensos.

As modificações observadas no presente estudo, principalmente no Latosol Vermelho Escuro - fase arenosa, su geriram, de maneira geral, que a menor mobilização do solo fa vorece a diminuição dos valores densidade global e aumenta os valores da porosidade e a agregação, principalmente na parte superficial do solo, confirmando PAGE et alii (1946), STEPHEN et aiii (1969), MACHADO (1976) e GOMES et alii (1978).

4.3. Algumas caracteristicas hídricas do Latosol Vermelho Escuro - fase arenosa, determinadas nos tratamentos $\mathrm{T}_{1}$ (preparo convencional de aração e gradagem) e $\mathrm{T}_{5}$ (cul tivo mínimo)

As caracteristicas hídricas, umidade em volume em função do potencial matricial, os perfis de umidade do so 
lo e a variação do armazenamento de água, foram determinadas no Latosol Vermelho Escuro - fase arenosa nas diferentes pro fundidades para os tratamentos $\mathrm{T}_{1}$ e $\mathrm{T}_{5}$.

Umidade em volume em função do potencial matricial

Os valores da umidade em volume $\left(\theta \mathrm{cm}^{3} \cdot \mathrm{cm}^{-3}\right) \mathrm{em}$ função da variação do potencial matricial para as diferentes profundidades do solo e ciclos agrícolas 1978/79, 1979/80 e 1980/81 são apresentados na Tabela 8. As curvas de retenção de água estão representadas nas Figuras 16 a 21 .

A análise dos dados apresentados revelou ini cialmente, que a retenção de água para as diferentes condi ções analisadas é relativamente homogênea, ocorrendo sempre diferenças muito pequenas, sugerindo que o efeito diferencial determinado pelas modalidades de preparo do solo foi de muito baixa intensidade.

o conjunto global das curvas de retenção de água permitiu averiguar que no primeiro ano as diferentes curvas de cada tratamento se mantiveram bastante próximas en tre si e que nos segundo e terceiro ano se apresentaram mais espaçadas, sugerindo, deste modo, maior uniformidade do solc no período inicial de implantação do experimento. Ressaltan do-se, no entanto, que as diferenças foram pequenas.

Comparando os dados entre tratamentos observouse de maneira geral, que as diferenças foram muito pequenas. $\mathrm{Na}$ condição de potencial matricial próximo de zero (solo satú rado) ocorreu no tratamento $\mathrm{T}_{5}$ uma maior retenção de água na 
TABELA 8 - Valores da umidade em volume $\left(\theta \mathrm{cm}^{3} . \mathrm{cm}^{-3}\right)$ em função da variação do potencial matri cial para as diferentes profundidades.

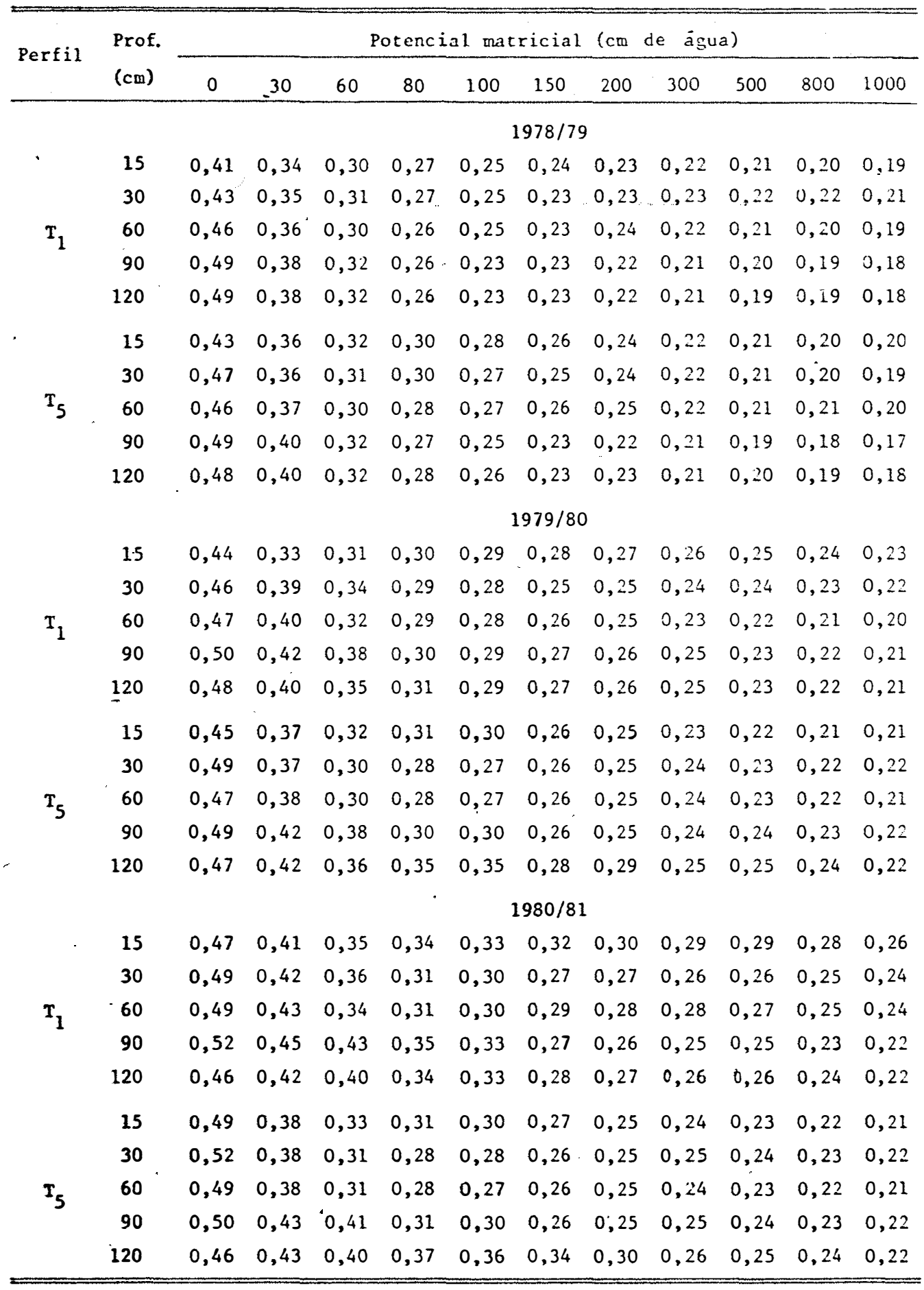


51

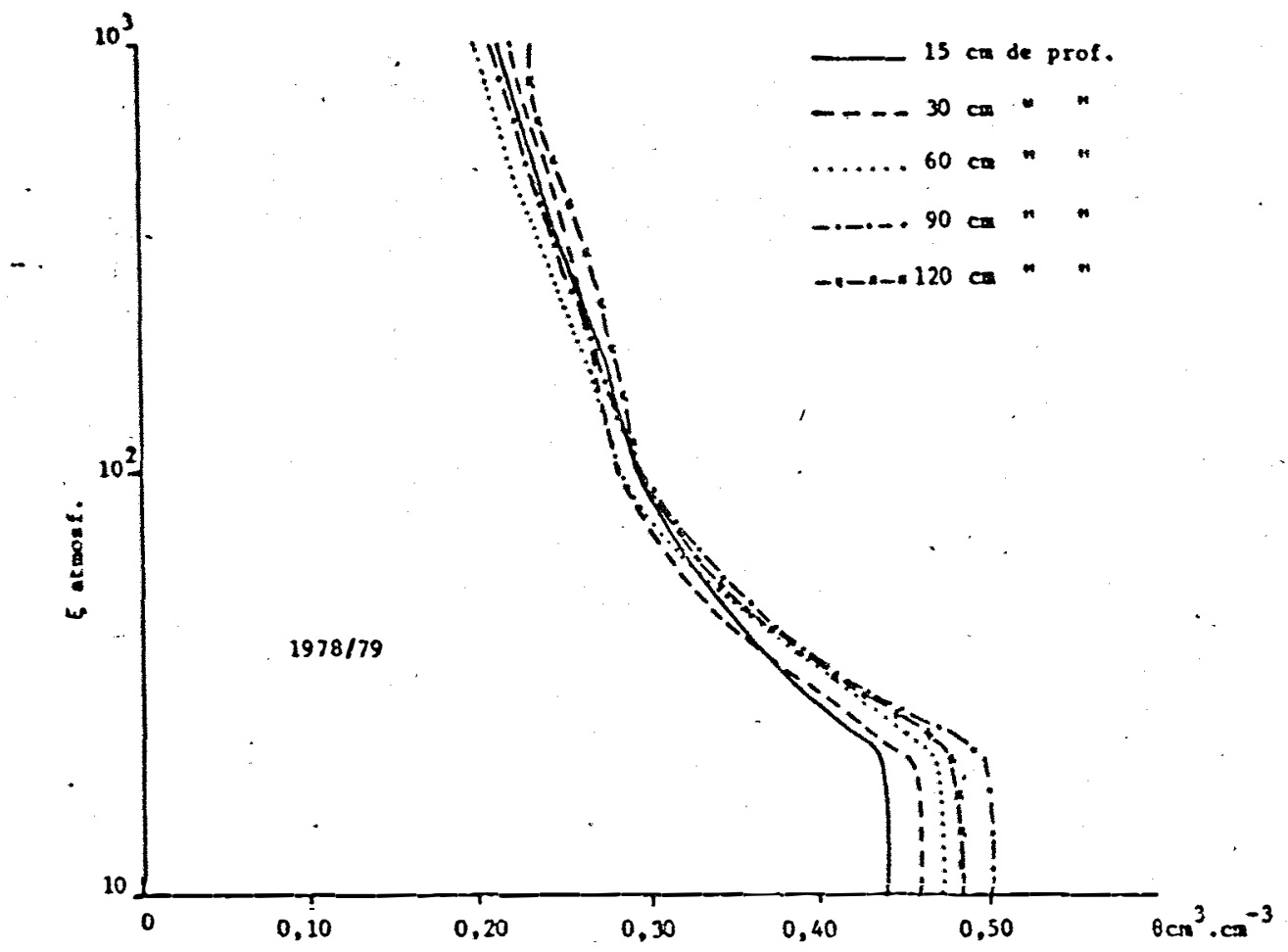

FIG. 16 - Curvas de retenção de água - tratamento $T_{1}-1978 / 79$.

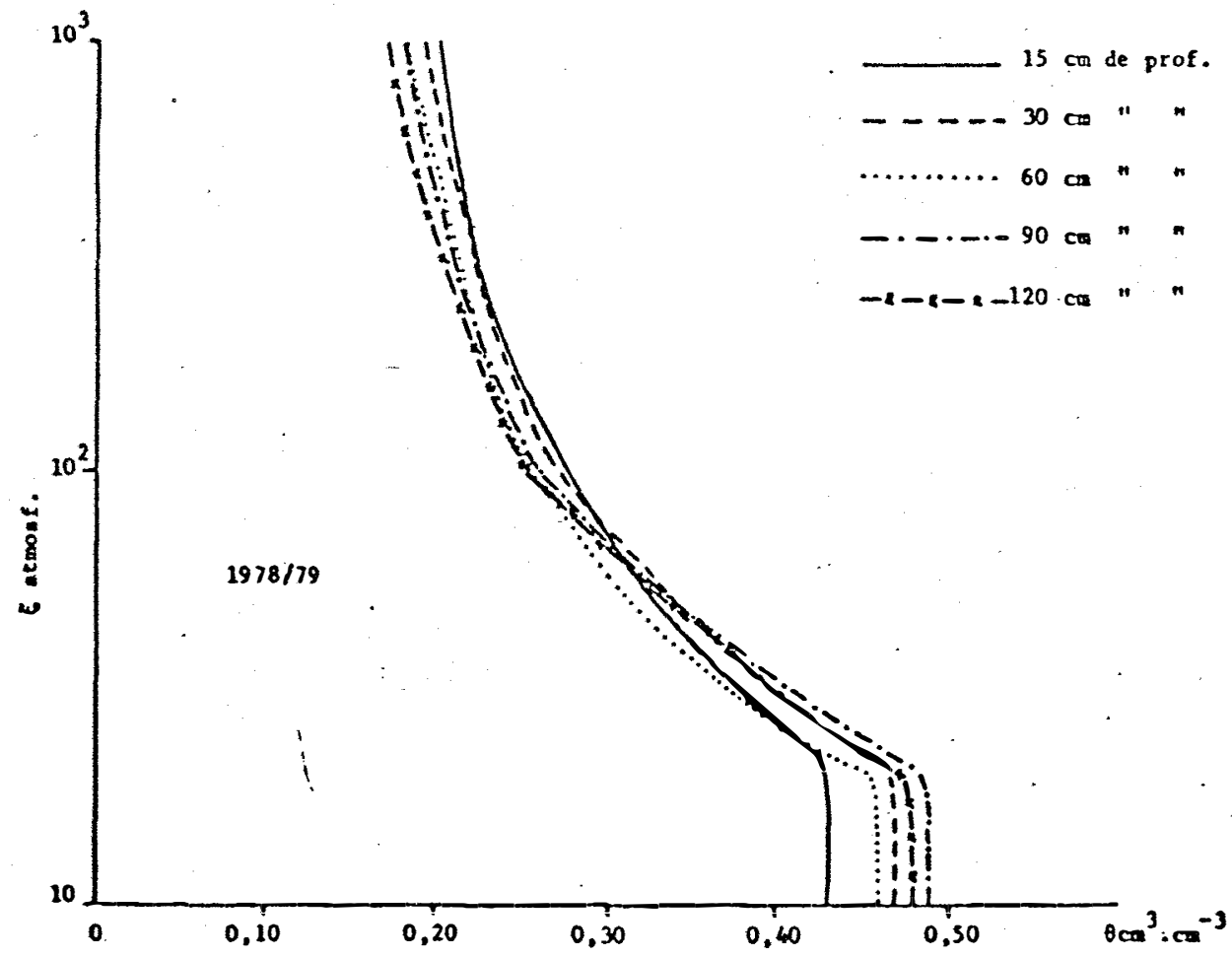

FIG. 17 - Curvas de retenção de água - tratamento $T_{5}-1978 / 79$. 


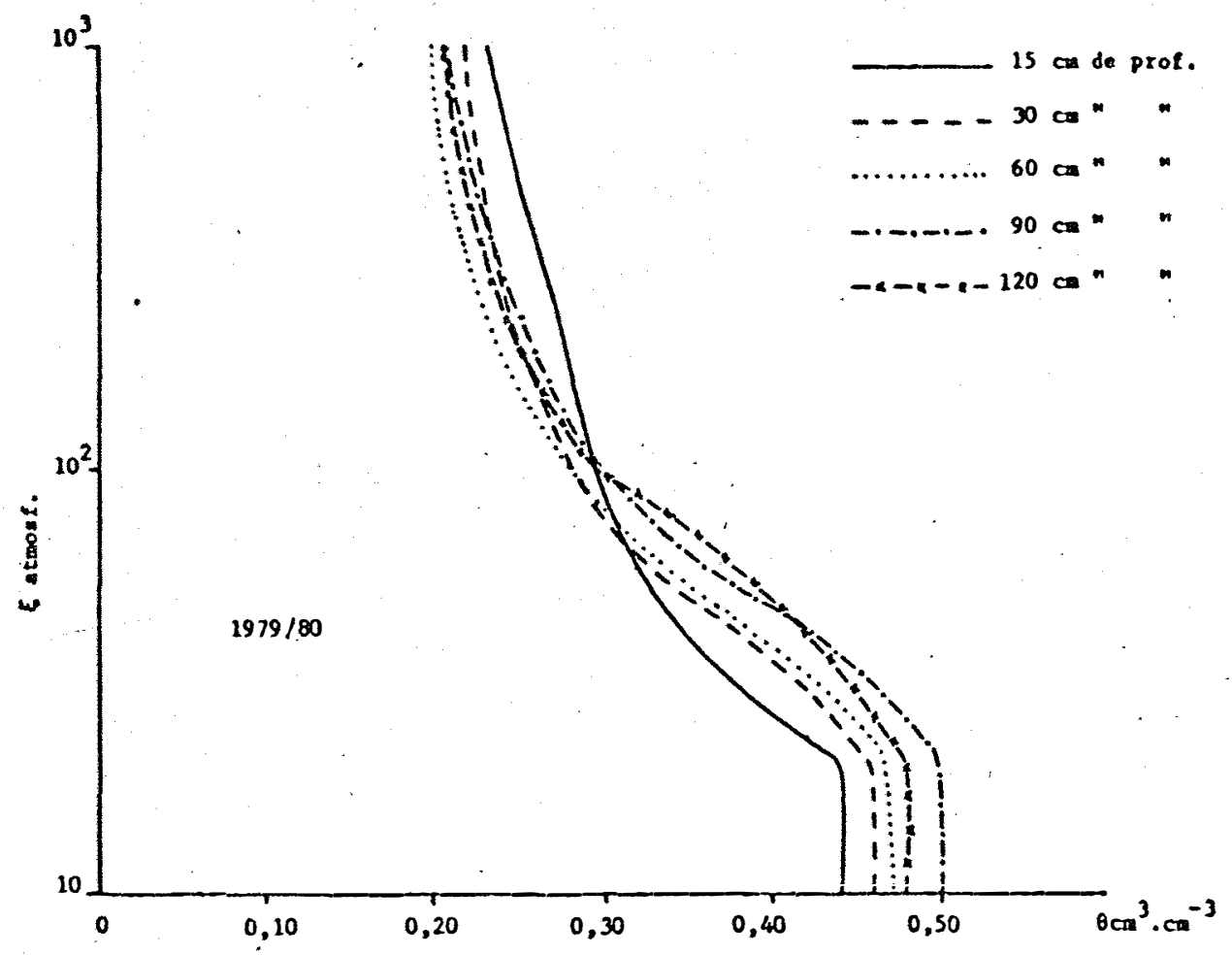

FIG. 18 - Curvas de retenção de água - tratamento $T_{1}-1979 / 80$.

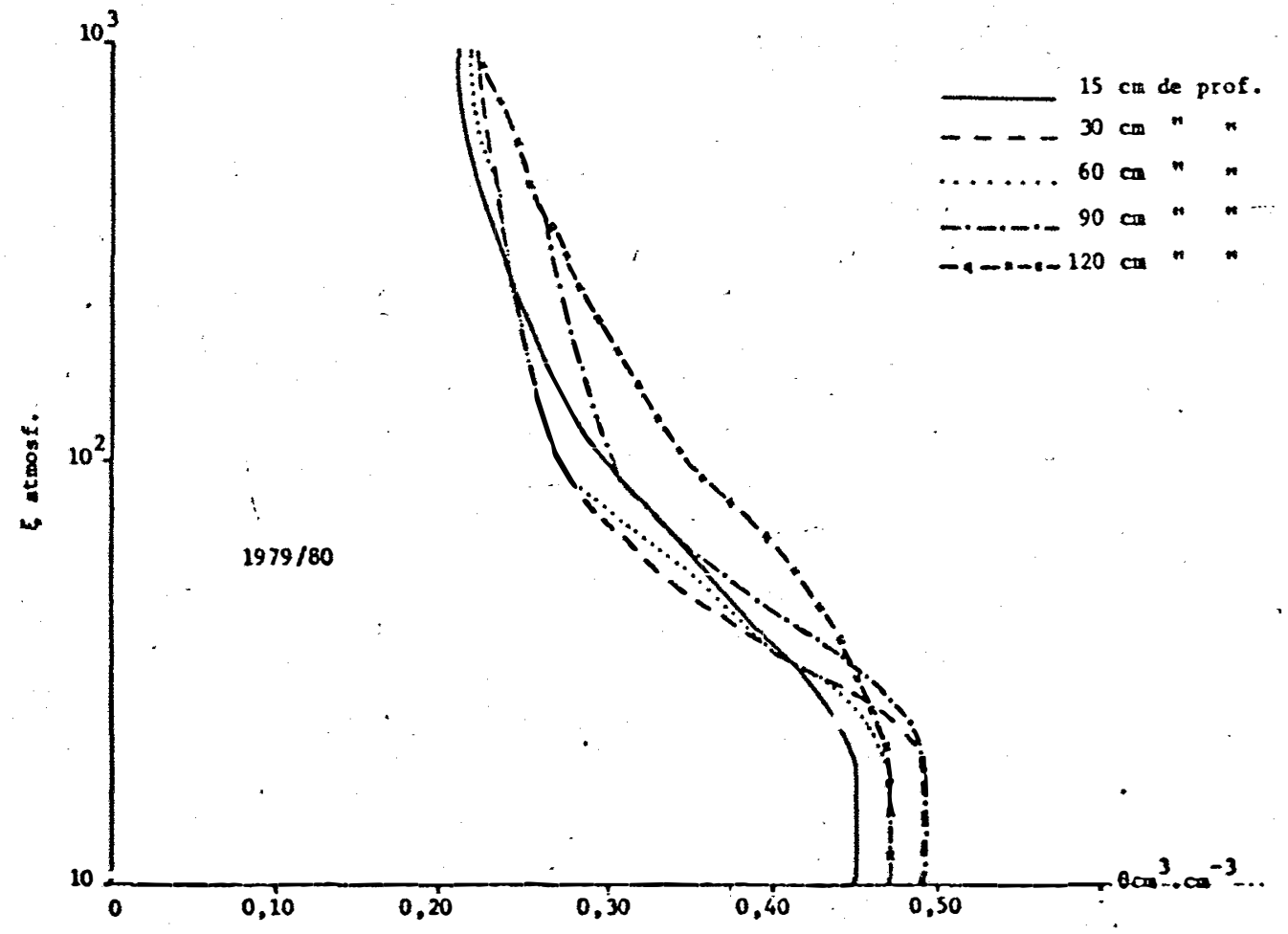

FIrs. 19 - Curvas de retenção de água - tratamento $\mathrm{T}_{5}-1979 / 80$. 


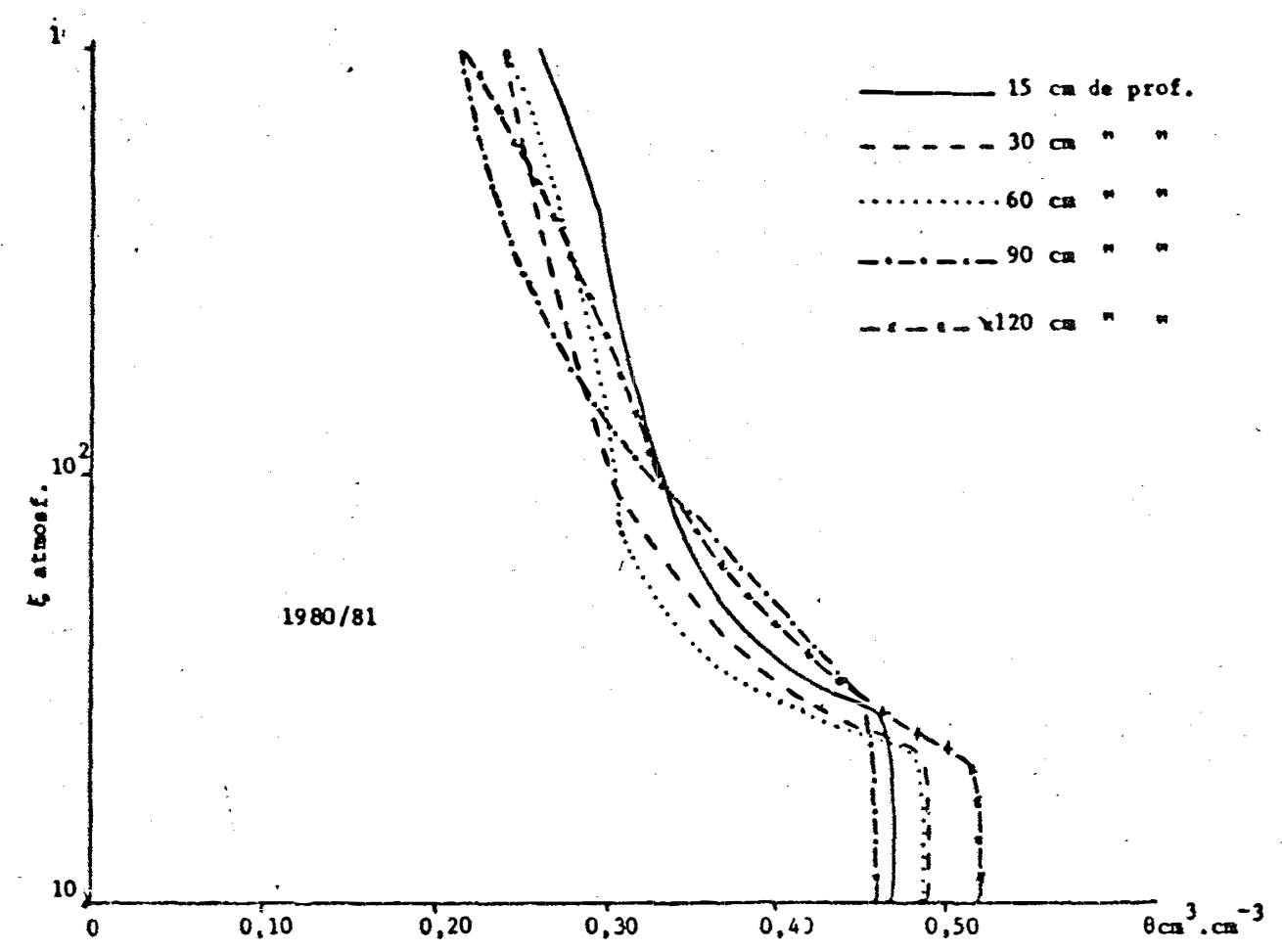

FIG. 20 - Curvas de retenção de água - tratamento $\mathrm{T}_{1}-1980 / 81$.

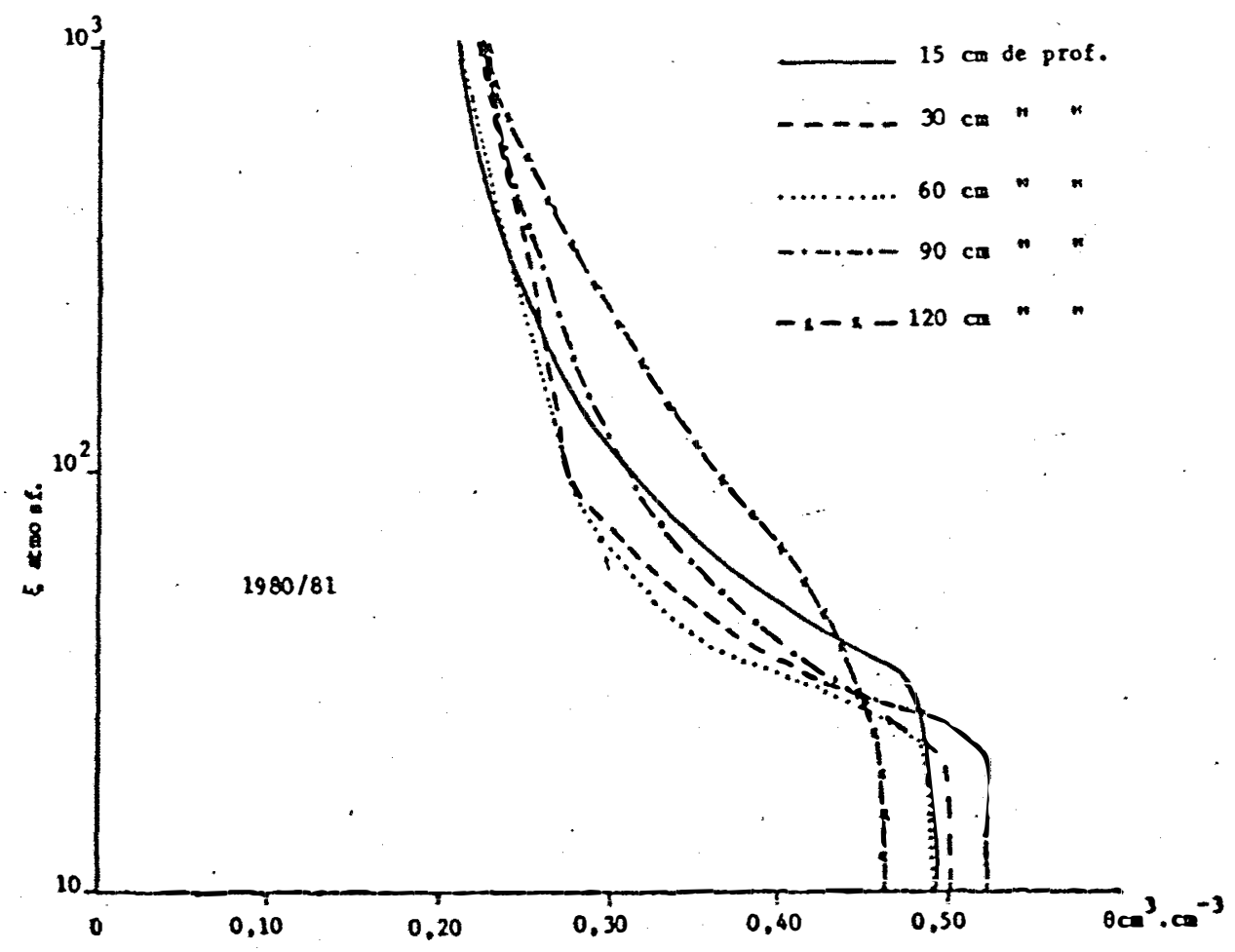

FIG. 21 - Curvas de retenção de água - tratamento $m_{5}-1980 / 81$. 
camada superficial do solo, com espessura de $30 \mathrm{~cm}$, nos três anos de experimentação. Na condição de potencial matricial de $30 \mathrm{~cm}$ de coluna de água se apresentaram valores mais altos nessa camada do solo, no tratamento $\mathrm{T}_{5}$, somente no primeiro ano ce experimentação. A partir do segundo ano ocorreu inver são, onde' os valores mais altos foram encontrados no tratamen to $T_{1}$, até a profundidade de $60 \mathrm{~cm}$. Na condição de poten cial matricial de $60 \mathrm{~cm}$ de coluna de água não foram observa das diferenças entre tratamentos nos dois primeiros anos e no terceiro ano, foram identificados valores mais altos no tratamento $\mathrm{T}_{1}$ até a profundidade de $60 \mathrm{~cm}$. Nas condições de potercial matricial com valores de 80 a $200 \mathrm{~cm}$ de coluna de áqua foram identificados valores mais altos no tratamento $\mathrm{T}_{1}$ somente no terceiro ano de experimentação, até a profundidade de $90 \mathrm{~cm}$. Para os potenciais matriciais de 300 a $1000 \mathrm{~cm}$ àe coluna de água não foram detectadas diferenças.

\section{Perfis de umidade do solo}

Os perfis de umidade do solo foram estabeleci dos para periodos entre duas chuvas consecutivas. Foi escolh do um periodo para cada ano de experimentação, com a particu laridade de localizá-lo sempre dentro do mesmo estágio de de senvolvimento da cultura. Dentro de cada periodo foram traça dos vários perfis, representando intervalos de 96 horas. Nas Figuras 22 e 23 foram representados os perfis referentes ao pe ríodo de 16 a 28/02/79, nas Figuras 24 e 25 os do perído de 28/01 a 08/02/80 e nas Figuras 26 e 27 os do periodo de 12 a 28/02/81. 


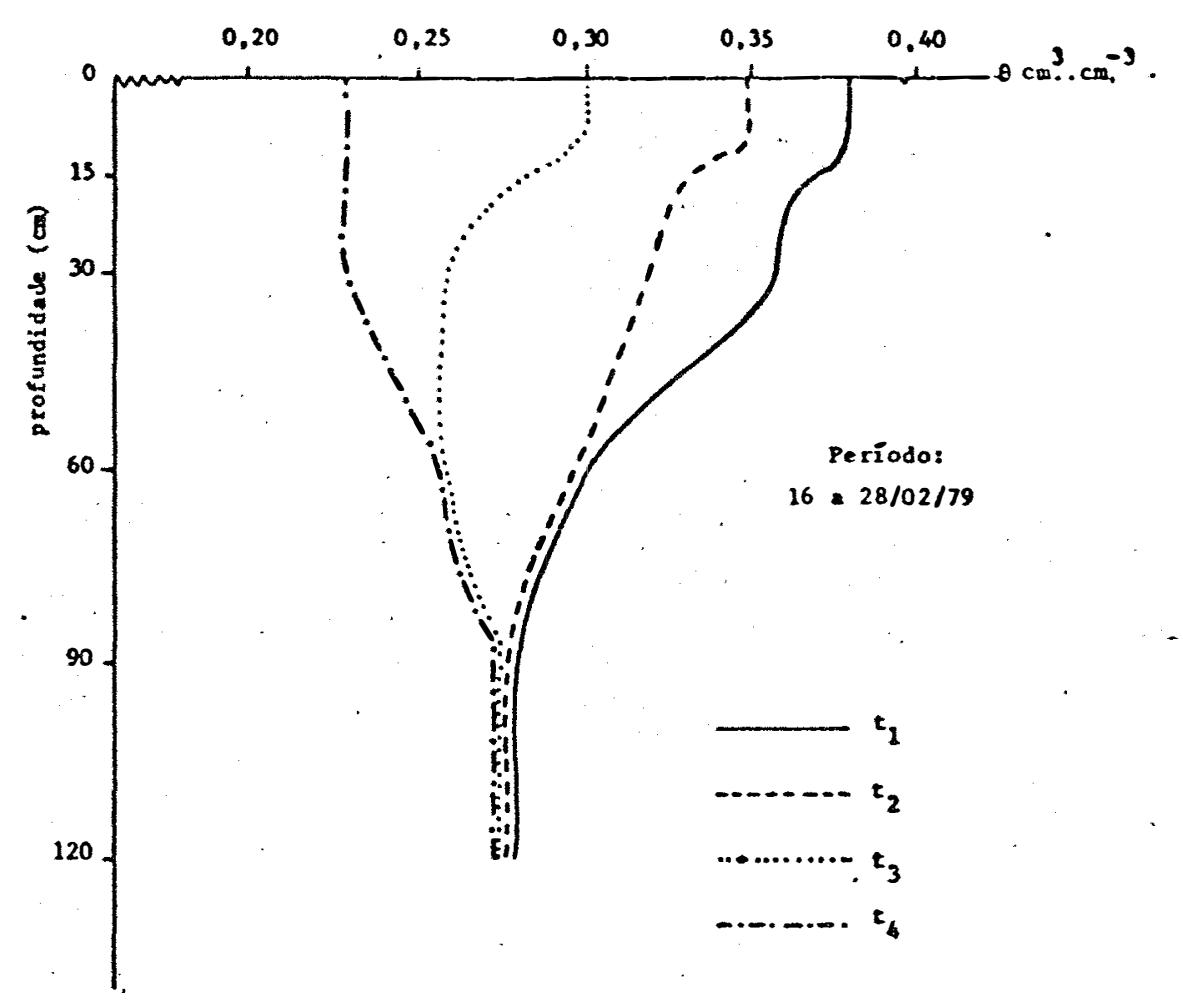

FIG. 22 - Perfis de umidade do s01o, em função da profun didade e do tempo para o tratamento $\mathrm{T}_{1}$.

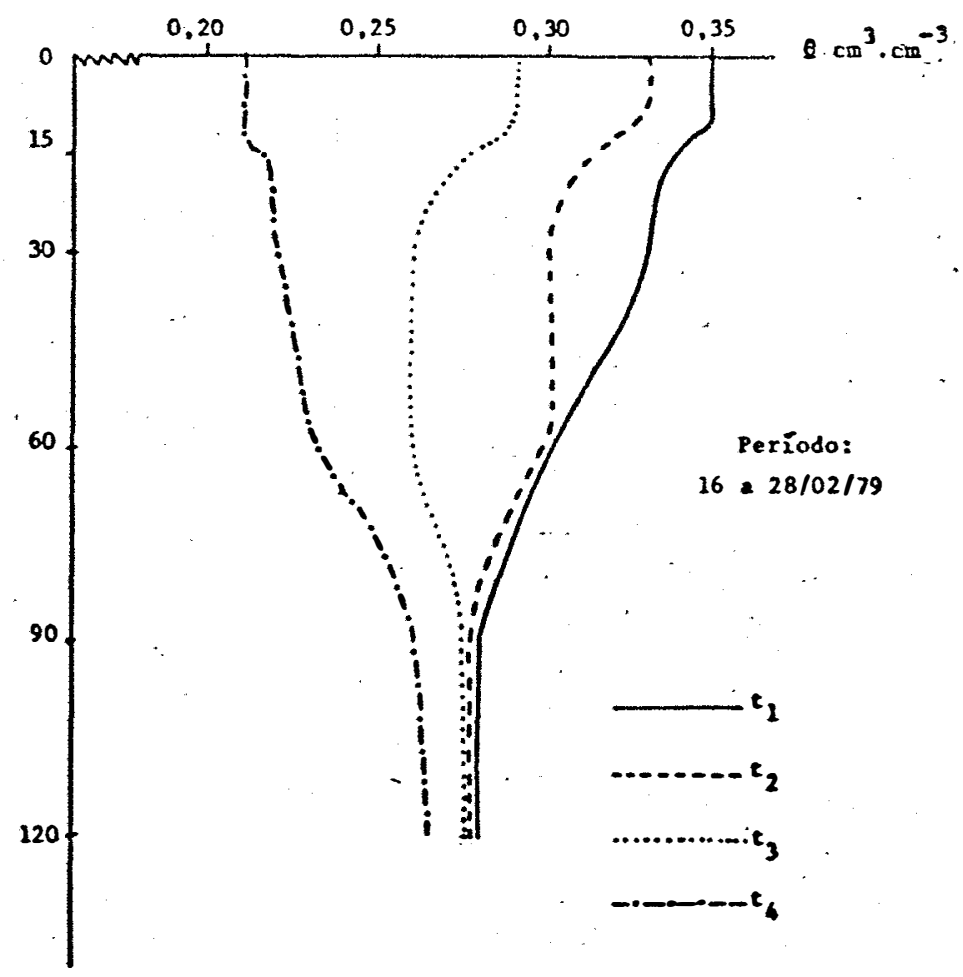

FIG. 23 - Perfis de umidade do solo, em função da profun didade e do tempo para o tratamento $\mathrm{T}_{5}$. 


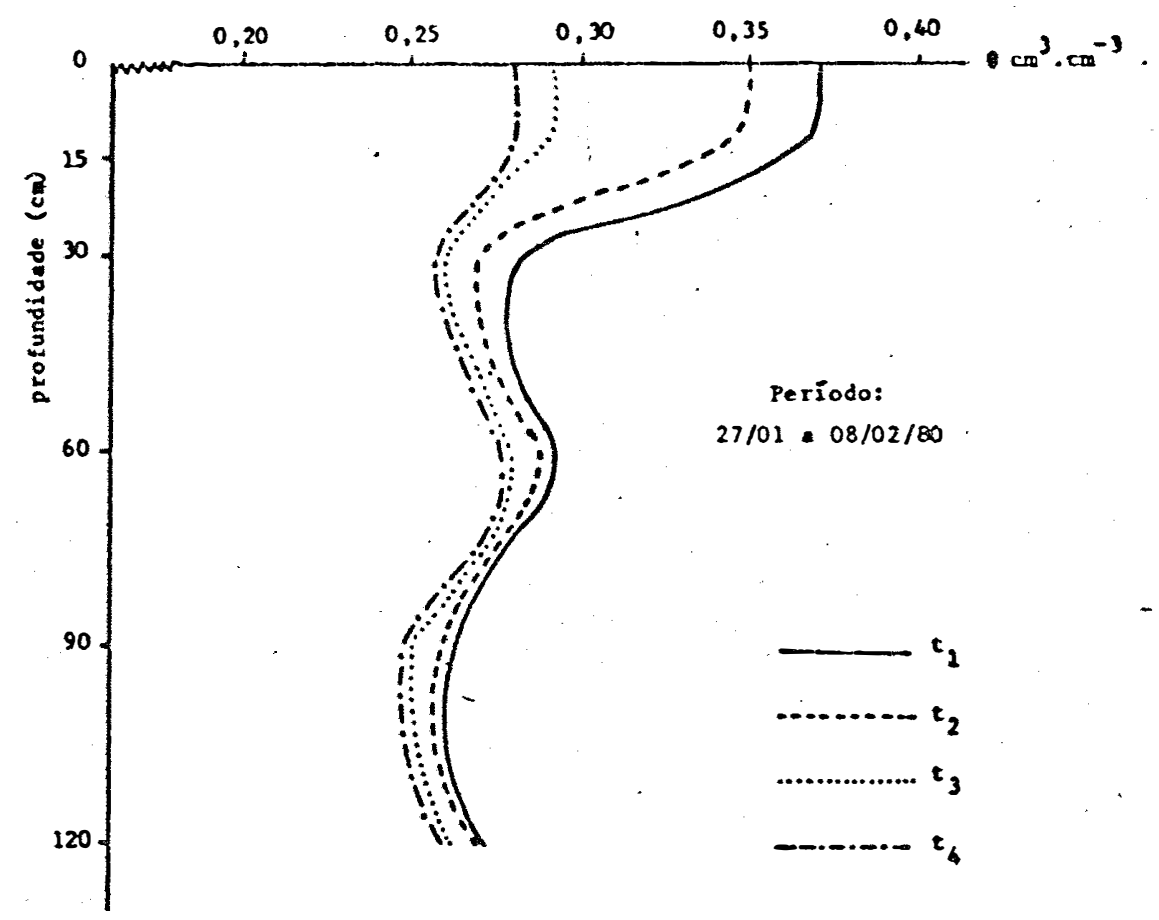

FIG. 24 - Perfis de umidade do solo, em função da profun didade e do tempo para o tratamento $T_{I}$.

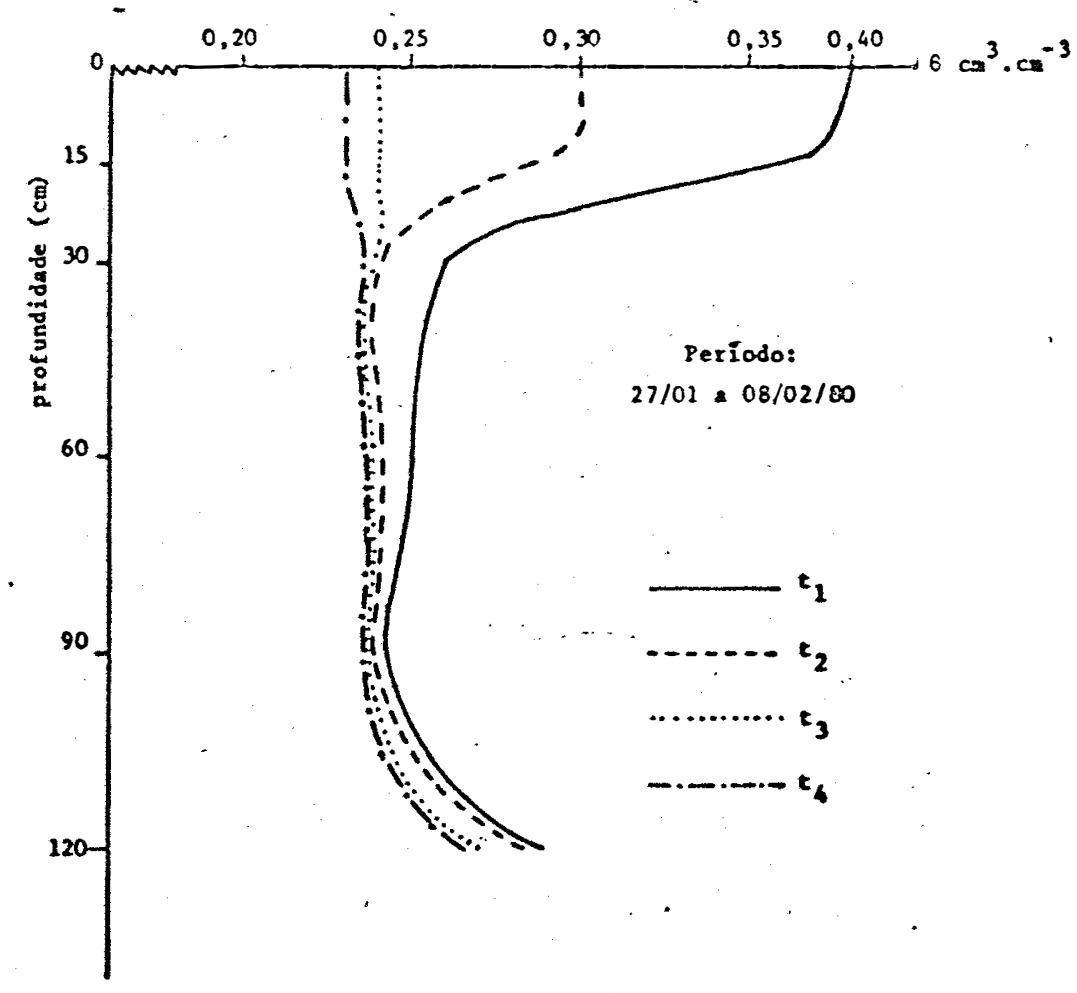

FIG. 25 - Perfis de umidade do solo, em função da profun didade e do tempo para o tratamento $\mathrm{T}_{5}$. 


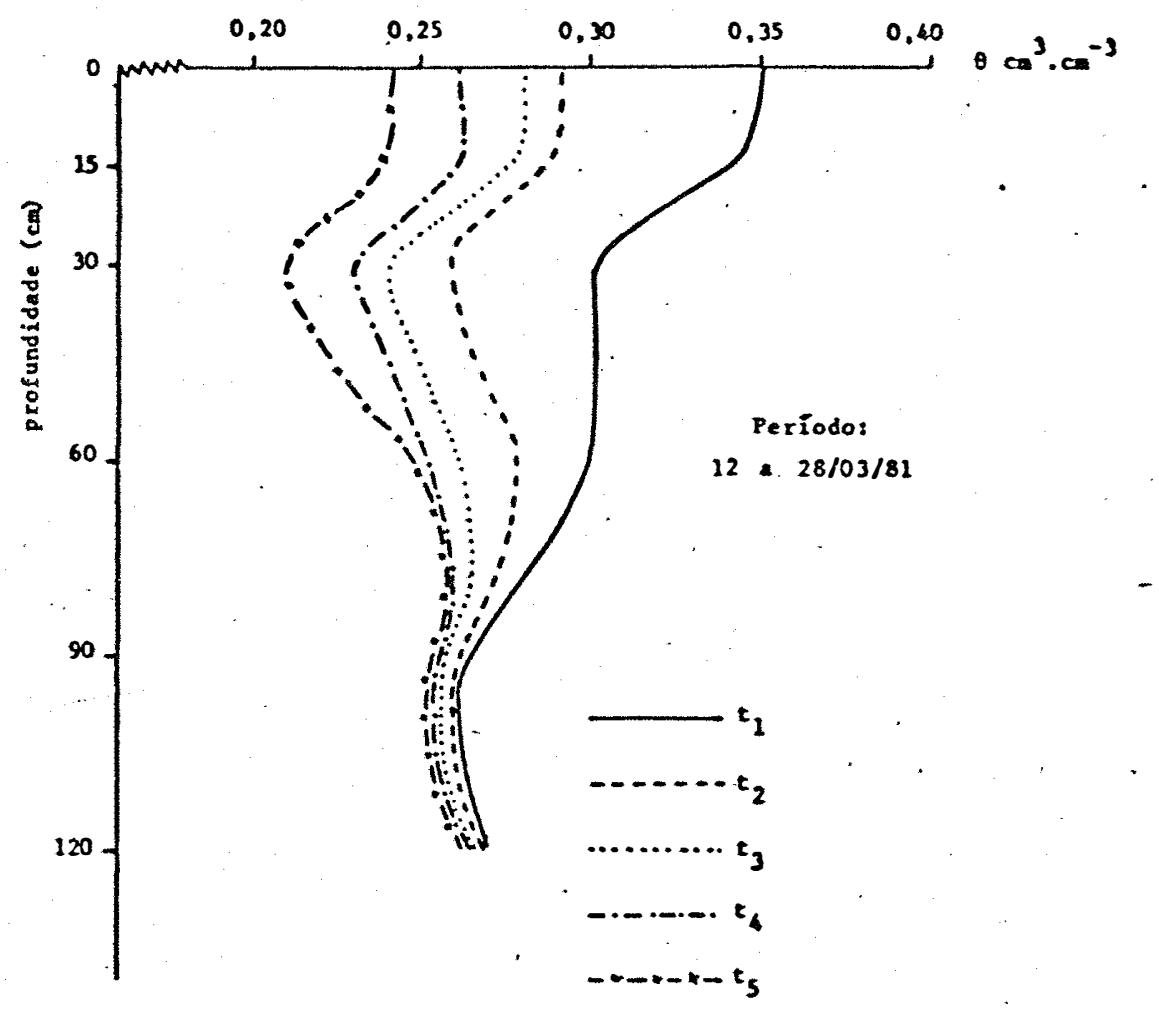

FIG. 26 - Perfis de umidade do solo, em função da profun didade e do tempo para o tratamento $\mathrm{T}_{1}$.

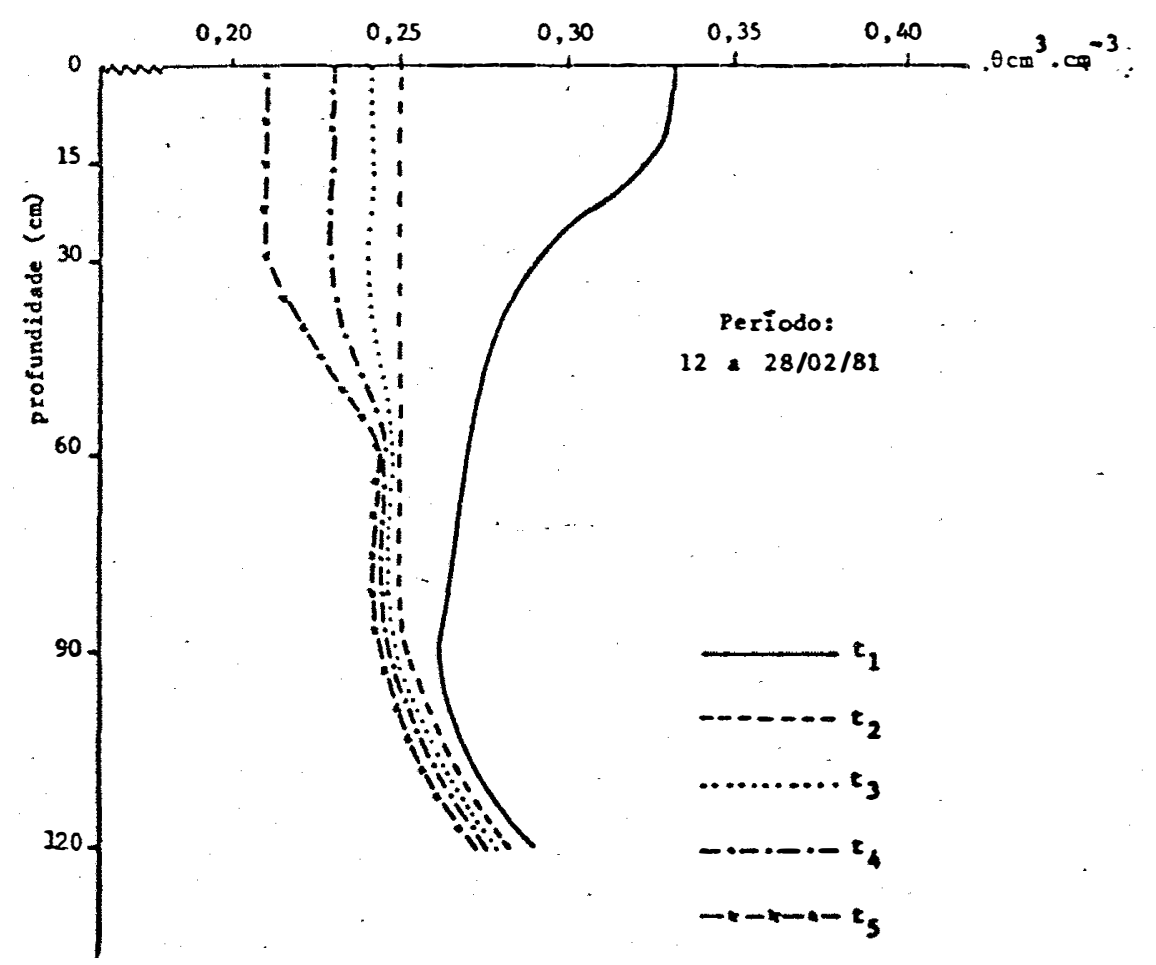

FIG. 27 - Perfis de umidade do solo, em função da profun didade e do tempo para o tratamento $\mathrm{T}_{5}$. 
Tratamento $\mathbf{T}_{1}$ - aração e gradagem

Pela Figura 22 pode-se constatar inicialmente, que no ano de 1979 o período entre duas chuvas consecutivas foi de 13 dias. O perfil de umidade referente ao tempo t ${ }^{\prime}$ logo após a chuva, mostrou que a quantidade de água fornecida ao solo pela última chuva não foi suficiente para dar condi ções de homogeneidade em todo o perfil do solo. Verificandose teores mäis elevados e aproximadamente iguais até a profun didade média de $15 \mathrm{~cm}$; um ligeiro decréscimo, aproximadamente de $0,02 \mathrm{~cm}^{3} \cdot \mathrm{cm}^{-3}$, na camada de 15 a $30 \mathrm{~cm}$ e teores praticamen te iguais, defasados em relação a superfície de aproximadamen te $0,08 \mathrm{~cm}^{3} \cdot \mathrm{cm}^{-3}$, em toda a porção do solo situada abaixo de $60 \mathrm{~cm}$.

Os perfis referentes aos tempos $t_{2}$ e $t_{3}$ indica ram que neste intervalo de tempo as perdas de água do solo fo ram uniformes, ocorrendo exclusivamente na camada superficial até a profundidade de $30 \mathrm{~cm}$. O perfil relativo ao tempo $t_{4}$ revelou que as perdas de água continuaram concentradas na ca madá superficial até $30 \mathrm{~cm}$, havendo inclusive, um pequeno aumento na intensidade dessas perdas. Mostrou também que as camadas subjacentes, situadas abaixo de $60 \mathrm{~cm}$ de profundida de, começaram a perder água, sendo que esta perda foi de ma neira uniforme em todas as profundidades consideradas, consta tando-se o início do movimento ascendente da água no solo.

Examinando a Figura 24, constatou-se inicialmen te, para o período considerado no ano de 1980, a existência de 13 dias entre duas chuvas consetuvidas. O perfil de umidä 
de referente ao tempo $t_{1}$ mostrou que a quantidade de água for necida pela última chuva não foi suficiente para a homogenei zação do perfil, acontecendo semelhantemente ao periodo consí derado no ano anterior. Neste período, já na profundidade de $30 \mathrm{~cm}$, foram observadas diferenças dos teores de umidade em relação a superfície. o perfil referente ao tempo $t_{2}$ indicou a diminuição de umidade em toco o perfil do solo, sendo esta mais intensá na camada superior até um pouco mais de $30 \mathrm{~cm} e$, praticamente inexpressivo nas posições abaixo de $60 \mathrm{~cm}$. O per fil referente ao tempo $t_{3}$ mostrou acentuado aumento de perda de água na camada superficial do solo até $15 \mathrm{~cm}$ de profundida de e perdas inexpressivas nas camadas inferiores a $30 \mathrm{~cm}$. 0 periodo referente ao tempo $t_{4}$ revelou sensivel diminuição das perdas de água neste intervalo de tempo, mesmo na superfície do solo. A disposição e a configuração dos perfis nesta figu ra mostra a variação das perdas de água do solo nos interva los de tempo considerados, sendo essas perdas principalmente na camada superior, até a profundidade de $15 \mathrm{~cm}$.

Pela Figura 26, referente ao período considera do no ano de 1981, observou-se inicialmente, a existência de 16 dias entre duas chuvas consecutivas. Os perfis de umidade referente aos tempos $t_{1}, t_{2}, t_{3}$ e $t_{4}$ reproduziram, com cer tas semelhanças, as condições observadas para o período do ano de 1979. Devendo-se destacar no entanto, que foram obser vadas, no perfil relativo ao tempo $t_{1}$, evidências de um gra diente mais acentuado de umidade na porção do solo compreendi da entre 15 e. $30 \mathrm{~cm}$ de profundidade, sendo isto, provavelmen 
te, devido ao menor fornecimento de água ao solo em relação ao ano de 1979. Esse maior gradiente de umidade ocorreu em todo o período analisado, conforme mostra as formas semelhan tes dos perfis.

\section{Tratamento $T_{5}$ - cultivo mínimo}

As Figuras 23, 25 e 27, representando os perfis de umidades considerados dos anos de 1979, 1980 e 1981, mos tram a existência de semelhanças entre os perfis de umidade dos tratamentos $\mathrm{T}_{1}$ e $\mathrm{T}_{5}$, revelando ausência de sensiveis alte rações diferenciais que poderiam ser provocadas pelas duas mo dalidades de preparo do solo. A principal diferença observa da foi uma menor retenção de áọua no solo até a profundidade de $90 \mathrm{~cm}$ apresentada pelo tratamento $\mathrm{T}_{5}$.

Variação do armazenamento da āgua do solo em função do tempo

As Figuras 28 a 30 representam a intensidade e a distribuição das chuvas e a variação do armazenamento da água no solo em função do tempo, para os três ciclos da cultụ ra. Pôde-se inicialmente constatar que os teores de água do solo inferidos por meio da observação empregando tensiômetros forneceram dados considerados compativeis com as intensidades das chuvas ocorridas. Verificou-se também, que dos três pe ríodos considerados, o primeiro, referente ao ciclo agrícola 1978/79, apresentou maiores variações do armazenamento de água do solo, fato relacionado as condições pluviométricas ocorridas no período. Neste período as condições de armazena mento, nas duas modalidades de preparo do solo, foram pratica 


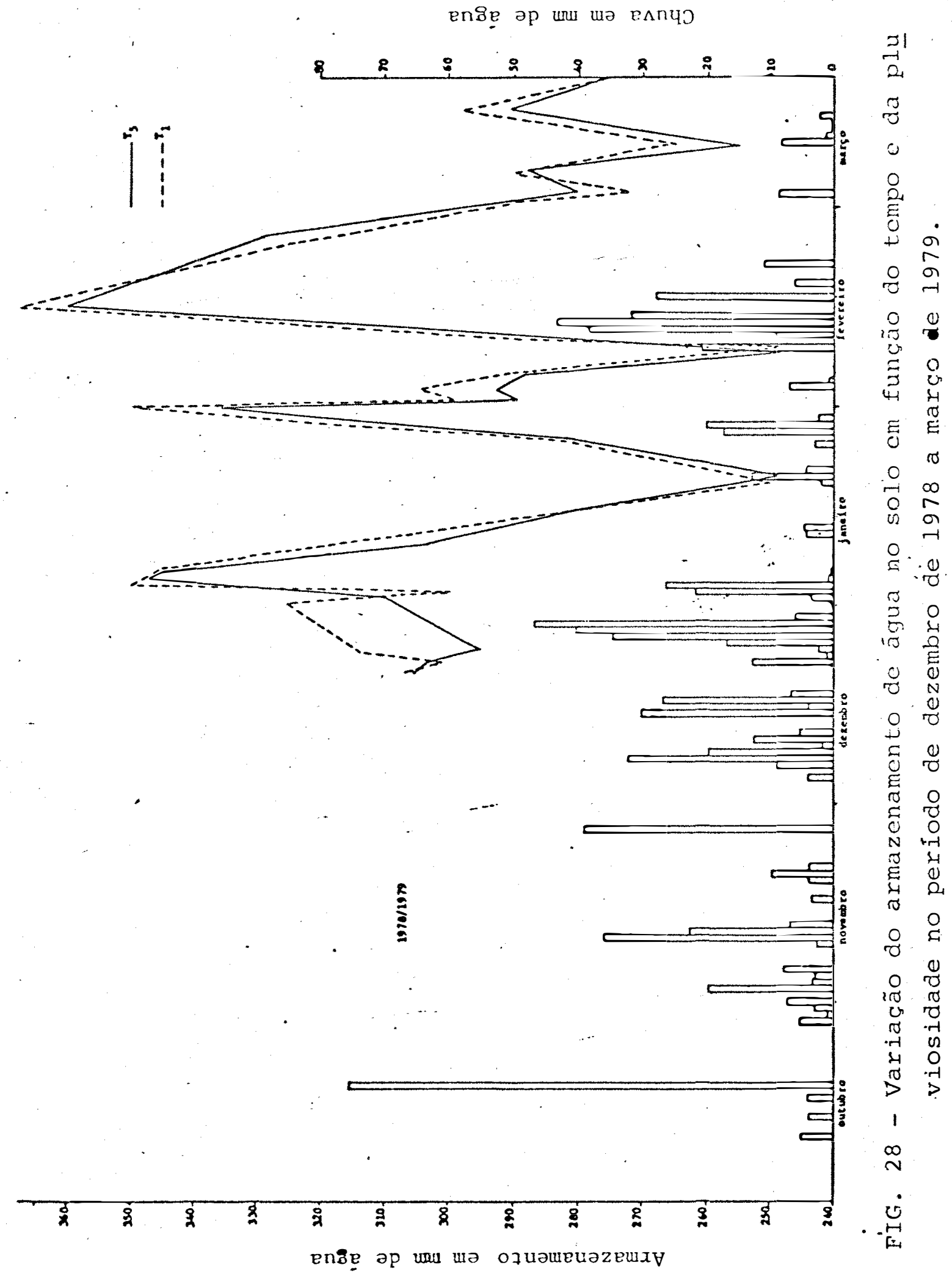




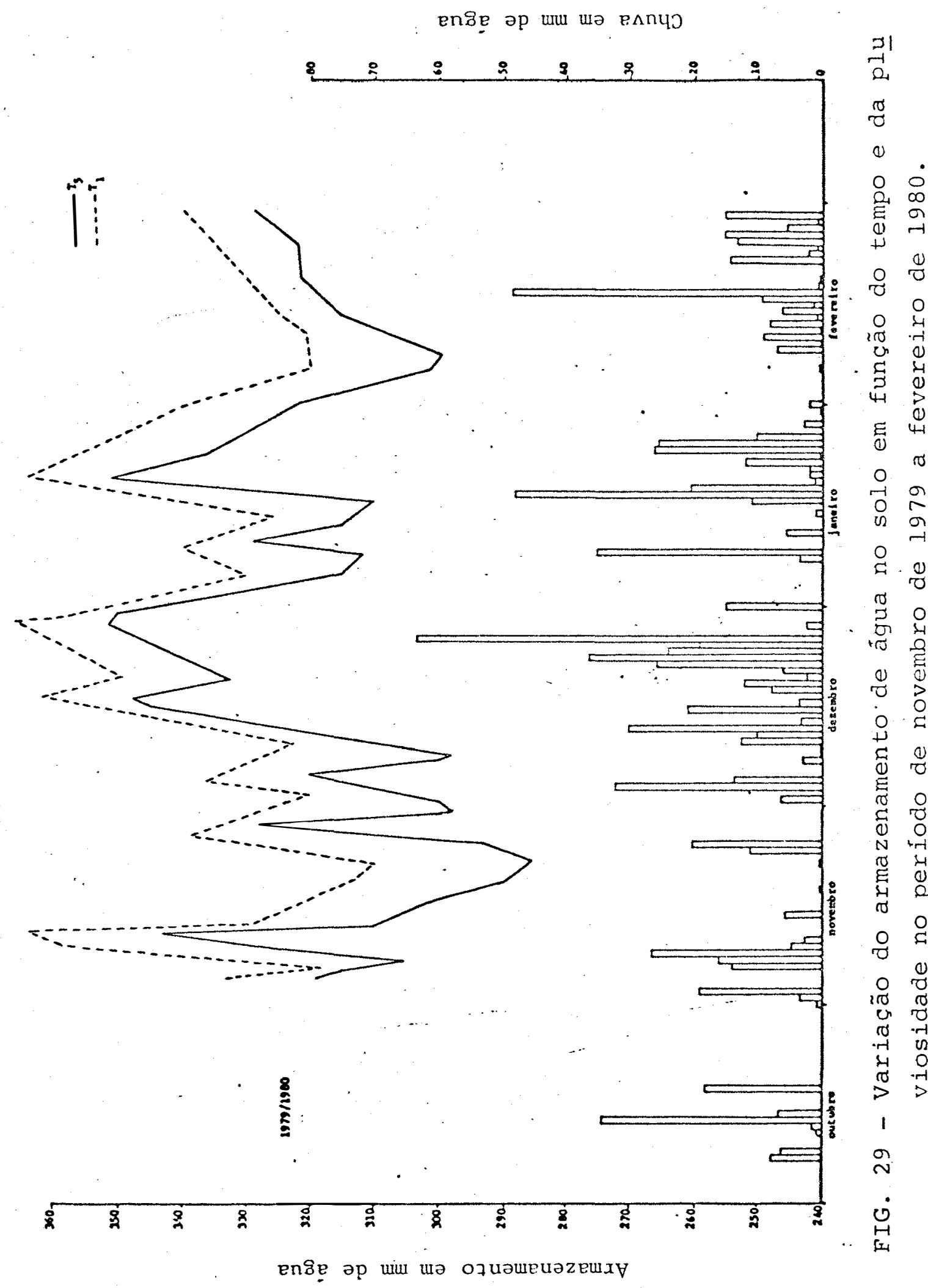




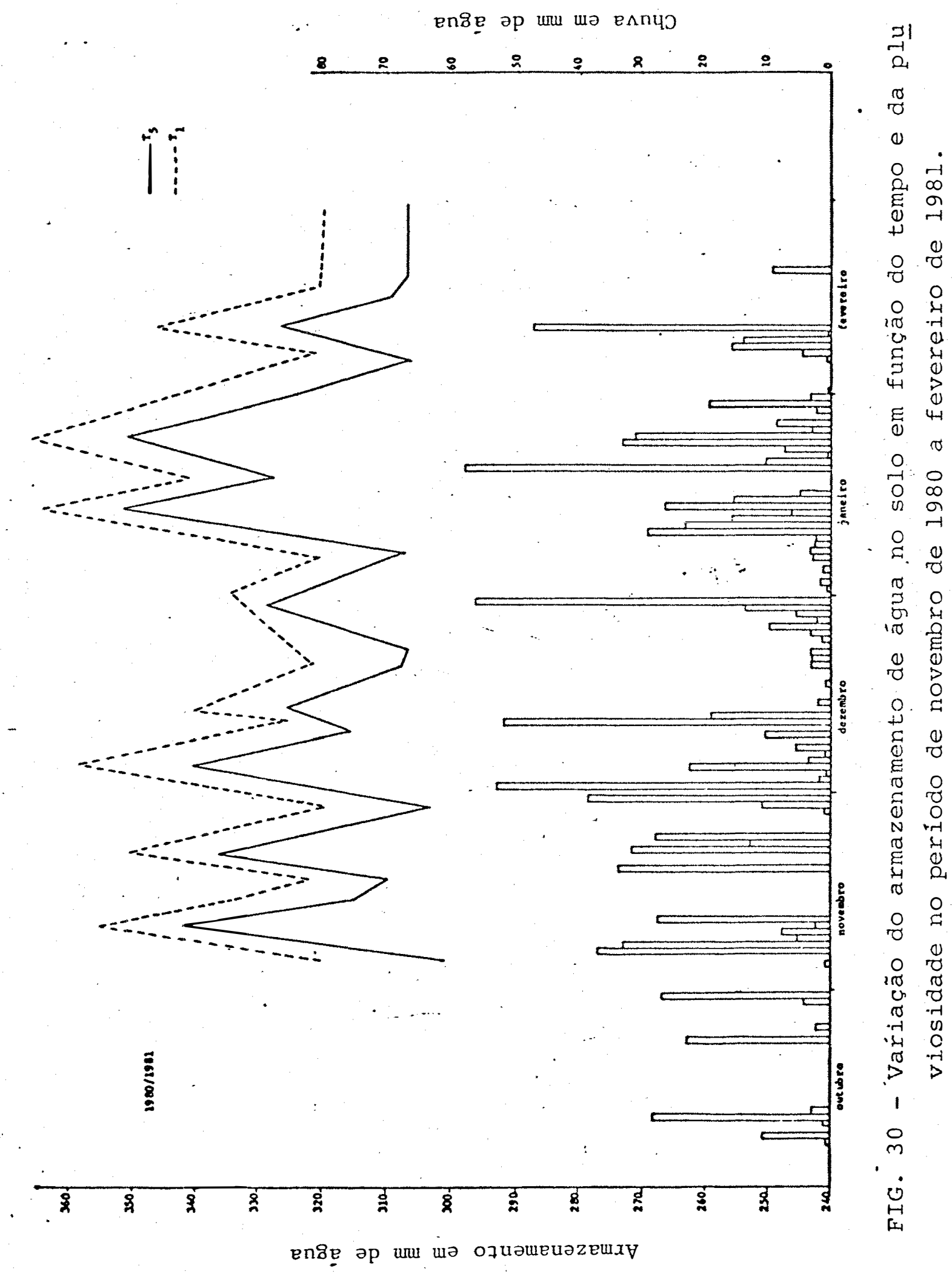


mente iguais.

Nos períodos referentes aos ciclos agrícolas 1979/80 e 1980/81, as variações do armazenamento de água se apresentaram muito semelhantes e menores intensidades do que as do primeiro periodo. Nestes períodos os valores do armaze namento de água do solo foram maiores no tratamento $\mathrm{T}_{1}$ (ara ção e gradagem), embora as diferenças tenham sido pequenas.

4.4. Produção de grãos

A produção de grãos das plantas de milho da área do Latosol Vermelho Escuro - fase arenosa é apresentada na Tabela 9 e a sua representação é mostrada pela Figura 31 . Na Tabela 10 estão apresentados os dados da análise estatisti ca. Pela análise dos dados apresentados verificou-se que os valores de $F$ foram significativos para tratamentos $(T)$ e anos (A), mas a interação tratamento (T) versus anos (A) não reve . lou valor de $\mathrm{F}$ significativo.

A comparação das médias anuais de produção, com a aplicação do teste de Tukey mostrou que as produções anuais apresentaram diferenças com significação estatística a nível de $1 \%$ de probabilidade, sendo a maior produção a do ciclo agrí cola 1979/80, cujo valor foi de $4140 \mathrm{~kg} / \mathrm{ha}$. A produção inter mediária foi a do ciclo 1980/81, com $3254 \mathrm{~kg} / \mathrm{ha}$ e a menor pro dução foi a de 1978/79, com $2518 \mathrm{~kg} / \mathrm{ha}$. A explicação para essas variações de produção esta ligada às distintas condi ções de pluviosidade ocorrida nesses períodos, principalmente 
TABELA 9 - Produção de milho em grãos no Latosol Vermelho Es curo - fase arenosa nos trēs anos agrícolas 1978/79, $1979 / 80$ e 1980/81, referentes aos tratamentos uti lizados.

\begin{tabular}{|c|c|c|c|c|}
\hline \multirow{2}{*}{ Tratamentos } & \multicolumn{3}{|c|}{ Anos agricolas } & \multirow{2}{*}{$\begin{array}{c}\text { Entre os anos } \\
\text { agrícolas }\end{array}$} \\
\hline & $1978 / 79$ & $1979 / 80$ & $1980 / 81$ & \\
\hline $\mathrm{T}_{1}$ & 2.782 & 4.033 & 3.175 & $3.330 \mathrm{~b}^{1 /}$ \\
\hline $\mathrm{T}_{2}$ & 3.133 & 4.503 & 3.607 & $3.748 \mathrm{a}$ \\
\hline $\mathrm{T}_{3}$ & 2.058 & 3.900 & 3.030 & $2.996 \mathrm{~b}$ \\
\hline $\mathrm{T}_{4}$ & 2.435 & 4.041 & 3.090 & $3.190 \mathrm{~b}$ \\
\hline $\mathrm{T}_{5}$ & 2.180 & 4.223 & 3.363 & $3.256 \mathrm{~b}$ \\
\hline $\begin{array}{c}\text { Dentro de cada } \\
\text { ano agrícola }\end{array}$ & $2.518 \mathrm{c}$ & $4.140 \mathrm{a}$ & $3.254 \mathrm{~b}$ & - \\
\hline
\end{tabular}

If As médias seguidas de letras iguais não diferem entre si pelo teste de Tukey a $5 \%$ de probabilidade.

TABELA 10 - Análise estatística da produção de milho no Lato sol Vermelho Escuro - fase arenosa.

$\begin{array}{lrccc}\text { Causas de Variação } & \text { G.L. } & \text { Teste F } & \text { d.m.s. (kg/ha) } & \text { C.V.(\%) } \\ \text { Blocos } & 5 & 1,81^{N S} & - & - \\ \text { Tratamentos (T) } & 4 & 10,06 * * & 373 & 11,2 \\ \text { Resíduo (a) } & 20 & - & - & - \\ \text { Parcelas } & 29 & - & 345 & 16,7 \\ \text { Anos (A) } & 2 & 64,85^{* *} & - & - \\ \text { Interação (T x A) } & 8 & 0,72^{\text {NS }} & - & - \\ \text { Resíduo (b) } & 50 & - & - & - \\ \text { Total } & 89 & - & \end{array}$

NS = não significativo.

** = significativo ao nivel de $1 \%$ de probabilidade. 


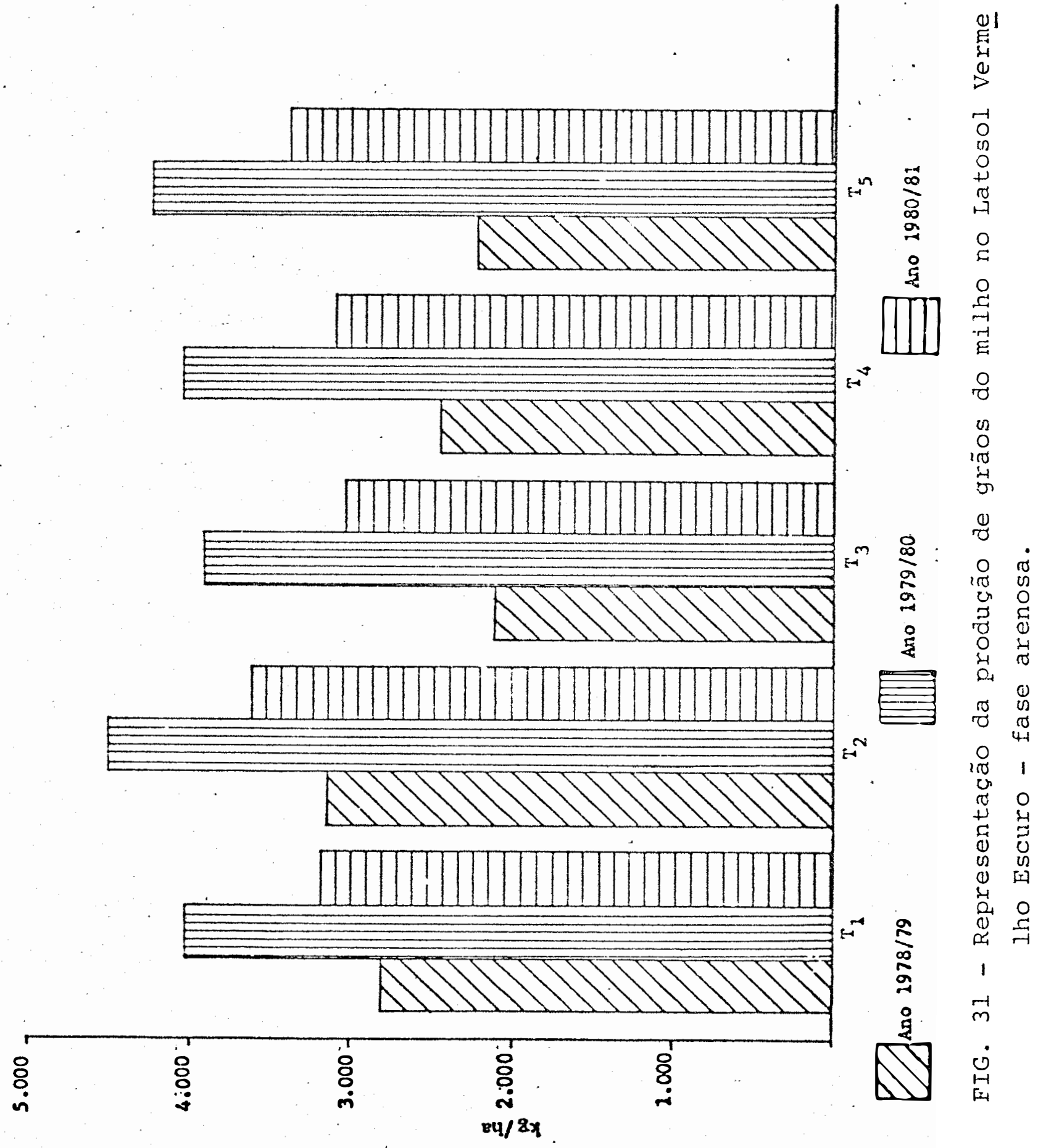


as do ciclo agrícola 1978/79. No ciclo agrícola 1978/79 ocor reu maior seca, existindo inclusive um veranico por ocasião da formação de grãos. No ano agrícola 1979/80 também foi oḅ servado um veranico, contudo este foi curto e tardio, ocorren do numa fase da cultura em que a falta de āgua já não afetava tanto a produção.

A comparação entre tratamentos mostrou que a maior produção do tratamento $\mathrm{T}_{2}$ (subsolagem mais aração e gra dagem) diferiu com significação estatística a nível de 5\% de probabilidade dos demais tratamentos. Para esta maior produ ção do tratamento $T_{2}$ não são encontradas justificativas, in clusive contraria as observações de LARSON et a lii (1960) de que a subsolagem não produziu o desejado aumento da produção de milho, existindo em certos casos redução da produção.

Os dados de produção de grãos da área do Lato sol Roxo são apresentados na Tabela 11 e na Figura 32 é mos trada a sua apresentação gráfica. A análise estatística dos dados está contida na Tabela 12 .

A análise dos dados apresentados permitiu verí ficar que, neste solo somente a produção referente ao ciclo agrícola 1979/80 apresentou diferenças com significação esta tística a nível de l\% de probabilidade, sendo esta produção a maior, $4290 \mathrm{~kg}$.

Não foram observadas diferenças significativas entre tratamentos. 
TABELA 11 - Produção de milho em grãos no Latossol Roxo nos três anos agrícolas 1978/79, 1979/80 e 1980/81, re ferentes aos tratamentos utilizados.

\begin{tabular}{|c|c|c|c|c|}
\hline \multirow{2}{*}{ Tratamentos } & \multicolumn{3}{|c|}{ Anos agricolas } & \multirow{2}{*}{$\begin{array}{c}\text { Entre anos } \\
\text { agrícolas }\end{array}$} \\
\hline & $1978 / 79$ & $1979 / 80$ & $1980 / 81$ & \\
\hline $\mathrm{T}_{1}$ & 3.541 & 4.428 & 3.387 & $3.785 \mathrm{a}^{1 /}$ \\
\hline $\mathrm{T}_{2}$ & 3.633 & 4.528 & 3.587 & $3.916 \mathrm{a}$ \\
\hline $\mathrm{T}_{3}$ & 3.605 & 4.017 & 2.987 & $3.536 \mathrm{a}$ \\
\hline $\mathrm{T}_{4}$ & 3.402 & 4.168 & 2.880 & $3.485 \mathrm{a}$ \\
\hline $\mathrm{T}_{5}$ & 3.144 & 4.305 & 3.278 & 3.576 a \\
\hline $\begin{array}{l}\text { Dentro de cada } \\
\text { ano agrícola }\end{array}$ & $3.465 \mathrm{~b}$ & $4.290 \mathrm{a}$ & $3.224 \mathrm{~b}$ & - \\
\hline
\end{tabular}

If As médias seguidas de letras iguais não diferem entre si pelo teste de Tukey a $5 \%$ de probabilidade.

TABELA 12 - Análise estatística da produção de milho no Lato sol Roxo.

\begin{tabular}{lcccc}
\hline Causas de Variação & G.L. & Teste F & d.m.s.(kg/ha) & C.V. (\%) \\
Blocos & 5 & $4,28^{\mathrm{NS}}$ & - & - \\
Tratamentos (T) & 4 & $2,48^{\mathrm{NS}}$ & - & - \\
Residuo (a) & 20 & - & - & - \\
Parcelas & 29 & - & 458 & -1 \\
Anos (A) & 2 & $17,23^{* *}$ & - & - \\
Interação (T x A) & 8 & $0,35^{\mathrm{NS}}$ & - & - \\
Residuo (b) & 50 & - & - & - \\
Total & 89 & - & -
\end{tabular}

NS = não significativo.

$* *$ = significativo ao nivel de $1 \%$ de probabilidade. 


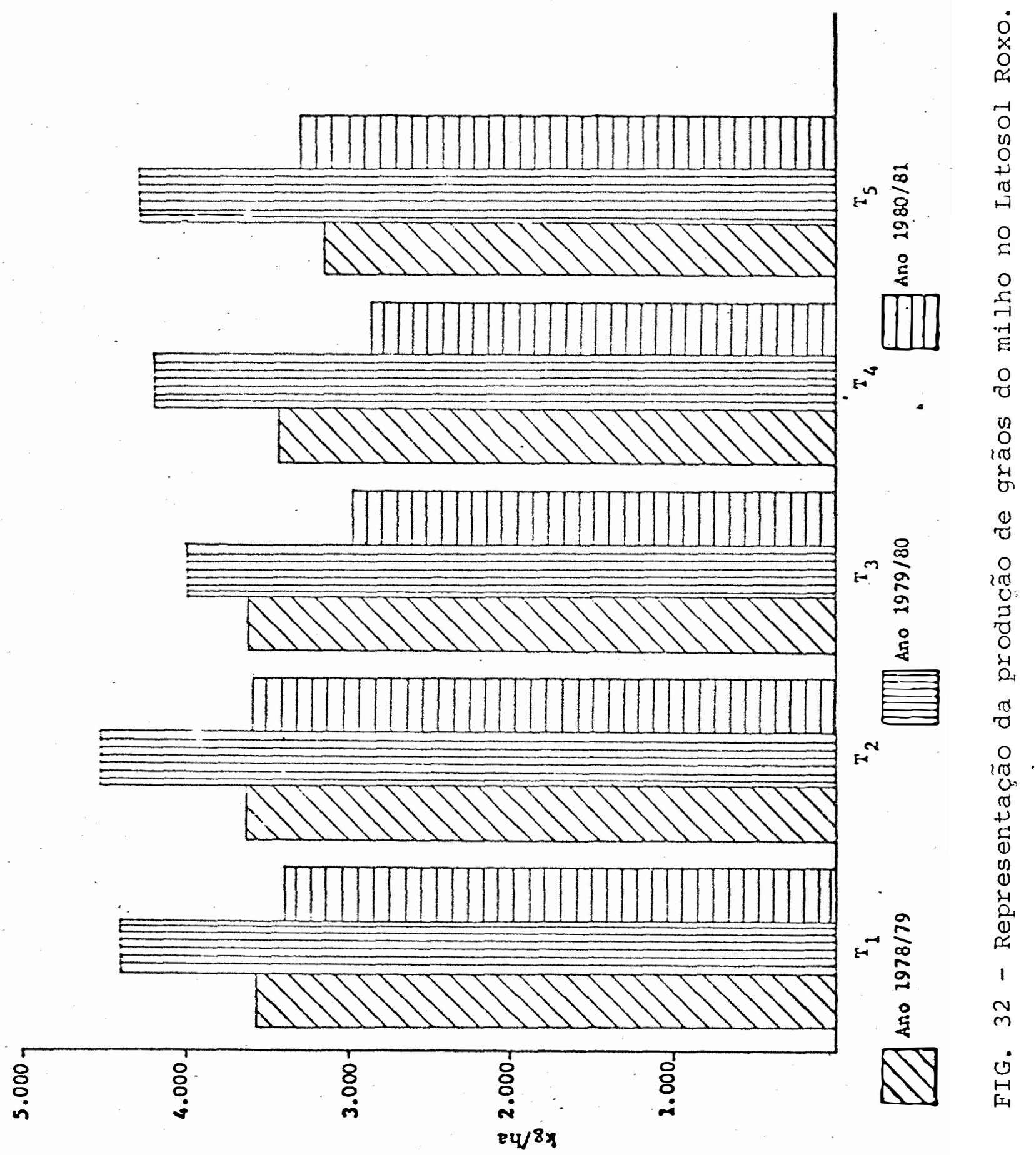


4.5. Análise do custo da modalidade de preparo do solo em função de suas produções

Na Tabela 13 são apresentadas a produção média por hectare, o custo da modalidade de preparo por hectare e 0 custo do quilograma de milho, referentes às modalidades de preparo do solo.

Pelos dados apresentados pôde-se verificar uma variação muito acentuada nos custos do preparo do solo em fun ção da modalidade empregada. O custo da modalidade de prepa ro apresentou variações até $170 \%$, quando se comparou o trata mento $\mathrm{T}_{5}$ - "cultivo mínimo" com o tratamento $\mathrm{T}_{3}$ - duas grada gens. A ordenação em ordem crescente, em função do custo, T ${ }^{\prime}$ $\mathrm{T}_{1}, \mathrm{~T}_{4}, \mathrm{~T}_{2}$ e $\mathrm{T}_{5}$, onde os demais tratamentos apresentam dife renças em relação ao $\mathrm{T}_{3}$ de respectivamente $40 \%$, 105\%, $135 \%$ e 170\%, mostrou a importância do elemento custo na análise so bre as possíveis opções para preparo do solo.

Ao considerar o custo da modalidade de preparo do solo por quilograma de milho produzido, foi observada a mesma ordenação em ordem crescente, ou seja: $\mathrm{T}_{3}, \mathrm{~T}_{1}, \mathrm{~T}_{4}, \mathrm{~T}_{2} \mathrm{e}$ $\mathrm{T}_{5}$. Constatou-se deste modo que o custo da modalidade de pre paro por hectare apresenta-se diretamente relacionado com 0 custo por quilograma de milho produzido. Contudo, essa rela ção varia em função do solo.

Como considerações finais, deve-se observar que não ficou constatada a relação direta entre custo da modalida de de preparo e produção de grãos. A modalidade de preparo $\mathrm{T}_{5}$ 


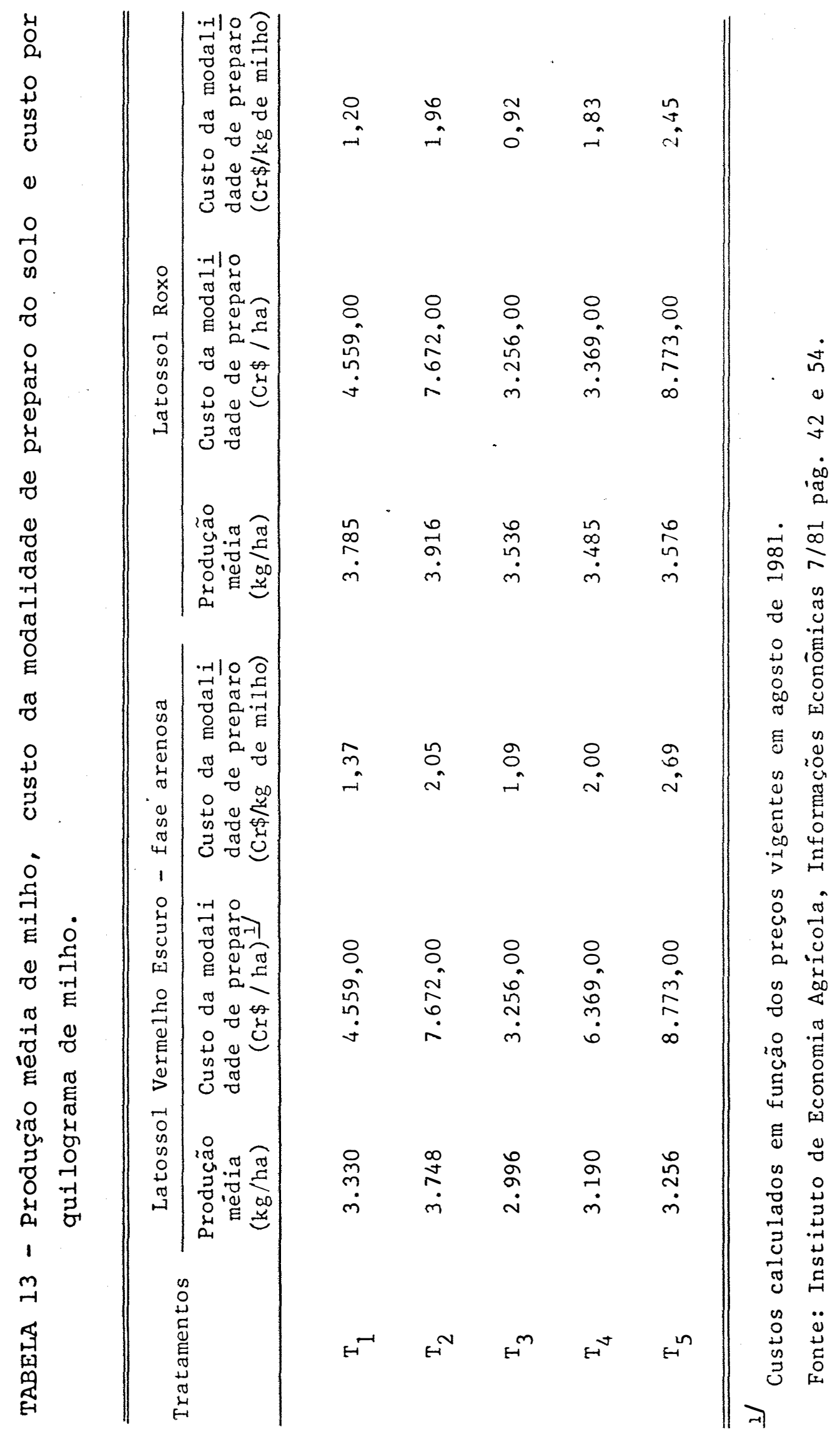


(cultivo minimo) apresentou nos dois solos o maior custo para o seu emprego e proporcionou contudo uma produção intermedi.a ria entre as diferentes modalidades empregadas. 
5. CONCLUSÕES

Os resultados obtidos neste trabalho, depois de analisados e discutidos, permitiram as conclusões apresenta das a seguir.

5.1. Conclusões parciais

a) o cultivo mínimo foi o único sistema de mane jo que apresentou indícios de melhorar as condições físicas dos solos estudados;

b) a densidade global foi a única propriedade que, nos dois solos, sofreu modificações diferenciais;

c) a porosidade total e a relação entre macro e microporosidade sofreram modificações, apenas no Latosol Roxo;

d) não houve modificações nã retenção, nem no armazenamento de água;'

e) houve indicios de que o cultivo minimo aumen ta a produção de milho. 
5.2. Conclusão geral

Não foram observadas alterações nas propriedạ des do solo, nem na produção de milho, devido ao efeito dos sistemas de preparo do solo que foram experimentados. Entre tanto, as tendências indicadas pelos dados obtidos concordam com as observações e com as afirmações contidas na bibliogra fia; podendo-se por essa razão, afirmar que o cultivo.mínimo deve modificar favoravelmente as propriedades dos solos e a produção de milho. A confirmação da hipótese inicial fica, no entanto, dependente da repetição dos tratamentos por perío dos mais longos. 
6. LITERATURA CITADA

ALOISI, R.R. e DEMATTE, J.L.I., 1974. Levantamento dos solos da Faculdade de Medicina Veterinária e Agronomia de Jaboti cabal. Cientifica, 2(2):123-136.

ALOISI SOBRINHO, J. e VAZ DE ARRUDA, H., 1960. Efeito do pre paro do solo na produção de milho. Bragantia, 19:215-219.

BAEUMER, K. e BAKERMANS, W.A.P., 1973. Zero-tillage. Adv. Agronomy, 25:78-120.

BAVER, L.D.; GARDNER, W.H. e GARDNER, W.R., 1972 . SOil physics. Fourth Edition, John Willey \& Sons, Inc. New York. 498 p.

BENATTI JUNIOR, R.; BERTONI, J. e MOREIRA, A.C., 1977. Perdas por erosão em plantio direto e convencional de milho em dois solos de são Paulo. Rev. Bras. Ci. Solo, 1:121-123.

BENEZ, S.H., 1980. Efeitos dos tipos de preparo do solo, cul tivos e calagem na cultura do milho (Zea mays L.). Botuca tu, FCMB (Tese de Livre-Docência). 
BLAKE, G.R., 1965. Bulk density. In: BLACK, C.A., ed. Methods of soil analysis. Madison, Amer. Soc. Agron., 1:371-390. BLEVINS, R.L.; COOK, D.; PHILLIPS, S.H. e PHILLIPS, R.E., 1971. Influence of no-tillage on soil moisture. Agron. J., 63 : $593-596$.

BOWERS, E. e BATEMAN, H.P., 1960. Research studies of minimum tillage. Trans. ASAE, $\underline{3}(2): 1-3$.

CANNEL, R.Q. e FINNEY, J.R., 1973. Effects of direct-drilling and reduced cultivation on soil conditions for root growth. Outlook Agric., I:148-149.

COMISSÃO DE SOLOS, 1960. Levantamento de reconhecimento dos solos do Estado de São Paulo. Ministério da Agricultura. C.N.E.P.A. Boletim n? 12.?

CORSINI; P.C., 1974. Modificações de características físicohídricas em perfis das séries Jaboticabal e Santa Teresa ocasionadas pelo cultivo intenso. Cientifica, 2:148-161.

DAY, P.R., 1965. Particle fractronation and particle size analysis. In: BLACK, C.A., ed. Methods of soil analysis. Madison, Amer. Soc. Agron. 1:371-390.

DAY, P.R. e HOLGREEN, G.G., 1952. Microscopic changes in soil structure during compression. Soil Sci. Am. Prod., 21:448.

ELTZ, F.L.F.; COGO, N.P. e MIELNICZUK, J., 1977. Perdas por erosão em diferentes manejos de solo e coberturas vegetais em solo Laterítico Bruno Avermelhado Destrófico (São Jerọ nimo). I. Resultados do primeiro ano. Rev. Bras. Ci. Solo, $\underline{1}: 123-127$. 
GOMES, A.S.; PATELLA, J.F. e PAULLETTO, E.A., 1978. Efeitos de sistemas e tempo de cultivo sobre a estrutura de um Pod zólico Vermelho Amarelo. Rev. Bras. Ci. Solo, 2:17-21.

JOHNSON, W.H. e TAYLOR, G.S. 1960. Tillage treatment for corn on clay soil. Trans. ASAE, $\underline{3}(2): 4-7$.

JONES, J.N.; MOODY, J.E.; SHEAR, G.M.; MOSCHLER, W.W. e LILLARD, J.H., 1968. The no-tillage sistem for corn Zea mays L. Agron. J., 60 (1):17-20.

LAL, R., 1976. No-tillage effects on soil properties under different crops in western Nigeria. Soil Sci. Soc. Am. J., $\underline{40}: 762-768$

LARSON, W.E.; LOVELY, W.G.; PESEK, J.T. E BURWELL, R.E., 1960. Effect of subsoiling and deep fertilizer placement on Yields of corn in Iowa an Illinois. Agron. J., 52:185-189. LUTZ, J.F., 1947. Apparatus for collecting indisturbed soil samples. Soil Sci., 64:399-401.

MACEDO, J.A. e BRUM, A.C.R., 1978. Efeito dos sistemas de cultivo reduzido e convencional na capacidade de infiltra ção da água no solo. In: II Encontro Nacional de Pesquisa sobre Conservação do Solo 2. Passo Fundo. EMBRAPA, Centro Nacional de Pesquisa de Trigo. 481 p.

MACHADO, J.A., 1976. Efeito do sistema convencional de culti vo na capacidade de'infiltração da água no solo. Santa Ma ria, Universidade Federal. 135 p. (Dissertação de Mestrado). 
MARCOS, Z.Z., 1971. Morfologic and physical properties of fine textured oxisols state of são Paulo. Graduate School of the Ohio State University. $272 \mathrm{p}$. (Tese de PHD).

MARQUES, J.Q.A. e BERTONI, J., 1961- Sistema de preparo do solo em relação a produção e a erosão. Bragartia, 20 (9): $403-458$

NELSON, L.R.; GALLAHER, R.N.; BRUCE, R.P. e HOLMES, M.R., 1977. Production of corn and sorghum grain in double-croping systems. Agron. J., 69-41-45.

ORTOLANI, A.F. 1977. Efeitos de diferentes tipos de preparo do solo sobre o comportamento do sistema solo-cultura de milho. Jaboticabal, FCAVJ-UNESP. 100 p. (Tese de LivreDocência).

PAGE, J.B.; WILLARD, C.J. e MCCUEM, G.W., 1946. Progress report on tillage methods in preparing land for corn. Soil Sci. Am. Prod., 11:77-80.

PASTANA, F.I., 1972. Efeito da retenção de um herbicida pela cobertura morta no solo no controle das ervas daninhas e na produção de milho com cultivo minimo. Bragantia, 31 : $259-274$

PHILLIPS, R.E. e DON KIRKHAN, 1962. Mechanical impedance and corn root growth. Soil Sci. Soc. Am. Proc., 26:319-332. PIMENTEL GOMES, F., 1966. Estatistica Experimental. ESALQUSP, Piracicaba. $268 \mathrm{p}$. 
PRIHAR, S.S. E VAN DOREN, D.M., 1967. Mode of response of weed free corn to post-planting cultivation. Agron. $J$., $\underline{59}: 513-515$.

REICHARDT, K., 1975. Processos de transferência no sistema solo-planta-atmosfera. Piracicaba. Publicação especial do CENA e Fundação Cargill. $286 \mathrm{p}$.

RICHARDS, L.A., 1947. Pressure apparatus, construction and use. Agron. Eng., 28:451-454.

SCARDUA, R., 1972. Porosidade livre de água de dois solos do município de Piracicaba. 83 p. (Dissertação de Mestrado). SHEAR, G.W., 1968. The development of the no-tillage concept the United States. Outlook on Agriculture, 5:247-25l.

STEPHEN, J.M.; HORNER, G.M.; COX, L.M. e CARY, E.E., 1967. Soil profile modification by Baekhoe Mixing and Deep. Plaving. Trans. ASAE, 10:775-779.

SWAMY, A.A.; HAY, R.C. e BATEMAN, F.P., 1960. Effect of minimum tillage on physical properties of soil and crop response. Trans. ASAE, $3: 8-11$.

TRIPLETT, G.B.; VAN DOREN, D.M. E JOHNSON, W.R., 1964. NOplowed strip tilled corn culture. Trans. ASAE, :ㅣㅇㅣ.

TROUSE, A.C. e HUMBERT, R.P., 1961. Some effects of soil compaction on the development of sugar cane roots. Soil Sci, $91: 208-217$. 
VAN DOREN, D.M.; TRIPLETT, G.B. e HENRY, J.E., 1976. Influence of long term tillage, crop rottation, and soil type combi nations on corn yield. Soir Sci. Soc. Am. J., 40:100-105.

VIEGAS, G.P., 1978. Práticas culturais. In: Melhoramento e produção do milho no Brasile Fundação Cargill. 650 p.

VOMOCIL, J.A., 1965. Porosity. In: BLAKE, A.C. Methods of soil analysis. Madison, Amer. Soc. Agron., Part 1. p. 299314 .

WILLIANSON, R.E., 1964. The effect of root beration of plant growth. Soil Sci. Soc. Prod., 28:86-87.

WITTSELL, L.E. e HOBBS, J.A. 1965. Soil compaction effects on field plant growth. Agron. J., 57:534-537. 


$$
\text { A } \underline{P} \underline{E} \underline{N} \underline{D} \underline{I} \underline{E}
$$


APENDICE 1 - Valores médios do potencial de umidade do solo às profundidades experimentais.

\begin{tabular}{|c|c|c|c|c|c|c|c|c|c|c|}
\hline \multirow{2}{*}{ Data } & \multicolumn{5}{|c|}{$\mathrm{T}_{1}$} & \multicolumn{5}{|c|}{$\mathrm{T}_{5}$} \\
\hline & 15,0 & 30,0 & 60,0 & 90.0 & 120,0 & 15,0 & 30,0 & 60,0 & 90,0 & 120,0 \\
\hline $20 / 12 / 78$ & 125,0 & 137,0 & 154,0 & 178,0 & 198,0 & 149,0 & 149,9 & 160,0 & 195,0 & 193,0 \\
\hline $21 / 12 / 78$ & 147,5 & 181,0 & 172,5 & 183,0 & 201,5 & 209,5 & 153,0 & 163,0 & 196,0 & 198,0 \\
\hline $22 / 12 / 78$ & 206,5 & 168,5 & 170,0 & 192,0 & 206,5 & 228,0 & 181,5 & 175,0 & 198,0 & 195,0 \\
\hline $23 / 12 / 78$ & 71,5 & 148,0 & 180,0 & 194,0 & 218,0 & 85,0 & 180,0 & 184,0 & 194,0 & 205,0 \\
\hline $24 / 12 / 78$ & 110,0 & 142,0 & 180,0 & 205,0 & 225,0 & 159,5 & 193,5 & 188,5 & 201,0 & 210,0 \\
\hline $30 / 12 / 78$ & 69,0 & 81,0 & 118,0 & 148,5 & 176,0 & 60,0 & 89,0 & 125,0 & 158,5 & 184,0 \\
\hline $31 / 12 / 78$ & 92,0 & 97,5 & 130,0 & 164,5 & 193,0 & 114,0 & 107,5 & 135,5 & 163,0 & 135,0 \\
\hline $02 / 01 / 79$ & 114,5 & 134,0 & 147,0 & 177,5 & 205,0 & 166,0 & 139,0 & 149,0 & 177,0 & 196,5 \\
\hline $03 / 01 / 79$ & 43,0 & 80,5 & 142,0 & 182,0 & 209,5 & 52,5 & 82,0 & 153,0 & 192,5 & 211,0 \\
\hline $05 / 01 / 79$ & 68,5 & 96,0 & 111,5 & 151,5 & 185,0 & 83,5 & 104,0 & 125,5 & 165,0 & 203,5 \\
\hline $06 / 01 / 79$ & 86,0 & 110,5 & 119,5 & 154,5 & 185,0 & 104,5 & 120,5 & 131,0 & 169,5 & 200,0 \\
\hline $07 / 01 / 79$ & 117,5 & 130,5 & 128,5 & 158,5 & 191,5 & 156,5 & 148,0 & 158,0 & 177,5 & 202,5 \\
\hline $08 / 01 / 79$ & 154,0 & 145,5 & 138,0 & 169,5 & 196,5 & 219,0 & 169,0 & 170,0 & 185,0 & 200,0 \\
\hline $09 / 01 / 79$ & 214,5 & 170,5 & 145,5 & 174,5 & 206,5 & 250,5 & 187,0 & 178,0 & 193,5 & 202,5 \\
\hline $10 / 01 / 79$ & 314,5 & 204,0 & 156,5 & 180,0 & 213,0 & 418,0 & 219,0 & 193,0 & 202,0 & 207,0 \\
\hline $13 / 01 / 79$ & 250,0 & 263,0 & 180,0 & 190,0 & 226,0 & 565,0 & 310,0 & 240,0 & 225,0 & 210,0 \\
\hline $14 / 01 / 79$ & 375,0 & 326,0 & 230,0 & 240,0 & 265,0 & 635,0 & 330,0 & 250,0 & $23 \dot{4}, 0$ & 210,0 \\
\hline $15 / 01 / 79$ & 578,5 & 410,0 & 240,0 & 250,0 & 277,0 & 742,0 & 445,0 & 285,0 & 245,0 & 207,0 \\
\hline $16 / 01 / 79$ & 604,5 & 564,0 & 254,0 & 260,0 & 295,0 & 780,0 & 333,0 & 330,0 & 230,0 & 220,0 \\
\hline $17 / 01 / 79$ & 676,0 & 585,0 & 285,0 & 275,0 & 305,0 & 770,0 & 353,0 & 438,0 & 280,0 & 270,0 \\
\hline $18 / 01 / 79$ & 765,0 & 670,0 & 330,0 & 290,0 & 330,0 & - & 480,0 & 520,0 & 330,0 & 265,0 \\
\hline $19 / 01 / 79$ & 715,0 & 715,0 & 475,0 & 310,0 & 300,0 & 550,0 & 445,0 & 475,0 & 345,0 & 300,0 \\
\hline $20 / 01 / 79$ & 645,0 & 725,0 & 397,0 & 320,0 & 380,0 & 580,0 & 430,0 & 550,0 & 250,0 & 305,0 \\
\hline $23 / 01 / 79$ & 495,0 & 630,0 & 403,0 & 330,0 & 421,0 & 414,0 & 392,0 & 537,0 & 404,0 & 362,0 \\
\hline $24 / 01 / 79$ & 288,0 & 476,0 & 435,0 & 405,0 & 435,0 & 390,0 & 390,0 & 520,0 & 430,0 & 375,0 \\
\hline $25 / 01 / 79$ & 430,0 & 440,0 & 440,0 & 380,0 & 505,0 & 530,0 & 451,0 & - & 462,0 & 443,0 \\
\hline $26 / 01 / 79$ & 513,0 & 530,0 & 515,0 & 395,0 & 445,0 & 575,0 & 442,0 & 480,0 & 450,0 & 460,0 \\
\hline $27 / 01 / 79$ & 580,0 & 585,0 & 530,0 & 389,0 & 300,0 & 490,0 & 380,0 & 450,0 & 480,0 & 500,0 \\
\hline $29 / 01 / 79$ & 59,0 & 110,0 & 145,0 & 180,0 & 300,0 & 115,0 & 130,0 & 240,0 & 230,0 & 350,0 \\
\hline $30 / 01 / 79$ & 95,0 & 105,0 & 150,0 & 230,0 & 290,0 & 90,0 & 130,0 & 245,0 & 250,0 & 310,0 \\
\hline $31 / 01 / 79$ & 160,0 & 150,0 & 200,0 & 270,0 & 290,0 & 210,0 & 180,0 & 225,0 & 245,0 & 245,0 \\
\hline $01 / 02 / 79$ & 190,0 & 150,0 & 180,0 & 200,0 & 230,0 & 175,0 & 200,0 & 230,0 & 250,0 & 190,0 \\
\hline $02 / 02 / 79$ & 225,0 & 160,0 & 195,0 & 240,0 & 280,0 & 205,0 & 225,0 & 255,0 & 285,0 & 285,0 \\
\hline $03 / 02 / 79$ & 245,0 & 215,0 & 235,0 & 250,0 & 280,0 & 175,0 & 185,0 & 230,0 & 285,0 & 220,0 \\
\hline $04 / 0$ & 324,0 & 260,0 & 245,0 & 268,0 & 287,0 & 330,0 & 214,0 & 266,0 & 310,0 & 308,0 \\
\hline $05 / 02 / 79$ & 406,0 & 226,0 & 286,0 & 331,0 & 285,0 & 598,0 & 391,0 & 351,0 & 267,0 & 280,0 \\
\hline $05 / 02 / 79$ & 454,0 & 266,0 & 339,0 & 314,0 & 290,0 & 685,0 & 537,0 & 392,0 & 390,0 & 290,0 \\
\hline $07 / 02 / 79$ & 532,0 & 312,0 & 338,0 & 326,0 & 290,0 & 608,0 & 567,0 & 422,0 & 300,0 & 300,0 \\
\hline $08 / 02 / 79$ & 618,0 & 385,0 & 515,0 & 393,0 & 290,0 & 639,0 & 605,0 & 496,0 & 451,0 & 300,0 \\
\hline $09 / 02 / 79$ & 683,0 & 421,0 & 524,0 & 349,0 & 290,0 & 670,0 & 646,0 & 556,0 & 575,0 & 530,0 \\
\hline $10 / 02 / 79$ & 126,0 & 207,0 & 394,0 & 396,0 & 340,0 & 100,0 & 340,0 & 487,0 & 580,0 & 530,0 \\
\hline $11 / 02 / 79$ & 108,0 & 110,0 & 200,0 & 260,0 & 300,0 & 104,0 & 178,0 & 320,0 & 320,0 & 325,0 \\
\hline $16 / 02 / 79$ & 120,0 & 120,0 & 155,0 & 175,0 & 190,0 & 140,0 & 160,0 & 150,0 & 162,0 & 185,0 \\
\hline $19 / 02 / 79$ & 120,0 & 120,0 & 161,0 & 175,0 & 261,0 & 138,0 & 125,0 & 157,0 & 175,0 & 186,0 \\
\hline $21 / 02 / 79$ & 170,0 & 139,0 & 178,0 & 190,0 & 220,0 & 143,0 & 153,0 & 191,0 & 185,0 & 210,0 \\
\hline $22 / 02 / 79$ & 153,0 & 165,0 & 196,0 & 234,0 & 260,0 & 184,0 & 150,0 & 168,0 & $1 \leqslant 7,0$ & 210,0 \\
\hline $24 / 02 / 79$ & 143,0 & 138,0 & 243,0 & 206,0 & 233,0 & 245,0 & 192,0 & 204,0 & 210,0 & 210,0 \\
\hline $25 / 02 / 79$ & 147,0 & 120,0 & 230,0 & 205,0 & 230,0 & 205,0 & 180,0 & 176,0 & 190,0 & 210,0 \\
\hline $26 / 02 / 79$ & 163,0 & 150,0 & 228,0 & 205,0 & 227,0 & 282,0 & 185,0 & 200,0 & 195,0 & 200,0 \\
\hline $27 / 02 / 79$ & 210,0 & 155,0 & 230,0 & 210,0 & 210,0 & 280,0 & 185,0 & 200,0 & 200,0 & 200,0 \\
\hline $28 / 02 / 79$ & 245,0 & 165,0 & 245,0 & 220,0 & 245,0 & 315,0 & 205,0 & 230,0 & 220,0 & 230,0 \\
\hline $01 / 03 / 79$ & 235,0 & 170,0 & 200,0 & 225,0 & 240,0 & 330,0 & 240,0 & 250,0 & 260,0 & 220,0 \\
\hline $02 / 03 / 79$ & 322,0 & 190,0 & 250,0 & 225,0 & 252,0 & 380,0 & 260,0 & 312,0 & 263,0 & 296,0 \\
\hline $04 / 03 / 79$ & 228,0 & 200,0 & 230,0 & 235,0 & 260,0 & 305,0 & 250,0 & 235,0 & 242,0 & 235,0 \\
\hline $06 / 03 / 79$ & 307,0 & 210,0 & 265,0 & 245,0 & 250,0 & 335,0 & 250,0 & 293,0 & 250,0 & 300,0 \\
\hline $07 / 03 / 79$ & 395,0 & 220,0 & 225,0 & 250,0 & 275,0 & 425,0 & 340,0 & 305,0 & 260,0 & 255,0 \\
\hline $08 / 03 / 79$ & 385,0 & 225,0 & 269,0 & 250,0 & 275,0 & 415,0 & 330,0 & 305,0 & 260,0 & 250,0 \\
\hline $09 / 03 / 79$ & 415,0 & 230,0 & 265,0 & 250,0 & 275,0 & 470,0 & 318,0 & 371,0 & 260,0 & 250,0 \\
\hline $10 / 03 / 79$ & 465,0 & 232,0 & 250,0 & 199,0 & 270,0 & 512,0 & 299,0 & 311,0 & 260,0 & 238,0 \\
\hline $16 / 03 / 79$ & 292,0 & 253,0 & 255,0 & 261,0 & 276,0 & 387,0 & 315,0 & 325,0 & 275,0 & 253,0 \\
\hline $17 / 03 / 79$ & 277,5 & 297,0 & 265,0 & 286,0 & 300,0 & 370,0 & 325,0 & 345,0 & $29 \dot{4}, 0$ & 312,0 \\
\hline $20 / 03 / 79$ & 398,0 & 279,0 & 271,0 & 284,0 & 302,0 & 545,0 & 358,0 & 331,0 & 304.0 & 312,0 \\
\hline
\end{tabular}


APENDICE 2 - Valores de umidade do solo $\left(\theta \mathrm{cm}^{3} . \mathrm{cm}^{-3}\right)$, obtidos através das curvas de retenção de água.

\begin{tabular}{|c|c|c|c|c|c|c|c|c|c|c|}
\hline \multirow{2}{*}{ Data } & \multicolumn{5}{|c|}{$\mathrm{T}_{1}$} & \multicolumn{5}{|c|}{$\mathrm{T}_{5}$} \\
\hline & $0-15$ & $15-30$ & $30-60$ & $60-90$ & $90-120$ & $0-15$ & $15-30$ & $30-60$ & $60-90$ & $90-120$ \\
\hline $20 / 12 / 78$ & 0,26 & 0,25 & 0,25 & 0,28 & 0,26 & 0,25 & 0,25 & 0,25 & 0,26 & 0,26 \\
\hline $21 / 12 / 78$ & 0,25 & 0,25 & 0,24 & 0,26 & 0,26 & 0,24 & 0,25 & 0,25 & 0,26 & 0,26 \\
\hline $22 / 12 / 78$ & 0,24 & 0,25 & 0,24 & 0,26 & 0,26 & 0,23 & 0,25 & 0,25 & 0,26 & 0,26 \\
\hline $23 / 12 / 78$ & 0,29 & 0,26 & 0,25 & 0,26 & 0,26 & 0,27 & 0,26 & 0,25 & 0,26 & 0,26 \\
\hline $24 / 12 / 78$ & 0,27 & 0,26 & 0,25 & 0,26 & 0,26 & 0,25 & 0,24 & 0,24 & 0,25 & 0,25 \\
\hline $30 / 12 / 78$ & 0,31 & 0,28 & 0,27 & 0,26 & 0,30 & 0,30 & 0,27 & 0,26 & 0,26 & 0,26 \\
\hline $31 / 12 / 78$ & 0,28 & 0,25 & 0,25 & 0,26 & 0,26 & 0,27 & 0,26 & 0,26 & 0,26 & 0,25 \\
\hline $02 / 01 / 79$ & 0,26 & 0,24 & 0,25 & 0,25 & 0,25 & 0,26 & 0,25 & 0,26 & 0,26 & 0,26 \\
\hline $03 / 01 / 79$ & 0,38 & 0,27 & 0,28 & 0,28 & 0,28 & 0,36 & 0,28 & 0,28 & 0,28 & 0,28 \\
\hline $05 / 01 / 79$ & 0,35 & 0,27 & 0,28 & 0,28 & 0,28 & 0,33 & 0,28 & 0,28 & 0,28 & 0,28 \\
\hline $06 / 01 / 79$ & 0,32 & 0,26 & 0,27 & 0,28 & 0,28 & 0,31 & 0,27 & 0,27 & 0,28 & 0,28 \\
\hline $07 / 01 / 79$ & 0,30 . & 0,25 & 0,26 & 0,27 & 0,28 & 0,29 & 0,25 & 0,26 & 0,28 & 0,28 \\
\hline $09 / 01 / 79$ & 0,28 & 0,25 & 0,26 & 0,27 & 0,28 & 0,27 & 0,24 & 0,26 & 0,27 & 0,28 \\
\hline $10 / 01 / 79$ & 0,26 & 0,23 & 0,25 & 0,26 & 0,27 & 0,25 & 0,23 & 0,26 & 0,27 & 0,27 \\
\hline $13 / 01 / 79$ & 0,23 & 0,23 & 0,24 & 0,26 & 0,26 & 0,22 & 0,22 & 0,25 & 0,26 & 0,26 \\
\hline $14 / 01 / 79$ & 0,22 & 0,22 & 0,23 & 0,25 & 0,26 & 0,21 & 0,21 & 0,24 & 0,25 & 0,26 \\
\hline $15 / 01 / 79$ & 0,21 & 0,21 & 0,22 & 0,24 & 0,26 & 0,20 & 0,21 & 0,23 & 0,24 & 0,25 \\
\hline $16 / 01 / 79$ & 0,20 & 0,20 & 0,21 & 0,23 & 0,25 & 0,20 & 0,20 & 0,21 & 0,23 & 0,25 \\
\hline $17 / 01 / 79$ & 0,20 & 0,20 & 0,20 & 0,22 & 0,24 & 0,20 & 0,20 & 0,20 & 0,22 & 0,24 \\
\hline $18 / 01 / 79$ & 0,20 & 0,20 & 0,20 & 0,21 & 0,22 & 0,20 & 0,20 & 0,20 & 0,21 & 0,22 \\
\hline $19 / 01 / 79$ & 0,20 & 0,20 & 0,20 & 0,22 & 0,22 & 0,20 & 0,20 & 0,20 & 0,21 & 0,22 \\
\hline $20 / 01 / 79$ & 0,24 & 0,22 & 0,20 & 0,22 & 0,22 & 0,23 & 0,22 & 0,20 & 0,21 & 0,22 \\
\hline $23 / 01 / 79$ & 0,28 & 0,26 & 0,21 & 0,22 & 0,22 & 0,26 & 0,24 & 0,21 & 0,21 & 0,22 \\
\hline $24 / 01 / 79$ & 0,27 & 0,25 & 0,21 & 0,22 & 0,22 & 0,25 & 0,24 & 0,21 & 0,21 & 0,22 \\
\hline $25 / 01 / 79$ & 0,28 & 0,26 & 0,22 & 0,22 & 0,22 & 0,26 & 0,25 & 0,22 & 0,22 & 0,22 \\
\hline $26 / 01 / 79$ & 0,30 & 0,28 & 0,24 & 0,22 & 0,22 & 0,28 & 0,26 & 0,23 & 0,22 & 0,22 \\
\hline $27 / 01 / 79$ & 0,31 & 0,28 & 0,24 & $0,2 \hat{j}$ & 0,23 & 0,20 & 0,28 & 0,23 & 0,22 & 0,22 \\
\hline $29 / 01 / 79$ & 0,38 & 0,36 & 0,30 & 0,28 & 0,26 & 0,35 & 0,33 & 0,28 & 0,26 & 0,24 \\
\hline $30 / 01 / 79$ & 0,34 & 0,30 & 0,28 & 0,28 & 0,28 & 0,32 & 0,28 & 0,27 & 0,27 & 0,26 \\
\hline $31 / 01 / 79$ & 0,30 & 0,27 & 0,27 & 0,28 & 0,28 & 0,28 & 0,25 & 0,26 & 0,27 & 0,27 \\
\hline $01 / 02 / 79$ & 0,26 & 0,24 & 0,24 & 0,27 & 0,28 & 0,25 & 0,23 & 0,23 & 0,26 & 0,27 \\
\hline $02 / 02 / 79$ & 0,24 & 0,23 & 0,23 & 0,26 & 0,27 & 0,23 & 0,23 & 0,23 & 0,25 & 0,26 \\
\hline $03 / 02 / 79$ & 0,26 & 0,24 & 0,23 & 0,26 & 0,27 & 0,25 & 0,24 & 0,23 & 0,25 & 0,26 \\
\hline $04 / 02 / 79$ & 0,23 & 0,23 & 0,23 & 0,26 & 0,26 & 0,22 & 0,23 & 0,23 & 0,26 & 0,26 \\
\hline $05 / 02 / 79$ & 0,23 & 0,22 & 0,23 & 0,25 & 0,26 & 0,22 & 0,22 & 0,23 & 0,25 & 0,26 \\
\hline $06 / 02 / 79$ & 0,22 & 0,21 & 0,22 & 0,25 & 0,26 & 0,21 & 0,21 & 0,22 & 0,25 & 0,26 \\
\hline $07 / 02 / 79$ & 0,21 & 0,21 & 0,21 & 0,24 & 0,25 & 0,20 & 0,20 & 0,21 & 0,24 & 0,25 \\
\hline $08 / 02 / 79$ & 0,20 & 0,20 & 0,20 & 0,23 & 0,24 & 0,20 & 0,20 & 0,20 & 0,23 & 0,24 \\
\hline $09 / 02 / 79$ & 0,20 & 0,20 & 0,20 & 0,21 & 0,22 & 0,20 & 0,20 & 0,20 & 0,21 & 0,22 \\
\hline $10 / 02 / 79$ & 0,30 & 0,24 & 0,21 & 0,21 & 0,22 & 0,28 & 0,23 & 0,21 & 0,21 & 0,22 \\
\hline $11 / 02 / 79$ & 0,32 & 0,28 & 0,25 & 0,22 & 0,22 & 0,30 & 0,28 & 0,24 & 0,21 & 0,22 \\
\hline $16 / 02 / 79$ & 0,38 & 0,36 & 0,30 & 0,28 & 0,28 & 0,35 & 0,33 & 0,30 & 0,28 & 0,28 \\
\hline $19 / 02 / 79$ & 0,38 & 0,38 & 0,30 & 0,28 & 0,28 & 0,35 & 0,34 & 0,30 & 0,28 & 0,28 \\
\hline $21 / 02 / 79$ & 0,35 & 0,32 & 0,30 & 0,28 & 0,28 & 0,33 & 0,30 & 0,30 & 0,28 & 0,28 \\
\hline $22 / 02 / 79$ & 0,34 & 0,30 & 0,30 & 0,28 & 0,28 & 0,33 & 0,32 & 0,30 & 0,28 & 0,28 \\
\hline $24 / 02 / 79$ & 0,33 & 0,28 & 0,28 & 0,28 & 0,28 & 0,32 & 0,28 & 0,28 & 0,28 & 0,28 \\
\hline $25 / 02 / 79$ & 0,30 & 0,26 & 0,26 & 0,28 & 0,28 & 0,29 & $0 ; 26$ & 0,26 & 0,28 & 0,28 \\
\hline $26 / 02 / 79$ & 0,28 & 0,25 & 0,26 & 0,28 & 0,28 & 0,27 & 0,25 & 0,25 & 0,28 & 0,28 \\
\hline $27 / 02 / 79$ & 0,26 & 0,24 & 0,25 & 0,27 & 0,28 & 0,25 & 0,3 & 0,24 & 0,27 & 0,28 \\
\hline $28 / 02 / 79$ & 0,24 & 0,23 & 0,23 & 0,27 & 0,27 & 0,23 & 0,23 & 0,24 & 0,27 & 0,27 \\
\hline $01 / 03 / 79$ & 0,23 & 0,22 & 0,22 & 0,26 & 0,26 & 0,22 & 0,22 & 0,23 & 0,26 & 0,26 \\
\hline $02 / 03 / 79$ & 0,22 & 0,21 & 0,21 & 0,24 & 0,26 & 0,21 & 0,21 & 0,22 & 0,24 & 0,26 \\
\hline $04 / 03 / 79$ & 0,28 & 0,25 & 0,22 & 0,24 & 0,26 & 0,26 & 0,24 & 0,23 & 0,24 & 0,26 \\
\hline $06 / 03 / 79$ & 0,25 & 0,23 & 0,22 & 0,24 & 0,26 & 0,23 & 0,22 & 0,23 & 0,24 & 0,26 \\
\hline $07 / 03 / 79$ & 0,23 & 0,22 & 0,22 & 0,24 & 0,25 & 0,22 & 0,21 & 0,22 & 0,24 & 0,26 \\
\hline $08 / 03 / 79$ & 0.22 & 0,21 & 0,21 & 0,24 & 0,25 & 0,21 & 0,20 & 0,21 & 0,24 & 0,26 \\
\hline $09 / 03 / 79$ & 0,21 & 0,20 & 0,20 & 0,23 & 0,25 & 0,20 & 0,20 & 0,20 & 0,23 & 0,25 \\
\hline $10 / 03 / 79$ & 0,20 & 0,20 & 0,20 & 0,22 & 0,24 & 0,20 & 0,20 & 0,20 & 0,22 & 0,23 \\
\hline $16 / 03 / 79$ & 0,28 & 0,26 & 0,24 & 0,24 & 0,24 & 0,26 & 0,25 & 0,24 & 0,24 & 0,24 \\
\hline $17 / 03 / 79$ & 0,26 & 0,24 & 0,24 & 0,24 & 0,24 & 0,24 & 0,23 & 0,24 & 0,24 & 0,24 \\
\hline $20 / 03 / 79$ & 0,22 & 0,23 & 0,23 & 0,24 & 0,24 & 0,22 & 0,22 & 0,23 & 0,24 & 0,24 \\
\hline
\end{tabular}


APENDICE 3 - Armazenamento de água no solo em milímetros.

\begin{tabular}{|c|c|c|c|c|c|c|c|c|c|c|c|c|}
\hline \multirow{2}{*}{ Data } & \multicolumn{6}{|c|}{$\mathrm{T}_{1}$} & \multicolumn{6}{|c|}{$\mathrm{T}_{5}$} \\
\hline & $0-15$ & $15-30$ & $30-60$ & $60-90$ & $90-120$ & $0-120$ & $0-15$ & $15-30$ & $30-60$ & $60-90$ & $90-120$ & $0-120$ \\
\hline 2710 & 39,0 & 37,5 & 75,0 & 78,0 & 78,0 & 307,0 & 37,5 & 37,5 & 75,0 & 78,0 & 78,0 & 306, \\
\hline 178 & 2 & 37,5 & 72,0 & 78,0 & 78,0 & 303,0 & 36,0 & 37,5 & 75,0 & 78,0 & 78,0 & 305,0 \\
\hline $22 / 12 / 78$ & 36,0 & 37,5 & 72,0 & 78,0 & 78,0 & 301,0 & 34,5 & 37,5 & 75,0 & 78,0 & 78,0 & 303,0 \\
\hline $23 / 12 / 78$ & $.43,5$ & 39,0 & 75,0 & 78,0 & 78,0 & 313,4 & 40,5 & 39,0 & 75,0 & 78,0 & 78,0 & 310,5 \\
\hline $24 / 12 / 78$ & 40,5 & 39,0 & 75,0 & 78,0 & 78,0 & 310,0 & 37,5 & 36,0 & 72,0 & 75,0 & 75,0 & 295,0 \\
\hline $30 / 12 / 78$ & 46,5 & 42,0 & 81,0 & 78,0 & 78,0 & 325,0 & 45,0 & 40,5 & 78,0 & 78,0 & 78,0 & 320,0 \\
\hline $31 / 12 / 78$ & 42,0 & 37,5 & 75,0 & 78,0 & 78,0 & 310,0 & 40,5 & 39,0 & 78,0 & 78,0 & 75,0 & 310,0 \\
\hline $02 / 01 / 79$ & 39,0 & 36,0 & 75,0 & 75,0 & 75,0 & 300,0 & 39,0 & 37,5 & 78,0 & 78,0 & 78,0 & 310,0 \\
\hline $03 /$ & 57,0 & 40,5 & 84,0 & 84,0 & 84,0 & 350,0 & 54,0 & 42,0 & 84,0 & 84,0 & 54,0 & 348,0 \\
\hline $05 / C$ & 52,5 & 40,5 & 84,0 & 84,0 & 84,0 & 345,0 & 49,5 & 42,0 & 84,0 & 84,0 & 84,0 & 44,0 \\
\hline $06 / 01 / 79$ & 48,0 & 39,0 & 81,0 & 84 & 84,0 & & 46,5 & & 81,0 & 84,0 & 4,0 & 36,0 \\
\hline /79 & 45,0 & 37,5 & 78,0 & 81 & 84,0 & 3 & & 5 & 78,0 & 84,0 & 4,0 & 27,0 \\
\hline $1 / 79$ & 42,0 & 36,0 & 78,0 & 81,0 & 84,0 & 321,0 & 0,5 & 36,0 & 78,0 & $8:, 0$ & 84,0 & 19,0 \\
\hline $10 / 01 / 79$ & 39,0 & 34,5 & 75,0 & 78,0 & 81,0 & 307,0 & 37,5 & 34,5 & 78,0 & 81,0 & 81,0 & 12,0 \\
\hline $13 / 01 / 79$ & 34,5 & 34,5 & 72,0 & 78,0 & 78,0 & 297,0 & 33,0 & 33,0 & 75,0 & 78,0 & 78,0 & 297,0 \\
\hline $14 / 01 / 79$ & 33,0 & 33,0 & 69,0 & 75,0 & 78,0 & 288,0 & 31,5 & $3 i, 5$ & 72,0 & 75,0 & 78,0 & 288,0 \\
\hline $15 / 01 / 79$ & 31,5 & 31,5 & 66,0 & 72,0 & 78,0 & 279,0 & 31,5 & 31,5 & 72,0 & 75,0 & 78,0 & 277,0 \\
\hline $16 / 01 / 79$ & 30,0 & 30,0 & 63,0 & 69,0 & 75,0 & 267,0 & 30,0 & 30,0 & 63,0 & 69,0 & 75,0 & 267,0 \\
\hline $1 / 79$ & 30,0 & 30,0 & 60,0 & 66,0 & 72,0 & 258,0 & 30,0 & 30,0 & 60,0 & 66,0 & 72,0 & 258,0 \\
\hline $1 / 79$ & 30,0 & 30,0 & 60,0 & 63,0 & 66,0 & 249,0 & 30,0 & 30,0 & 60,0 & 63,0 & 66,0 & 249,0 \\
\hline $19 /$ & 30,0 & 30,0 & 60,0 & 66, & 66,0 & 25 & 30,0 & 30,0 & 60,0 & 0 & 66,0 & 249,0 \\
\hline $20 /$ & 36,0 & 30,0 & 60,0 & & 66,0 & 25 &, 5 & 3,0 & 60,0 & 0 & 6,0 & 6,0 \\
\hline $23 / C$ & 42,0 & 39,0 & 63,0 & 66 & 66,0 & & & 0 & 63,0 & 63,0 & 6,0 & 67,0 \\
\hline 179 & 40,5 & 37,5 & 63,0 & 66,0 & 66,0 & 273,0 & 37,5 & 36,0 & 63,0 & 63,0 & 66,0 & 265,0 \\
\hline $25 / 01 / 79$ & 42,0 & 39,0 & 66,0 & 66,0 & 66,0 & 279,0 & 39,0 & 37,5 & 66,0 & 66,0 & 66,0 & 274,0 \\
\hline $26 / 01 / 79$ & 45,0 & 42,0 & 72,0 & 66,0 & 66,0 & 291,0 & 42,0 & 39,0 & 69,0 & 66,0 & 66,0 & 282,0 \\
\hline $27 / 01 / 79$ & 46,5 & 42,0 & 72,0 & 69,0 & 69,0 & 298,0 & 45,0 & 42,0 & 69,0 & 63,0 & 63,0 & 282,0 \\
\hline $29 / 01 / 79$ & 57,0 & 54,0 & 90,0 & 84,0 & 78,0 & 348,0 & 52,5 & 49,5 & 84,0 & 78,0 & 72,0 & 336,0 \\
\hline $30 / 01 / 79$ & 51,0 & 45,0 & 84,0 & 84,0 & 84,0 & 348,0 & 48,0 & 42,0 & 81,0 & 81,0 & 78,0 & 330,0 \\
\hline 179 & 45,0 & 40,5 & 81,0 & 84,0 & 34,0 & 33 & 42,0 & 37,5 & 78,0 & 81,0 & 81,0 & 20,0 \\
\hline 79 & 39,0 & 36 , & 72,0 & 81,0 & 4,0 & 3 & & 34,5 & 69,0 & 0 & 81,0 &, 0 \\
\hline 021 & 36,0 & 34,5 & 69,0 & 78 & 1,0 & & 5 &, 5 & 69,0 & 0 & 7 & 1,0 \\
\hline $03 /$ & 39,0 & 36,0 & 69,0 & 78,0 & 1,0 & 3 &, 5 & 36,0 & 69,0 & 75,0 & 78,0 & 295,0 \\
\hline $04 / 02 / 79$ & 34,5 & 34,5 & 69,0 & 78,0 & 78,0 & 294,0 & 33,0 & 34,5 & 69,0 & 78,0 & 78,0 & 292,0 \\
\hline $05 / 02 / 79$ & 34,5 & 33,0 & 69,0 & 75,0 & 78,0 & 290,0 & 33,0 & 33,0 & 69,0 & 75,0 & 78,0 & 288,0 \\
\hline $06 / 02 / 79$ & 33,0 & 31,5 & 66,0 & 75,0 & 78,0 & 284,0 & 33,0 & 33,0 & 66,0 & 75.0 & 78,0 & 285,0 \\
\hline $07 / 02 / 79$ & 31,5 & 31,5 & 63,0 & 72,0 & 75,0 & 273,0 & 30,0 & 30,0 & 63,0 & 72,0 & 75,0 & 270,0 \\
\hline $08 / 02 / 79$ & 30,0 & 30,0 & 60,0 & 69,0 & 72,0 & 261,0 & 30,0 & 30,0 & 60,0 & 69,0 & 72,0 & 261,0 \\
\hline 179 & 30,0 & 30,0 & 60,0 & 63,0 & 66,0 & 249,0 & 30,0 & 30,0 & 30,0 & 63,0 & 66,0 & 249,0 \\
\hline & 45,0 & 36,0 & 63,0 & 63,0 & 66,0 & 2 & 0 & 34,5 & 63,0 & 63,0 & 66,0 & 3,0 \\
\hline & 48,0 & 4 & 75,0 & 66, & & & & 0 & 0 & & &, 0 \\
\hline $16 / 0$ & 57,0 & 54,0 & 90,0 & 84,0 & 84,0 & 36 & 52,5 & 49,5 & 90,0 & 84,0 & 84,0 & 360,0 \\
\hline $19 / 02 / 79$ & 57,0 & 57,0 & 90,0 & 84,0 & 84,0 & 372,0 & 52,5 & 51,0 & 90,0 & 84,0 & 84,0 & 361,0 \\
\hline $21 / 02 / 79$ & 52,5 & 48,0 & 90,0 & 84,0 & 84,0 & 358,0 & 49,5 & 45,0 & 90,0 & 84,0 & 84,0 & 352,0 \\
\hline $22 / 02 / 79$ & 51,0 & 45,0 & 90,0 & 84,0 & 84,0 & 354,0 & 49,5 & 48,0 & 90,0 & 84,0 & 84,0 & 355,0 \\
\hline $24 / 02 / 79$ & 49,5 & 42,0 & 84,0 & 84,0 & 84,0 & 343,0 & 48,0 & 42,0 & 84,0 & 84,0 & 84,0 & 342,0 \\
\hline $25 / 02 / 79$ & 45,0 & 39,0 & 78,0 & 84,0 & 84,0 & 325,0 & 43,5 & 39,0 & 78,0 & 84,0 & $8 \div, 0$ & 328,0 \\
\hline $26 /$ & 42,0 & 37,5 & 78,0 & 84,0 & 84,0 & 325,0 & 40,5 & 37,5 & 75,0 & 84,0 & 84,0 & 321,0 \\
\hline $27 / c$ & 39,0 & 36,0 & 75,0 & 81,0 & 84,0 & 315, & 37,5 & 34,5 & 72,0 & 81,0 & 84,0 & 309,0 \\
\hline 2 & 36,0 & 34,5 & 69,0 & 1,0 & 81,0 & 3 & 4,5 & 34,5 & 72,0 &, 0 & 81,0 & 03,0 \\
\hline $01 / c$ & 34,5 & 33,0 & 66,0 & 78,0 & 78,0 & 289,0 & 33,0 & 33,0 & 69,0 & 78,0 & 78,0 & 291,0 \\
\hline $02 / 03 / 79$ & 33,0 & 31,5 & 63,0 & 72,0 & 78,0 & 278,0 & 31,5 & 31,5 & 66,0 & 72,0 & 78,0 & 279,0 \\
\hline 041 & 42,0 & 37,5 & 66,0 & 72,0 & 78,0 & 295,0 & 39,0 & 36,0 & 69,0 & 72,0 & 78,0 & 294,0 \\
\hline $06 / 03 / 79$ & 37,5 & 34,5 & 66,0 & 72,0 & 78,0 & 283,0 & 34,5 & 33,0 & 69,0 & 72,0 & 78,0 & 286,0 \\
\hline $07 / 03 / 79$ & 34,5 & 33,0 & 66,0 & 72,0 & 75,0 & 280,0 & 33,0 & 31,5 & 66,0 & 72,0 & 78,0 & 280,0 \\
\hline $08 / 03 / 79$ & 33,0 & 31,5 & 63,0 & $72 ; 0$ & 75,0 & 274,0 & 31,5 & 30,0 & 63,0 & 72,0 & 78,0 & 274,0 \\
\hline $09 / 03 / 79$ & 31,5 & 30,0 & 60,0 & 69,0 & 75,0 & 265 , & 30,0 & 30,0 & 60,0 & 69,0 & 75,0 & 255,0 \\
\hline $10 / 03 / 79$ & 30,0 & 30,0 & 60,0 & 66,0 & 72,0 & 258, & 30,0 & 30,0 & 60,0 & 66,0 & 69.0 & 255,0 \\
\hline $16 / 03 / 79$ & 42,0 & 39,0 & 72,0 & 72,0 & 72,0 & 297,0 & 39,0 & 37,5 & 72,0 & 72,0 & 72.0 & 292,0 \\
\hline $17 / 0$ & 39,0 & 36,0 & 72,0 & 72,0 & 72,0 & 291,0 & 36,0 & 34,5 & 72,0 & 72,0 & 72,0 & 286,0 \\
\hline $20 / 03 / 79$ & 33,0 & 34,5 & 69,0 & 72,0 & 72,0 & 280,0 & 33,0 & 33,0 & 69,0 & 72,0 & 72,0 & 279,0 \\
\hline
\end{tabular}


APENDICE 4 - Valores médios do potencial de umidade do solo às profundidades experimentais.

\begin{tabular}{|c|c|c|c|c|c|c|c|c|c|c|}
\hline \multirow{2}{*}{ Data } & \multicolumn{5}{|c|}{$\mathrm{I}_{1}$} & \multicolumn{5}{|c|}{$\mathrm{T}_{5}$} \\
\hline & 15,0 & 30,0 & 60,0 & 90,0 & 120,0 & 15,0 & 30,0 & 60,0 & 90,0 & 120,0 \\
\hline $03 / 11 / 79$ & 102,5 & 152,5 & 178,0 & 196,5 & 234,5 & 118,0 & 153,0 & 178,5 & 222,0 & 253,5 \\
\hline $04 / 11 / 7.9$ & 190,5 & 184,5 & 184,0 & 196,5 & 234,5 & 181,0 & 184,5 & 184,5 & 235,0 & 253,5 \\
\hline $05 / 11 / 79$ & 260,0 & 241,0 & 222,0 & $215 ; 5$ & 234,5 & 259,5 & 228,5 & 228,5 & 222,0 & 253,5 \\
\hline $06 / 11 / 79$ & 354,0 & 341,5 & 297,5 & 260,0 & 247,0 & 373,0 & 335,0 & 310,5 & 272,5 & 259,5 \\
\hline $07 / 11 / 79$ & 39,0 & 140,0 & 234,5 & 260,0 & 260,0 & 39,5 & 153,0 & 240,5 & 266,0 & 266,0 \\
\hline $08 / 11 / 79$ & 33,0 & 71,0 & 184,5 & 234,5 & 253,5 & 33,0 & 83,5 & 171,5 & 253,5 & 272,5 \\
\hline $11 / 11 / 79$ & 39,5 & 52,0 & 121,0 & 197,0 & 222,0 & 46,0 & 52,0 & 133,5 & 209,5 & 241,0 \\
\hline $12 / 11 / 79$ & 109,0 & 64,5 & 121,0 & 197,0 & 228,0 & 121,0 & 146,0 & 133,5 & 184,5 & 241,0 \\
\hline $13 / 11 / 79$ & 354,5 & 304,0 & 159,0 & 203,0 & 228,0 & 228,0 & 323,0 & 172,0 & 203,0 & 235,0 \\
\hline $14 / 11 / 79$ & 436,0 & 455,0 & 285,0 & 241,0 & 241,0 & 411,0 & 444,0 & 298,0 & 247,0 & 241,0 \\
\hline $15 / 11 / 79$ & 272,5 & 297,5 & 285,0 & 247,0 & 247,0 & 348,0 & 367,0 & 292,0 & 260,0 & 247,0 \\
\hline $16 / 11 / 79$ & 480,0 & 430,0 & 285,0 & 247,0 & 247,0 & 511,0 & 461,0 & 291,5 & 260,0 & 247,0 \\
\hline $17 / 11 / 79$ & 587,5 & 543,5 & 360,5 & 272,5 & 247,0 & 581,0 & 550,0 & 367,0 & 285,0 & 247,0 \\
\hline $18 / 11 / 79$ & 657,0 & 625,0 & 417,0 & 298,0 & 260,0 & 656,0 & 625,0 & 430,0 & 298,0 & 260,0 \\
\hline $19 / 11 / 79$ & 695,0 & 657,0 & 486,0 & $316 ; 0$ & 285,0 & 701,0 & 676,0 & 505,5 & 335,5 & 278,5 \\
\hline $20 / 11 / 79$ & 720,0 & 694,5 & 531,0 & 354,5 & 316,5 & 732,5 & 707,0 & 556,0 & 367,0 & 316,7 \\
\hline $21 / 11 / 79$ & 738,5 & 726,0 & 581,0 & 411,0 & 341,5 & 745,0 & 732,5 & 575,0 & 442,5 & 348,5 \\
\hline $22 / 11 / 79$ & 770,0 & 758,0 & 612,0 & 436,0 & 373,5 & 785,0 & 757,5 & 606,5 & 461,5 & 383,5 \\
\hline $23 / 11 / 79$ & 770,0 & 770,0 & 619,0 & 442,5 & 392,5 & 776,5 & 776,5 & 625,0 & 474,0 & 423,5 \\
\hline $24 / 11 / 79$ & 782,5 & 770,0 & 619,0 & 442,5 & 405,0 & 776,0 & 785,0 & 625,0 & 493,0 & 449,0 \\
\hline $25 / 11 / 79$ & 121,0 & 537,0 & 575,0 & 442,5 & 405,0 & 127,5 & 650,5 & 587,5 & 493,0 & 449,0 \\
\hline $26 / 11 / 79$ & 39,5 & 121,0 & 190,0 & 304,0 & 335,0 & 33,0 & 178,0 & 178,0 & 285,0 & 323,0 \\
\hline $27 / 11 / 79$ & 178,0 & 253,5 & 190,0 & 291,0 & 310,0 & 178,0 & 260,0 & 178,0 & 278,0 & 291,0 \\
\hline $28 / 11 / 79$ & 449,0 & 543,0 & 354,0 & 310,0 & 285,0 & 467,5 & 556,0 & 373,0 & 316,0 & 291,0 \\
\hline $29 / 11 / 79$ & 398,5 & 499,0 & 354,5 & 297,5 & 291,0 & 436,5 & 537,0 & 360,5 & 298,0 & 291,0 \\
\hline $30 / 11 / 79$ & 449,0 & 543,5 & 354,9 & 310,5 & 285,0 & 467,5 & 556,0 & 373,0 & 316,5 & 291,0 \\
\hline $01 / 12 / 79$ & 493,0 & 461,0 & 322,5 & 310,5 & 272,0 & 524,0 & 487,0 & 329,0 & 316,5 & 272,0 \\
\hline $02 / 12 / 79$ & 278,5 & 449,0 & 329,0 & 323,0 & 285,0 & 272,5 & 461,5 & 329,0 & 304,0 & 272,0 \\
\hline $03 / 12 / 79$ & 461,5 & 449,0 & 322,5 & 316,5 & 285,0 & 455,0 & 449,0 & 322,5 & 304,0 & 278,5 \\
\hline $04 / 12 / 79$ & 39,5 & 342,0 & 316,5 & 310,5 & 285,0 & 64,5 & 354,5 & 323,0 & 304,0 & 278,5 \\
\hline $05 / 12 / 79$ & 39,5 & 203,0 & 297,5 & 297,5 & 285,0 & 46,0 & 209,5 & 310,0 & 298,0 & 272,5 \\
\hline $06 / 12 / 79$ & 323,0 & 216,0 & 297,5 & 297,5 & 285,0 & 329,0 & 222,0 & 310,0 & 298,0 & 278,5 \\
\hline $07 / 12 / 79$ & 455,0 & 316,5 & 304,0 & 297,5 & 285,0 & 480,5 & 316,5 & 310,0 & 298,0 & 278,5 \\
\hline $08 / 11 / 79$ & 550,0 & 386,0 & 316,0 & 297,0 & 285,0 & 562,0 & 417,0 & 323,0 & 298,0 & 278,5 \\
\hline $09 / 12 / 79$ & 631,5 & 461,5 & 323,0 & 304,0 & 285,0 & 625,5 & 474,0 & 323,0 & 304,0 & 278,5 \\
\hline $10 / 12 / 79$ & 669,5 & 512,0 & 323,0 & 304,0 & 285,0 & 670,0 & 530,0 & 329,0 & 304,0 & 278,5 \\
\hline $11 / 12 / 79$ & 171,5 & 474,0 & 323,0 & 304,0 & 285,0 & 165,5 & 492,5 & 323,0 & 304,0 & 273,5 \\
\hline $12 / 12 / 79$ & 83,5 & 215,5 & 291,0 & 304,0 & 285,0 & 71,0 & 209,5 & 291,0 & 304,0 & 278,5 \\
\hline $13 / 13 / 79$ & 46,0 & 96,0 & 234,5 & 278,5 & 272,5 & 33,0 & 77,0 & 247,0 & 278,0 & 266,0 \\
\hline $17 / 12 / 79$ & 33,0 & 64,5 & 121,0 & 215,0 & 241,0 & 33,0 & 52,0 & 121,0 & 228,0 & 241,0 \\
\hline $18 / 12 / 79$ & 89,5 & 71,0 & 121,0 & 215,0 & 241,0 & 77,0 & 71,0 & $121 ; 0$ & 228,0 & 241,0 \\
\hline $20 / 12 / 79$ & 46,0 & 71,0 & 121,0 & 215,0 & 241,0 & 52,0 & 71,0 & 121,0 & 228,0 & 247,0 \\
\hline $23 / 12 / 79$ & 33,0 & 58,5 & 115,0 & 209,0 & 228,0 & 33,0 & 46,0 & 109,0 & 209,0 & 228,0 \\
\hline $27 / 12 / 79$ & 33,0 & 58,5 & 96,0 & 178,0 & 222,0 & 33,0 & 46,0 & 96,0 & 197,0 & 222,0 \\
\hline $30 / 12 / 79$ & 64,5 & 58,5 & 96,0 & 178,0 & 222,0 & 58,5 & 46,0 & 96,0 & 197,0 & 222,0 \\
\hline
\end{tabular}


APENDICE 4 - Continuação.

\begin{tabular}{|c|c|c|c|c|c|c|c|c|c|c|}
\hline \multirow{2}{*}{ Data } & \multicolumn{5}{|c|}{$\mathrm{T}_{1}$} & \multicolumn{5}{|c|}{$T_{5}$} \\
\hline & 15,0 & 30,0 & 60,0 & 90,0 & 120,0 & 15,0 & 30,0 & 60,0 & 90,0 & 120,0 \\
\hline $03 / 01 / 80$ & 115,0 & 96,0 & 121,0 & 184,0 & 222,0 & 127,0 & 108,0 & 127,0 & 190,0 & 222,0 \\
\hline $04 / 01 / 80$ & 152,0 & 108,0 & 121,0 & 184,0 & 222,0 & 184,5 & 127,0 & 127,0 & 197,0 & 222,0 \\
\hline $05 / 01 / 80$ & 228,0 & 140,0 & 140,0 & 184,0 & 222,0 & 266,0 & 159,0 & 140,0 & 197,0 & 222,0 \\
\hline $06 / 01 / 80$ & 373,0 & 203,0 & 165,5 & 184,5 & 222,0 & 417,0 & 216,0 & 178,0 & 197,0 & 222,0 \\
\hline $07 / 01 / 80$ & 467,0 & 247,0 & 178,0 & 197,0 & 222,0 & 493,0 & 266,0 & 190,5 & 203,0 & 222,0 \\
\hline $09 / 01 / 80$ & 45,0 & 146,0 & 197,0 & 203,0 & 222,0 & 58,0 & 184,0 & 209,0 & 209,0 & 222,0 \\
\hline $10 / 01 / 80$ & 58,5 & 115,0 & 197,0 & 203,0 & 222,0 & 64,5 & 140,0 & 209,0 & 215,0 & 222,0 \\
\hline $11 / 01 / 80$ & 178,0 & 140,0 & 197,0 & 203,0 & 222,0 & 184,0 & 165,0 & 203,0 & 209,0 & 222,0 \\
\hline $12 / 01 / 80$ & 165,0 & 152,2 & 203,0 & 209,0 & 228,0 & 197,0 & 178,0 & 203,0 & 215,0 & 222,0 \\
\hline $13 / 01 / 8 ?$ & 215,0 & 190,0 & 203,0 & 209,0 & 228,0 & 241,0 & 203,0 & 197.0 & 209,0 & 222,0 \\
\hline $14 / 01 / 80$ & 310,0 & 222,0 & 203,0 & 209,0 & 228,0 & 335,0 & 228,0 & 197,0 & 209,0 & 222,0 \\
\hline $15 / 01 / 80$ & 348,0 & 285,0 & 209,0 & 209,0 & 228,0 & 361,0 & 298,0 & 209,0 & 209,0 & 222,0 \\
\hline $16 / 01 / 80$ & 373,0 & 348,0 & 216,0 & 216,0 & 222,0 & 373,0 & 342,0 & 216,0 & 216,0 & 222,0 \\
\hline $18 / 01 / 80$ & 20,0 & 46,0 & 121,0 & 209,0 & 222,0 & 46,0 & 46,0 & 134,0 & 209,0 & 222,0 \\
\hline $21 / 01 / 80$ & 46,0 & 89,0 & 165,0 & 215,0 & 222,0 & 52,0 & 102,0 & 146,0 & 209,0 & 222,0 \\
\hline $23 / 01 / 80$ & $-\quad 46,0$ & 108,0 & 172,0 & 215,0 & 222,0 & 52,0 & 115,0 & 165,0 & 209,0 & 222,0 \\
\hline $27 / 01 / 80$ & 46,0 & 90,0 & 159,0 & 203,0 & 222,0 & 52,0 & 121,0 & 159,0 & 197,0 & 222,0 \\
\hline $28 / 01 / 80$ & 52,0 & 127,0 & 159,0 & 203,0 & 222,0 & 71,0 & 152,0 & 172,0 & 197,0 & 222,0 \\
\hline $29 / 01 / 80$ & 71,0 & 140,0 & 172,0 & 203,0 & 222,0 & 89,0 & 165,0 & 172,0 & 197,0 & 222,0 \\
\hline $31 / 01 / 80$ & 71,0 & 178,0 & 184,0 & 203,0 & 222,0 & 102,0 & 203,0 & 197,0 & 197,0 & 209,0 \\
\hline $01 / 02 / 80$ & 90,0 & 209,0 & 197,0 & 197,0 & 222,0 & 134,0 & 234,0 & 203,0 & 203,0 & 215,0 \\
\hline $02 / 02 / 80$ & 203,0 & 354,0 & 209,0 & 209,0 & 228,0 & 209,0 & 342,0 & 203,0 & 203,0 & 222,0 \\
\hline $03 / 02 / 80$ & 247,0 & 392,0 & 222,0 & 222,0 & 235,0 & 253,0 & 385,0 & 209,0 & 203,0 & 222,0 \\
\hline $04 / 02 / 80$ & 304,0 & 442,0 & 235,0 & 235,0 & 235,0 & 304,0 & 455,0 & 228,0 & 216,0 & 235,0 \\
\hline $05 / 02 / 80$ & 348,0 & 493,0 & 235,0 & 235,0 & 235,0 & 342,0 & 500,0 & 242,0 & 235,0 & 235,0 \\
\hline $06 / 02 / 80$ & 373,0 & 530,0 & 247,0 & 241,0 & 241,0 & 367,0 & 524,0 & 241,0 & 235,0 & 235,0 \\
\hline $07 / 02 / 80$ & 385,0 & 581,0 & 253,0 & 247,0 & 241,0 & 392,0 & 556,0 & 253,0 & 241,0 & 241,0 \\
\hline $08 / 02 / 80$ & 411,0 & 619,0 & 253,0 & 247,0 & 241,0 & 417,0 & 600,0 & 253,0 & 241,0 & 241,0 \\
\hline $09 / 02 / 80$ & 216,0 & 556,0 & 253,0 & 247 & 241,0 & 209,0 & 518,0 & 253,0 & 241,0 & 241,0 \\
\hline $10 / 02 / 80$ & 216,0 & 537,0 & 253,0 & 247,0 & 241,0 & 196,0 & 499,0 & 253,0 & 241,0 & 241,0 \\
\hline $11 / 02 / 80$ & 184,0 & 524,0 & 253,0 & 247,0 & 241,0 & 165,0 & 480,0 & 253,0 & 241,0 & 241,0 \\
\hline $12 / 02 / 80$ & 203,0 & 556,0 & 253,0 & 247,0 & 241,0 & 190,0 & 505,0 & 253,0 & 241,0 & 241,0 \\
\hline $\begin{array}{l}13 / 02 / 80 \\
14 / 02 / 80\end{array}$ & $\begin{array}{l}159,0 \\
140,0\end{array}$ & $\begin{array}{l}512,0 \\
499,0\end{array}$ & $\begin{array}{l}253,0 \\
253,0\end{array}$ & $\begin{array}{l}247,0 \\
247,0\end{array}$ & $\begin{array}{l}241,0 \\
241,0\end{array}$ & $\begin{array}{l}146,0 \\
127,0\end{array}$ & $\begin{array}{l}461,0 \\
461,0\end{array}$ & $\begin{array}{l}253,0 \\
253,0\end{array}$ & $\begin{array}{l}241,0 \\
241,0\end{array}$ & $\begin{array}{l}241,0 \\
241,0\end{array}$ \\
\hline $15 / 02 / 80$ & 128,0 & 462,0 & 253,0 & 247,0 & 241,0 & 121,0 & 449,0 & 260,0 & 247,0 & 247,0 \\
\hline $16 / 02 / 80$ & 102,0 & 404,0 & 253,0 & 247,0 & 235,0 & 102,0 & 298,0 & 260,0 & 247,0 & 247,0 \\
\hline $19 / 02 / 80$ & 46,0 & 196,0 & 247,0 & 247,0 & 241,0 & 52,0 & 184,0 & 247,0 & 247,0 & 241,0 \\
\hline $20 / 02 / 80$ & 64,0 & 153,0 & 241,0 & 241,0 & 241,0 & 71,0 & 184,0 & 241,0 & 241,0 & 235,0 \\
\hline $21 / 02 / 80$ & 77,0 & 184,0 & 241,0 & 241,0 & 241,0 & 83,0 & 184,0 & 241,0 & 241,0 & 235,0 \\
\hline $23 / 02 / 80$ & 83,0 & 184,0 & 235,0 & 235,0 & 235,0 & 77,0 & 172,0 & 235,0 & 235,0 & 235,0 \\
\hline $24 / 02 / 80$ & 58,0 & 184,0 & 235,0 & 235,0 & 235,0 & 71,0 & 178,0 & 235,0 & 241,0 & 235,0 \\
\hline $27 / 02 / 80$ & 46,0 & 184,0 & 235,0 & 235,0 & 235,0 & 46,0 & 172,0 & 235,0 & 235,0 & 235,0 \\
\hline $28 / 02 / 80$ & 40,0 & 178,0 & 228,0 & 228,0 & 235,0 & 40,0 & 172,0 & 235,0 & 235,0 & 235,0 \\
\hline
\end{tabular}


APENDICE 5 - Valores de umidade do solo $\left(\theta \mathrm{cm}^{3} . \mathrm{cm}^{-3}\right)$, obtidos através das curvas de retenção de água.

\begin{tabular}{|c|c|c|c|c|c|c|c|c|c|c|}
\hline \multirow{2}{*}{ Data } & \multicolumn{5}{|c|}{$\mathrm{T}_{1}$} & \multicolumn{5}{|c|}{$\mathrm{T}_{5}$} \\
\hline & $0-15$ & $15-30$ & $30-60$ & $60-90$ & $90-120$ & $0-15$ & $15-30$ & $30-60$ & $60-90$ & $90-120$ \\
\hline $03 / 11 / 79$ & 0,33 & 0,27 & 0,29 & 0,26 & 0,26 & 0,28 & 0,26 & 0,26 & 0,25 & 0,28 \\
\hline $04 / 11 / 79$ & 0,31 & 0,27 & 0,29 & 0,26 & 0,26 & 0,26 & 0,26 & 0,26 & 0,25 & 0,28 \\
\hline $0.5 / 11 / 79$ & 0,29 & 0,27 & 0,28 & 0,26 & 0,26 & 0,24 & 0,25 & 0,26 & 0,25 & 0,28 \\
\hline $06 / 11 / 79$ & 0,29 & 0,26 & 0,28 & 0,25 & 0,26 & 0,23 & 0,25 & 0,24 & 0,25 & 0,28 \\
\hline $07 / 11 / 79$ & 0,39 & 0,28 & 0,28 & 0,25 & 0,26 & 0,37 & 0,26 & 0,25 & 0,25 & 0,27 \\
\hline $08 / 11 / 79$ & 0,41 & 0,35 & 0,29 & 0,26 & 0,26 & 0,38 & 0,28 & 0,26 & $0 ; 25$ & 0,27 \\
\hline $11 / 11 / 79$ & 0,39 & 0,38 & 0,30 & 0,26 & 0,27 & 0,36 & 0,33 & 0,27 & 0,25 & 0,28 \\
\hline $12 / 11 / 79$ & 0,33 & 0,36 & 0,30 & 0,26 & 0,27 & 0,27 & 0,25 & 0,27 & 0,26 & 0,28 \\
\hline $13 / 11 / 79$ & 0,29 & 0,26 & 0,29 & 0,26 & 0,27 & 0,24 & 0,25 & 0,26 & 0,25 & 0,28 \\
\hline $14 / 11 / 79$ & 0,29 & 0,26 & 0,28 & 0,25 & 0,26 & 0,23 & 0,24 & 0,24 & 0,25 & 0,28 \\
\hline $15 / 11 / 79$ & 0,29 & 0,26 & 0,28 & 0,25 & 0,26 & 0,23 & 0,25 & 0,24 & 0,25 & 0,28 \\
\hline $16 / 11 / 79$ & 0,29 & 0,26 & 0,28 & 0,25 & 0,26 & 0,22 & 0,24 & 0,24 & 0,25 & 0,28 \\
\hline $17 / 11 / 79$ & 0,28 & 0,26 & 0,28 & 0,25 & 0,26 & 0,22 & 0,24 & 0,24 & 0,25 & 0,28 \\
\hline $18 / 11 / 79$ & 0,28 & 0,26 & 0,27 & 0,25 & 0,26 & 0,21 & 0,24 & 0,24 & 0,25 & 0,28 \\
\hline $19 / 11 / 79$ & 0,28 & 0,26 & 0,27 & 0,25 & 0,26 & 0,21 & 0,23 & 0,23 & 0,25 & 0,27 \\
\hline $20 / 11 / 79$ & 0,28 & 0,25 & 0,27 & 0,25 & 0,26 & 0,21 & 0,23 & 0,23 & 0,25 & 0,26 \\
\hline $21 / 11 / 79$ & 0,28 & 0,25 & 0,27 & 0,25 & 0,26 & 0,21 & 0,23 & 0,23 & 0,24 & 0,26 \\
\hline $22 / 11 / 79$ & 0,28 & 0,25 & 0,26 & 0,25 & 0,26 & 0,21 & 0,23 & 0,23 & 0,24 & 0,26 \\
\hline $23 / 11 / 79$ & 0,28 & 0,25 & 0,26 & 0,25 & 0,26 & 0,21 & 0,23 & 0,23 & 0,24 & 0,26 \\
\hline $24 / 11 / 79$ & 0,28 & 0,25 & 0,26 & 0,25 & 0,27 & 0,21 & 0,23 & 0,23 & 0,24 & 0,25 \\
\hline $25 / 11 / 79$ & 0,33 & 0,26 & 0,27 & 0,25 & 0,26 & 0,28 & 0,24 & 0,23 & 0,24 & 0,25 \\
\hline $26 / 11 / 79$ & 0,39 & 0,29 & 0,28 & 0,25 & 0,26 & 0,38 & 0,26 & 0,26 & 0,25 & 0,26 \\
\hline $27 / 11 / 79$ & 0,31 & 0,27 & 0,28 & 0,25 & 0,26 & 0,25 & 0,25 & 0,26 & 0,25 & 0,26 \\
\hline $28 / 11 / 79$ & 0,29 & 0,26 & 0,28 & 0,25 & 0,26 & 0,24 & 0,25 & 0,25 & 0,25 & 0,26 \\
\hline $29 / 11 / 79$ & 0,29 & 0,26 & 0,28 & 0,25 & 0,26 & 0,23 & 0,24 & 0,24 & 0,25 & 0,26 \\
\hline $30 / 11 / 79$ & 0,29 & 0,26 & 0,28 & 0,25 & 0,26 & 0,23 & 0,24 & 0,24 & 0,25 & 0,26 \\
\hline $01 / 12 / 79$ & 0,29 & 0,26 & 0,28 & 0,25 & 0,26 & 0,22 & 0,24 & 0,24 & 0,25 & 0,27 \\
\hline $02 / 12 / 79$ & 0,29 & 0,26 & 0,28 & 0,25 & 0,26 & 0,24 & 0,24 & 0,24 & 0,25 & 0,27 \\
\hline $03 / 12 / 79$ & 0,29 & 0,26 & 0,28 & 0,25 & 0,26 & 0,23 & 0,24 & 0,24 & 0,25 & 0,27 \\
\hline $04 / 12 / 79$ & 0,39 & 0,26 & 0,28 & 0,25 & 0,26 & 0,34 & 0,25 & 0,23 & 0,25 & 0,27 \\
\hline $05 / 12 / 79$ & 0,39 & 0,27 & 0,28 & 0,25 & 0,26 & 0,36 & 0,25 & 0,24 & 0,25 & 0,27 \\
\hline $06 / 12 / 79$ & 0,29 & 0,27 & 0,28 & 0,25 & 0,26 & 0,25 & 0,25 & 0,24 & 0,25 & 0,27 \\
\hline $07 / 12 / 79$ & 0,29 & 0,26 & 0,28 & 0,25 & 0,26 & 0,24 & 0,25 & 0,24 & 0,25 & 0,27 \\
\hline $08 / 12 / 79$ & 0,29 & 0,26 & 0,28 & 0,25 & 0,26 & 0,23 & 0,24 & 0,24 & 0,25 & 0,27 \\
\hline $09 / 12 / 79$ & 0,29 & 0,26 & 0,28 & 0,25 & 0,26 & 0,23 & 0,24 & 0,24 & 0,25 & 0,27 \\
\hline $10 / 12 / 79$ & 0,28 & 0,26 & 0,28 & 0,25 & 0,26 & 0,22 & 0,24 & 0,24 & 0,25 & 0,27 \\
\hline $11 / 12 / 79$ & 0,31 & 0,26 & 0,28 & 0,25 & 0,26 & 0,28 & 0,24 & 0,24 & 0,25 & 0,27 \\
\hline $12 / 12 / 79$ & 0,34 & 0,27 & 0,28 & 0,25 & 0,26 & 0,32 & 0,25 & 0,24 & 0,25 & 0,27 \\
\hline $13 / 12 / 79$ & 0,37 & 0,30 & 0,28 & 0,25 & 0,26 & 0,38 & 0,28 & 0,25 & 0,25 & 0,27 \\
\hline $17 / 12 / 79$ & 0,41 & 0,36 & 0,30 & 0,26 & 0,26 & 0,39 & 0,33 & 0,27 & 0,25 & 0,28 \\
\hline $18 / 12 / 79$ & 0,34 & 0,35 & 0,30 & 0,26 & 0,26 & 0,31 & 0,30 & 0,27 & 0,25 & 0,28 \\
\hline $20 / 12 / 79$ & 0,37 & 0,35 & 0,30 & 0,26 & 0,26 & 0,35 & 0,30 & 0,27 & 0,25 & 0,28 \\
\hline $23 / 12 / 79$ & 0,41 & 0,36 & 0,30 & 0,26 & 0,27 & 0,39 & 0,33 & 0,27 & 0,25 & 0,29 \\
\hline $27 / 12 / 79$ & 0,41 & 0,36 & 0,31 & 0,26 & 0,27 & 0,39 & 0,33 & 0,27 & 0,25 & 0,29 \\
\hline $30 / 12 / 79$ & 0,35 & 0,36 & 0,31 & 0,26 & 0,27 & 0,38 & 0,33 & 0,27 & 0,25 & 0,29 \\
\hline
\end{tabular}


APENDICE 5 - Continuação.

\begin{tabular}{|c|c|c|c|c|c|c|c|c|c|c|}
\hline \multirow{2}{*}{ Data } & \multicolumn{5}{|c|}{$\mathrm{T}_{1}$} & \multicolumn{5}{|c|}{$\mathrm{T}_{5}$} \\
\hline & $0-15$ & $15-30$ & $30-60$ & $60-90$ & $90-120$ & $0-15$ & $15-30$ & $30-60$ & $60-90$ & $90-120$ \\
\hline $03 / 01 / 80$ & 0,33 & 0,30 & 0,30 & 0,26 & 0,27 & 0,28 & 0,27 & 0,27 & 0,25 & 0,29 \\
\hline $04 / 01 / 80$ & 0,33 & 0,30 & 0,30 & 0,26 & 0,27 & 0,25 & 0,26 & 0,27 & 0,25 & 0,29 \\
\hline $05 / 01 / 80$ & 0,32 & 0,30 & 0,30 & 0,26 & 0,27 & 0,24 & 0,26 & 0,26 & 0,25 & 0,29 \\
\hline $06 / 01 / 80$ & 0,30 & 0,28 & 0.29 & 0,26 & 0,27 & 0,23 & 0,28 & 0,26 & 0,25 & 0,29 \\
\hline $07 / 01 / 80$ & 0,29 & $0,2 \%$ & 0,29 & 0,26 & 0,27 & 0,23 & 0,25 & 0,25 & 0,25 & 0,29 \\
\hline $09 / 01 / 80$ & 0,37 & 0,27 & 0,28 & 0,26 & 0,27 & 0,35 & 0,26 & 0,25 & 0,25 & 0,29 \\
\hline $10 / 01 / 80$ & 0,35 & 0,29 & 0,28 & 0,26 & 0,27 & 0,35 & 0,25 & 0,25 & 0,25 & 0,29 \\
\hline $11 / 01 / 80$ & 0,31 & 0,28 & 0,28 & 0,26 & 0,27 & 0,26 & 0,26 & 0,25 & 0,25 . & 0,29 \\
\hline $12 / 01 / 80$ & 0,31 & 0,27 & 0,28 & 0,26 & 0,27 & 0,25 & 0,26 & 0,25 & 0,25 & 0,29 \\
\hline $13 / 01 / 80$ & 0,30 & 0,27 & 0,28 & 0,26 & 0,27 & 0,25 & 0,25 & 0,25 & 0,25 & 0,29 \\
\hline $14 / 01 / 80$ & 0,29 & 0,27 & 0,28 & 0,26 & 0,27 & 0,24 & 0,25 & 0,25 & 0,25 & 0,29 \\
\hline $15 / 01 / 80$ & 0,29 & 0,27 & 0,28 & 0,26 & 0,27 & 0,24 & 0,25 & 0,25 & 0,25 & 0,29 \\
\hline $16 / 01 / 80$ & 0,29 & 0,26 & 0,28 & 0,26 & 0,27 & 0,24 & 0,25 & 0,25 & 0,25 & 0,29 \\
\hline $18 / 01 / 80$ & 0,41 & 0,33 & 0,28 & 0,26 & 0,27 & 0,38 & 0,28 & 0,25 & 0,25 & 0,29 \\
\hline $20 / 01 / 80$ & 0,41 & 0,38 & 0,29 & 0,26 & 0,27 & 0,39 & 0,33 & 0,27 & 0,27 & 0,29 \\
\hline $21 / 01 / 80$ & 0,37 & 0,32 & 0,29 & 0,26 & 0,27 & 0,38 & 0,27 & 0,26 & 0,25 & 0,29 \\
\hline $23 / 01 / 80$ & 0,37 & 0,30 & 0,29 & 0,26 & 0,27 & 0,38 . & 0,27 & 0,26 & 0,25 & 0,29 \\
\hline $27 / 01 / 80$ & 0,37 & 0,30 & 0,29 & 0,26 & 0,27 & 0,38 & 0,27 & 0,26 & 0,25 & 0,29 \\
\hline $28 / 01 / 80$ & 0,37 & 0,28 & 0,29 & 0,26 & 0,27 & 0,37 & 0,26 & 0,26 & 0,25 & 0,29 \\
\hline $29 / 01 / 80$ & 0,35 & 0,28 & 0,29 & 0,26 & 0,27 & 0,32 & 0,26 & 0,26 & 0,25 & 0,29 \\
\hline $31 / 01 / 80$ & 0,35 & 0,27 & 0,29 & 0,26 & 0,27 & 0,30 & 0,25 & 0,25 & 0,25 & 0,30 \\
\hline $01 / 02 / 80$ & 0,34 & 0,27 & 0,28 & 0,26 & 0,27 & 0,28 & 0,25 & 0,25 & 0,25 & 0,29 \\
\hline $02 / 02 / 80$ & 0,30 & 0,26 & 0,28 & 0,26 & 0,27 & 0,25 & 0,25 & 0,25 & 0,25 & 0,29 \\
\hline $03 / 02 / 80$ & 0,30 & 0,26 & 0,28 & 0,26 & 0,26 & 0,24 & 0,25 & 0,25 & 0,25 & 0,29 \\
\hline $04 / 02 / 80$ & 0,29 & 0,26 & 0,28 & 0,25 & 0,26 & 0,24 & 0,24 & 0,25 & 0,25 & 0,28 \\
\hline $05 / 02 / 80$ & 0,29 & 0,26 & 0,28 & 0,25 & 0,26 & 0,24 & 0,24 & 0,25 & 0,25 & 0,28 \\
\hline $06 / 02 / 80$ & 0,29 & $.0,26$ & 0,28 & 0,25 & 0,26 & 0,24 & 0,24 & 0,25 & 0,25 & 0,28 \\
\hline $07 / 02 / 80$ & 0,29 & 0,26 & 0,28 & 0,25 & 0,26 & 0,23 & 0,24 & 0,25 & 0,25 & 0,28 \\
\hline $08 / 02 / 80$ & 0,29 & 0,26 & 0,28 & 0,25 & 0,26 & 0,23 & 0,24 & 0,25 & 0,25 & 0,28 \\
\hline $09 / 02 / 80$ & 0,30 & 0,26 & 0,28 & 0,25 & 0,26 & 0,25 & 0,24 & 0,25 & 0,25 & 0,28 \\
\hline $10 / 02 / 80$ & 0,30 & 0,26 & 0,28 & 0,25 & 0,26 & 0,25 & 0,24 & 0,25 & 0,25 & 0,28 \\
\hline $11 / 02 / 80$ & 0,31 & 0,26 & 0,28 & 0,25 & 0,26 & 0,26 & 0,24 & 0,25 & 0,25 & 0,28 \\
\hline $12 / 02 / 80$ & 0,30 & 0,26 & 0,28 & 0,25 & 0,26 & 0,25 & 0,24 & 0,25 & 0,25 & 0,28 \\
\hline $13 / 02 / 80$ & 0,32 & 0,26 & 0,28 & 0,25 & 0,26 & 0,27 & 0,24 & 0,25 & 0,25 & 0,28 \\
\hline $14 / 02 \% 80$ & 0,32 & 0,26 & 0,28 & 0,25 & 0,26 & 0,29 & 0,24 & 0,25 & 0,25 & 0,28 \\
\hline $15 / 02 / 80$ & 0,32 & 0,26 & 0,28 & 0,25 & 0,26 & 0,29 & 0,24 & 0,25 & 0,25 & 0,28 \\
\hline $16 / 02 / 80$ & 0,33 & 0,26 & 0,28 & 0,25 & 0,26 & 0,30 & 0,25 & 0,25 & 0,25 & 0,28 \\
\hline $19 / 02 / 80$ & 0,37 & 0,27 & 0,28 & 0,25 & 0,26 & 0,36 & 0,26 & 0,25 & 0,25 & 0,28 \\
\hline $20 / 02 / 80$ & 0,35 & 0,27 & 0,28 & 0,25 & 0,26 & 0,33 & 0,26 & 0,25 & 0,25 & 0,28 \\
\hline $21 / 02 / 80$ & 0,34 & 0,27 & 0,28 & 0,25 & 0,26 & 0,31 & 0,26 & 0,25 & 0,25 & 0,28 \\
\hline $22 / 02 / 80$ & 0,34 & 0,27 & 0,28 & 0,25 & 0,26 & 0,31 & 0,26 & 0,25 & 0,25 & 0,28 \\
\hline $23 / 02 / 80$ & 0,34 & 0,27 & 0,28 & 0,25 & 0,26 & 0,31 & 0,26 & 0,25 & 0,25 & 0,28 \\
\hline $24 / 02 / 80$ & 0,35 & 0,27 & 0,28 & 0,25 & 0,26 & 0,33 & 0,26 & 0,25 & 0,25 & 0,28 \\
\hline $27 / 02 / 80$ & 0,37 & 0,27 & 0,28 & 0,25 & 0,26 & 0,36 & 0,26 & 0,25 & 0,25 & 0,28 \\
\hline $28 / 02 / 80$ & 0,39 & 0,27 & 0,28 & 0,26 & 0,26 & 0,37 & 0,26 & 0,25 & 0,25 & 0,28 \\
\hline
\end{tabular}


APENDICE 6 - Armazenamento de água no solo em milímetros.

\begin{tabular}{|c|c|c|c|c|c|c|c|c|c|c|c|c|}
\hline \multirow{2}{*}{ Data } & \multicolumn{6}{|c|}{$\mathrm{T}_{1}$} & \multicolumn{6}{|c|}{$\mathrm{T}_{5}$} \\
\hline & $0-15$ & $15-30$ & $30-60$ & $60-90$ & $90-120$ & $0-120$ & $0-15$ & $15-30$ & $30-60$ & $60-90$ & $90-120$ & $0-120$ \\
\hline $03 / 11 / 79$ & 49,5 & 40,5 & 87,0 & 78,0 & 78,0 & 333,0 & 42,0 & 39,0 & 78,0 & $75, \bullet$ & 84,0 & 318,0 \\
\hline $04 / 11 / 79$ & 46,5 & 40,5 & 87,0 & 78,0 & 78,0 & 330,0 & 39,0 & 39,0 & 78,0 & 75,0 & 84,0 & 315,0 \\
\hline $05 / 11 / 79$ & 43,5 & 40,5 & 84,0 & 78,0 & 78,0 & 324,0 & 36,0 & 37,5 & 75,0 & 75,0 & 84,0 & 307,5 \\
\hline $06 / 11 / 79$ & 43,5 & 39,0 & 84,0 & 75,0 & 78,0 & 319,5 & 34,5 & 37,5 & 72,0 & 75,0 & 84,0 & 303,0 \\
\hline $07 / 11 / 79$ & 58,5 & 42,0 & 84,0 & 75,0 & 78,0 & 337,5 & 55,5 & 39,0 & 75,0 & 75,0 & 81,0 & 325,5 \\
\hline $08 / 11 / 79$ & 61,5 & 52,5 & 87,0 & 78,0 & 78,0 & 357,0 & 57,0 & 42,0 & 78,0 & 75,0 & 81,0 & 333,0 \\
\hline $11 / 11 / 79$ & 58,5 & 57,0 & 90,0 & $78, \bullet$ & 81,0 & 364,5 & 54,0 & 49,5 & 81,0 & 75,0 & 84,0 & 343,5 \\
\hline $12 / 11 / 79$ & 49,5 & 54,0 & 90,0 & 78,0 & 81,0 & 352,5 & 40,5 & 37,5 & 81,0 & 78,0 & 84,0 & 321,0 \\
\hline $13 / 11 / 79$ & 43,5 & 39,0 & 87,0 & 78,0 & 81,0 & 328,5 & 36,0 & 37,5 & 78,0 & 75,0 & 84,0 & 310,5 \\
\hline $14 / 11 / 79$ & 43,5 & 39,0 & 84,0 & 75,0 & 78,0 & 319,5 & 34,5 & 36,0 & $7 i, 0$ & 75,0 & 84,0 & 301,5 \\
\hline $15 / 11 / 79$ & 43,5 & 39,0 & 84,0 & 75,0 & 78,0 & 319,5 & 34,5 & 37,5 & $7=, 0$ & 75,0 & 84,0 & 303,0 \\
\hline $16 / 11 / 79$ & 43,5 & 39,0 & 84,0 & 75,0 & 78,0 & 319,5 & 33,0 & 36,0 & 72,0 & 75,0 & 84,0 & 300,0 \\
\hline $17 / 11 / 79$ & 42,0 & 39,0 & 84,0 & 75,0 & 78,0 & 318,0 & 33,0 & 36,0 & 72,0 & 75,0 & 84,0 & 300,0 \\
\hline $18 / 11 / 79$ & 42,0 & 39,0 & 81,0 & 75,0 & 78,0 & 315,0 & 31,5 & 36,0 & 72,0 & 75,0 & 84,0 & 298,5 \\
\hline $19 / 11 / 79$ & 42,0 & 39,0 & 81,0 & 75,0 & 78,0 & 315,0 & 31,5 & 34,5 & 69,0 & 75,0 & 81,0 & 291,0 \\
\hline $20 / 11 / 79$ & 42,0 & 37,5 & 81,0 & 75,0 & 78,0 & 313,5 & 31,5 & 34,5 & 69,0 & 75,0 & 78,0 & 288,0 \\
\hline $21 / 11 / 79$ & 42,0 & 37,5 & 81,0 & 75,0 & 78,0 & 313,5 & 31,5 & 34,5 & 69,0 & 72,0 & 78,0 & 285,0 \\
\hline $22 / 11 / 79$ & 42,0 & 37,5 & 78,0 & 75,0 & 78,0 & 310,5 & 31,5 & 34,5 & 69,0 & 72,0 & 78,0 & 285,0 \\
\hline $23 / 11 / 79$ & 42,0 & 37,5 & 78,0 & 75,0 & 78,0 & 310,5 & 31,5 & 34,5 & 69,0 & 72,0 & 78,0 & 285,0 \\
\hline $24 / 11 / 79$ & 42,0 & 37,5 & 78,0 & 75,0 & 78,0 & 310,5 & 31,5 & 34,5 & 69,0 & 72,0 & 75,0 & $28 \geq, 0$ \\
\hline $25 / 11 / 79$ & 42,0 & 36,0 & 69,0 & 72,0 & 75,0 & 294,0 & 49,5 & 39,0 & 81,0 & 75,0 & 78,0 & 322,5 \\
\hline $26 / 11 / 79$ & 57,0 & 39,0 & 78,0 & 75,0 & 78,0 & 327,0 & 58,5 & 43,5 & 84,0 & 75,0 & 78,0 & 339,0 \\
\hline $27 / 11 / 79$ & 37,5 & 37,5 & 78,0 & 75,0 & 78,0 & 306,0 & 46,5 & 40,5 & 34,0 & 75,0 & 78,0 & 324,0 \\
\hline $28 / 11 / 79$ & 36,0 & 37,5 & 75,0 & 75,0 & 78,0 & 301,5 & 43,5 & 39,0 & 84,0 & 75,0 & 78,0 & 319,5 \\
\hline $29 / 11 / 79$ & 34,5 & 36,0 & 72,0 & 75,0 & 78,0 & 295,5 & 43,5 & 39,0 & 84,0 & 75,0 & 78,0 & 319,5 \\
\hline $30(11 / 79$ & 34,5 & 36,0 & 72,0 & 75,0 & 78,0 & 295,5 & 43,5 & 39,0 & 84,0 & 75,0 & 78,0 & 319,5 \\
\hline $01 / 12 / 79$ & 33,0 & 36,0 & 72,0 & 75,0 & 81,0 & 297,0 & 43,5 & 39,0 & 84,0 & 75,0 & 78,0 & 319,5 \\
\hline $02 / 12 / 79$ & 36,0 & 36,0 & 72,0 & 75,0 & 81,0 & 300,0 & 43,5 & 39,0 & 84,0 & 75,0 & 78,0 & 319,5 \\
\hline $03 / 12 / 79$ & 34,5 & 36,0 & 72,0 & 75,0 & 81,0 & 298,5 & 43,5 & 39,0 & 84,0 & 75,0 & 78,0 & 319,5 \\
\hline $04 / 12 / 79$ & 51,0 & 37,5 & 69,0 & 75,0 & 81,0 & 313,5 & 58,5 & 39,0 & 84,0 & 75,0 & 78,0 & 334,5 \\
\hline $05 / 12 / 79$ & 54,0 & 37,5 & 72,0 & 75,0 & 81,0 & 319,5 & 58,5 & 40,5 & 84,0 & 75,0 & 78,0 & 336,0 \\
\hline $06 / 12 / 79$ & 43,5 & 40,5 & 84,0 & 750 & 780 & 321,0 & 37,5 & 37,5 & 72,0 & 75,0 & 81,0 & 303,0 \\
\hline $07 / 12 / 79$ & 43,5 & 39,0 & 84,0 & 75,0 & 78,0 & 319,5 & 36,0 & 37,5 & 72,0 & 75,0 & 81,0 & 301,5 \\
\hline $08 / 12 / 79$ & 43,5 & 39,0 & 84,0 & 75,0 & 78,0 & 319,5 & 34,5 & 36,0 & 72,0 & 75,0 & 81,0 & 298,5 \\
\hline $09 / 12 / 79$ & 43,5 & 39,0 & 84,0 & 75,0 & 78,0 & 319,5 & 34,5 & 36,0 & $i 2,0$ & 75,0 & 81,0 & 298,5 \\
\hline $10 / 12 / 79$ & 43,5 & 39,0 & 84,0 & 75,0 & 78,0 & 319,5 & 33,0 & 36,0 & 72,0 & 75,0 & 81,0 & 297,0 \\
\hline $11 / 12 / 79$ & 46,5 & 39,0 & 84,0 & 75,0 & 78,0 & 322,5 & 42,0 & 36,0 & 72,0 & 75,0 & 81,0 & 306,0 \\
\hline $12 / 12 / 79$ & 51,0 & 40,5 & 84,0 & 75,0 & 78,0 & 328,5 & 48,0 & 37,5 & 72,0 & 75,0 & 81,0 & 313,5 \\
\hline $13 / 12 / 79$ & 55,5 & 45,0 & 84,0 & 75,0 & 78,0 & 337,5 & 57,0 & 42,0 & 75,0 & 75,0 & 81,0 & 330,0 \\
\hline $17 / 12 / 79$ & 61,5 & 54,0 & 90,0 & 78,0 & 78,0 & 361,5 & 58,5 & 49,5 & 81,0 & 75,0 & 84,0 & 348,0 \\
\hline $18 / 12 / 79$ & 51,0 & 37,5 & 90,0 & 78,0 & 78,0 & 334,5 & 46,5 & 45,0 & 81,0 & 75,0 & 84,0 & 331,5 \\
\hline $20 / 12 / 79$ & 55,5 & 52,5 & 90,0 & 78,0 & 78,0 & 354,0 & 52,5 & 45,0 & 81,0 & 75,0 & 84,0 & 337,5 \\
\hline $23 / 12 / 79$ & 61,5 & 54,0 & 90,0 & 78,0 & 81,0 & 364,5 & 58,5 & 49,5 & 81,0 & 75,0 & 87,0 & 351,0 \\
\hline $27 / 12 / 79$ & 61,5 & 54,0 & 93,0 & 78,0 & 81,0 & 367,5 & 58,5 & 49,5 & 81,0 & 75,0 & 87,0 & 351,0 \\
\hline $30 / 12 / 79$ & 52,5 & 54,0 & 93,0 & 78,0 & 81,0 & 358,5 & 57,0 & 49,5 & 81,0 & 75,0 & 87,0 & 349,5 \\
\hline
\end{tabular}


APENDICE 6 - Continuação.

\begin{tabular}{|c|c|c|c|c|c|c|c|c|c|c|c|c|}
\hline \multirow{2}{*}{ Data } & \multicolumn{6}{|c|}{$T_{1}$} & \multicolumn{6}{|c|}{$T_{5}$} \\
\hline & $0-15$ & $15-30$ & $30-60$ & $60-90$ & $90-120$ & $0-120$ & $0-15$ & $15-30$ & $30-60$ & $60-90$ & $90-120$ & $0-120$ \\
\hline $03 / 01 / 80$ & 49,5 & 45,0 & 90,0 & 78,0 & 81,0 & 343,5 & 42,0 & 40,5 & 81,0 & 75,0 & 87,0 & 325,5 \\
\hline $04 / 01 / 80$ & 48,0 & 45,0 & 90,0 & 78,0 & 81,0 & 342,0 & 37,5 & 39,0 & 81,0 & 75,0 & 87,0 & 319,5 \\
\hline $05 / 01 / 80$ & 45,0 & 42,0 & 87,0 & 78,0 & 81,0 & 333,0 & 36,0 & 39,0 & 78,0 & 75,0 & 87,0 & 315,0 \\
\hline $06 / 01 / 80$ & 43,5 & 40,5 & 87,0 & 78,0 & 81,0 & 330,0 & 34,5 & 42,0 & 78,0 & 75,0 & 87,0 & 316,5 \\
\hline $07 / 01 / 80$ & 43,5 & 40,5 & 87,0 & 78,0 & 81,0 & 330,0 & 34,5 & 37,5 & 75,0 & 75,0 & 87,0 & 309,0 \\
\hline $09 / 01 / 80$ & 55,5 & 40,5 & 84,0 & 78,0 & 81,0 & 339,0 & 52,5 & 39,0 & 75,0 & 75,0 & 87,0 & 328,5 \\
\hline $10 / 01 / 80$ & 52,5 & 43,5 & 84,0 & 78,0 & 81,0 & 339,0 & 52,5 & 37,5 & 75,9 & 75,0 & 87,0 & 327,0 \\
\hline $11 / 01 / 80$ & 46,5 & 42,0 & 84,0 & 78,0 & 81,0 & 331,5 & 39,0 & 39,0 & 75,0 & 75,0 & 87,0 & 315,0 \\
\hline $12 / 01 / 80$ & 46,5 & 40,5 & 84,0 & 78,0 & 81,0 & 330,0 & 37,5 & 39,0 & 75,0 & 75,0 & 87,0 & 313,5 \\
\hline $13 / 01 / 80$ & 45,0 & 40,5 & 84,0 & 78,0 & 81,0 & 328,5 & 37,5 & 37,5 & 75,0 & 75,0 & 87,0 & 312,0 \\
\hline $14 / 01 / 80$ & 43,5 & 40,5 & 84,0 & 78,0 & 81,0 & 327,0 & 36,0 & 37,5 & 75,0 & 75,0 & 87,0 & 310,5 \\
\hline $15 / 01 / 80$ & 43,5 & 40,5 & 84,0 & 78,0 & 81,0 & 327,0 & 36,0 & 37,5 & 75,0 & 75,0 & 87,0 & 310,5 \\
\hline $16 / 01 / 80$ & 43,5 & 39,0 & 84,0 & 78,0 & 81,0 & 325,5 & 36,0 & 37,5 & 75,0 & 75,0 & 87,0 & 310,5 \\
\hline $18 / 01 / 80$ & 61,5 & 49,5 & 84,0 & 78,0 & 81,0 & 354,0 & 57,0 & 42,0 & 75,0 & 75,0 & 87,0 & 336,0 \\
\hline $20 / 01 / 80$ & 61,5 & 57,0 & 87,0 & 78,0 & 81,0 & 364,5 & 58,5 & 49,5 & 81,0 & 75,0 & 87,0 & 351,0 \\
\hline $21 / 01 / 80$ & 55,5 & 48,0 & 87,0 & 78,0 & 81,0 & 349,5 & 57,0 & 40,5 & 78,0 & 75,0 & 87,0 & 337,5 \\
\hline $23 / 01 / 80$ & 55,5 & 45,0 & 87,0 & 78,0 & 81,0 & 346,5 & 57,0 & 40,5 & 78,0 & 75,0 & 87,0 & 337,5 \\
\hline $27 / 01 / 80$ & 55,5 & 45,0 & 87,0 & 78,0 & 81,0 & 346,5 & 57,0 & 40,5 & 78,0 & 75,0 & 87,0 & 337,5 \\
\hline $28 / 01 / 80$ & 55,5 & 42,0 & 87,0 & 78,0 & 81,0 & 343,5 & 55,5 & 39,0 & 78,0 & 75,0 & 87,0 & 337,5 \\
\hline $29 / 01 / 80$ & 52,5 & 42,0 & 37,0 & 78,0 & 81,0 & 340,5 & 48,0 & 39,0 & 78,0 & 75,0 & 87,0 & 327,0 \\
\hline $31 / 01 / 80$ & 52,5 & 40,5 & 87,0 & 78,0 & 81,0 & 339,0 & 45,0 & 37,5 & 75,0 & 75,0 & 90,0 & 322,5 \\
\hline $01 / 02 / 80$ & 51,0 & 40,5 & 84,0 & 78,0 & 81,0 & 334,5 & 42,0 & 37,5 & 75,0 & 75,0 & 87,0 & 316,5 \\
\hline $02 / 02 / 80$ & 45,0 & 39,0 & 84,0 & 78,0 & 81,0 & 327,0 & 37,5 & 37,5 & 75,0 & 75,0 & 87,0 & 312,0 \\
\hline $03 / 02 / 80$ & 45,0 & 39,0 & 84,0 & 78,0 & 78,0 & 324,0 & 36,0 & 37,5 & 75,0 & 75,0 & 87,0 & 310,5 \\
\hline $04 / 02 / 80$ & 43,5 & 39,0 & 84,0 & 75,0 & 78,0 & 319,5 & 36,0 & 36,0 & 75,0 & 75,0 & 84,0 & 306,0 \\
\hline $05 / 02 / 80$ & 43,5 & 39,0 & 84,0 & 75,0 & 78,0 & 319,5 & 36,0 & 36,0 & 75,0 & 75,0 & 84,0 & 306,0 \\
\hline $06 / 02 / 80$ & 43,5 & 39,0 & 84,0 & 75,0 & 78,0 & 319,5 & 36,0 & 36,0 & 75,0 & 75,0 & 84,0 & 306,0 \\
\hline $07 / 02 / 80$ & 43,5 & 39,0 & 84,0 & 75,0 & 78,0 & 319,5 & 34,5 & 36,0 & 75,0 & 75,0 & 84,0 & 304,5 \\
\hline $08 / 02 / 80$ & 43,5 & 39,0 & 84,0 & 75,0 & 78,0 & 319,5 & 34,5 & 36,0 & 75,0 & 75,0 & 84,0 & 304,5 \\
\hline $09 / 02 / 80$ & 45,0 & 39,0 & 84,0 & 75,0 & 78,0 & 321,0 & 37,5 & 36,0 & 75,0 & 75,0 & 84,0 & 307,5 \\
\hline $10 / 02 / 80$ & 45,0 & 39,0 & 84,0 & 75,0 & 78,0 & 321,0 & 37,5 & 36,0 & 75,0 & 75,0 & 84,0 & 307,5 \\
\hline $11 / 02 / 80$ & 46,5 & 39,0 & 84,0 & 75,0 & 78,0 & 322,5 & 39,0 & 36,0 & 75,0 & 75,0 & 84,0 & 309,0 \\
\hline $12 / 02 / 80$ & 45,0 & 39,0 & 84,0 & 75,0 & 78,0 & 321,0 & 37,5 & 35,0 & 75,0 & 75,0 & 84,0 & 307,5 \\
\hline $13 / 02 / 80$ & 48,0 & 39,0 & 84,0 & 75,0 & 78,0 & 324,0 & 40,5 & 36,0 & 75,0 & 75,0 & $8 \dot{4}, 0$ & 310,5 \\
\hline $14 / 02 / 80$ & 48,0 & 39,0 & 84,0 & 75,0 & 78,0 & 324,0 & 43,5 & 36,0 & 75,0 & 75,0 & 84,0 & 313,5 \\
\hline $15 / 02 / 80$ & 48,0 & 39,0 & 84,0 & 75,0 & 78,0 & 324,0 & 43,5 & 36,0 & 75,0 & 75,0 & 84,0 & 313,5 \\
\hline $16 / 02 / 80$ & 49,5 & 39,0 & 84,0 & 75,0 & 78,0 & 325,5 & 45,0 & 37,5 & 75,0 & 75,0 & 84,0 & 316,5 \\
\hline $19 / 02 / 80$ & 55,5 & 40,5 & 84,0 & 75,0 & 78,0 & 333,0 & 54,0 & 39,0 & 75,0 & 75,0 & 84,0 & 327,0 \\
\hline $20 / 02 / 80$ & 52,5 & 40,5 & 84,0 & 75,0 & 78,0 & 330,0 & 49,5 & 39,0 & 75,0 & 75,0 & 84,0 & 322,5 \\
\hline $21 / 02 / 80$ & 51,0 & 40,5 & 84,0 & 75,0 & 78,0 & 328,5 & 46,5 & 39,0 & 75,0 & 75,0 & 84,0 & 319,5 \\
\hline $23 / 02 / 80$ & 51,0 & 40,5 & 84,0 & 75,0 & 78,0 & 328,5 & 46,5 & 39,0 & 75,0 & 75,0 & 84,0 & 319,5 \\
\hline $24 / 02 / 80$ & 52,5 & 40,5 & 84,0 & 75,0 & 78,0 & 330,0 & 49,5 & 39,0 & 75,0 & 75,0 & 84,0 & 322,5 \\
\hline $27 / 02 / 80$ & 55,5 & 40,5 & 84,0 & 75,0 & 78,0 & 333,0 & 54,0 & 39,0 & 75,0 & 75,0 & 84,0 & 327,0 \\
\hline $28 / 02 / 80$ & 58,5 & 40,5 & 84,0 & 78,0 & 78,0 & 339,0 & 55,5 & 39,0 & 75,0 & 75,0 & 84,0 & 328,5 \\
\hline
\end{tabular}


APENDICE 7 - Valores médios do potencial de umidade do solo às profundidades experimentais.

\begin{tabular}{|c|c|c|c|c|c|c|c|c|c|c|}
\hline \multirow{2}{*}{ Data } & \multicolumn{5}{|c|}{$\mathrm{T}_{1}$} & \multicolumn{5}{|c|}{$\mathrm{T}_{5}$} \\
\hline & 15,0 & 30,0 & 60,0 & 90,0 & 120,0 & 15,0 & 30,0 & 60,0 & 90,0 & 120,0 \\
\hline $05 / 11 / 80$ & 537,0 & 461,0 & 294,0 & 254,0 & 247,0 & 543,0 & 455,0 & 304,0 & 266,0 & 247,0 \\
\hline $06 / 11 / 80$ & 568,0 & 493,0 & 316,0 & 260,0 & 247,0 & 575,0 & 474,0 & 310,0 & 266,0 & 254,0 \\
\hline $08 / 11 / 80$ & 46,0 & 102,0 & 260,0 & 241,0 & 235,0 & 40,0 & 96,0 & 254,0 & 235,0 & 230,0 \\
\hline $10 / 11 / 80$ & 26,0 & 58,0 & 241,0 & 235,0 & 222,0 & 33,0 & 64,0 & 235,0 & 235,0 & 222,0 \\
\hline $12 / 11 / 80$ & 46,0 & 71,0 & 228,0 & 228,0 & 222,0 & 46,0 & 64,0 & 215,0 & 235,0 & 222,0 \\
\hline $13 / 11 / 80$ & 108,0 & 71,0 & 228,0 & 228,0 & 222,0 & 71,0 & 64,0 & 215,0 & 235,0 & 228,0 \\
\hline $14 / 11 / 80$ & 171,0 & 108,0 & 228,0 & 228,0 & 222,0 & 190,0 & 127,0 & 222,0 & 235,0 & 228,0 \\
\hline $16 / 11 / 80$ & 348,0 & 285,0 & 228,0 & 228,0 & 222,0 & 341,0 & 278,0 & 228,0 & 235,0 & 228,0 \\
\hline $17 / 11 / 80$ & 429,0 & 379,5 & 247,0 & 235,0 & 222,0 & 436,5 & 367,0 & 241,0 & 235,0 & 228,0 \\
\hline $18 / 11 / 80$ & 512,0 & 430,0 & 260,0 & 241,0 & 228,0 & 543,5 & 455,0 & 260,0 & 235,0 & 228,0 \\
\hline $20 / 11 / 80$ & 71,0 & 146,5 & 260,0 & 241,0 & 228,0 & 83,0 & 159,0 & 260,0 & 235,0 & 228,0 \\
\hline $21 / 11 / 80$ & 45,5 & 58,5 & 235,0 & 235,0 & 228,0 & 45,5 & 71,0 & 235,0 & 235,0 & 228,0 \\
\hline $26 / 11 / 80$ & 197,5 & 140,0 & 235,0 & 235,0 & $\cdot 228,0$ & 203,0 & 140,0 & 235,0 & 235,0 & 235,0 \\
\hline $27 / 11 / 80$ & 316,5 & 216,0 & 235,0 & 235,0 & 228,0 & 323,0 & 215,5 & 235,0 & 235,0 & 235,0 \\
\hline $28 / 11 / 80$ & 424,0 & 297,5 & 241,0 & 235,0 & 235,0 & 411,0 & 304,0 & 241,0 & 235,0 & 235,0 \\
\hline $29 / 11 / 80$ & 480,0 & 385,0 & 260,0 & 235,0 & 235,0 & 480,0 & 392,5 & 266,0 & 241,0 & 235,0 \\
\hline $03 / 12 / 80$ & 46,0 & 71,0 & 184,5 & 228,5 & 228,5 & 33,0 & 58,0 & 209,0 & 235,0 & 235,0 \\
\hline $06 / 12 / 80$ & 39,5 & 52,0 & 197,0 & $228, j$ & 228,5 & 39,5 & 46,0 & 197,0 & 235,0 & 235,0 \\
\hline $07 / 12 / 80$ & 89,5 & 96,0 & 197,0 & $228, j$ & 228,5 & 89,5 & 96,0 & 197,0 & 235,0 & 235,0 \\
\hline $08 / 12 / 80$ & 71,0 & 96,0 & 197,0 & 228,5 & 228,5 & 77,0 & 96,0 & 203,0 & 235,0 & 235,0 \\
\hline $09 / 12 / 80$ & 96,0 & 121,0 & 197,0 & 228,5 & 228,5 & 115,0 & 121,0 & 197,0 & 235,0 & 235,0 \\
\hline $11 / 12 / 80$ & 133,5 & 171,5 & 203,0 & 235,0 & 235,0 & 134,0 & 178,0 & 209,0 & 235,0 & 235,0 \\
\hline $14 / 12 / 80$ & 58,5 & 83,5 & 203,0 & 235,0 & 235,0 & 58,5 & 77,0 & 203,0 & 235,0 & 235,0 \\
\hline $15 / 12 / 80$ & 77,0 & 133,5 & 203,0 & 235,0 & 228,0 & 83,0 & 133,5 & 203,0 & 235,0 & 235,0 \\
\hline $16 / 12 / 80$ & 102,5 & 178,0 & 209,0 & 235,0 & 235,0 & 96,0 & 178,0 & 209,0 & 235,0 & 235,0 \\
\hline $17 / 12 / 80$ & 127,5 & $\cdot 247,5$ & 209,0 & 235,0 & 228,5 & 127,5 & 266,0 & 209,0 & 235,0 & 235,0 \\
\hline $18 / 12 / 80$ & 171,5 & 335,0 & 222,0 & 235,0 & 235,0 & 184,5 & 348,0 & 222,0 & 235,0 & 235,0 \\
\hline $19 / 12 / 80$ & 209,5 & 385,0 & 235,0 & 235,0 & 235,0 & 222,0 & 373,0 & 235,0 & 235,0 & 235,0 \\
\hline $20 / 12 / 80$ & 228,0 & 417,5 & 241,0 & 235,0 & 235,0 & 247,0 & 436,0 & 235,0 & 235,0 & 235,0 \\
\hline $21 / 12 / 80$ & 234,5 & 449,0 & 247,0 & 235,0 & 235,0 & 247,0 & 461,0 & 241,0 & 235,0 & $2.35,0$ \\
\hline $22 / 12 / 80$ & 253,5 & 480,5 & 247,0 & 235,0 & 235,0 & 266,0 & 500,0 & 253,0 & 235,0 & 235,0 \\
\hline $23 / 12 / 80$ & 253,5 & 505,0 & 247,0 & 235,0 & 235,0 & 272,5 & 518,0 & 253,5 & 235,0 & 235,0 \\
\hline $27 / 12 / 80$ & 197,0 & 455,0 & 253,0 & 241,0 & 235,0 & 171,5 & 424,0 & 260,0 & 235,0 & 235,0 \\
\hline $31 / 12 / 80$ & 58,5 & 96,0 & 235,0 & 235,0 & 235,0 & 58,5 & 71,0 & 216,0 & 228,5 & 235,0 \\
\hline
\end{tabular}


APENDICE 7 - Continuação.

\begin{tabular}{|c|c|c|c|c|c|c|c|c|c|c|}
\hline \multirow{2}{*}{ Data } & \multicolumn{5}{|c|}{$\mathrm{T}_{1}$} & \multicolumn{5}{|c|}{$\mathrm{T}_{5}$} \\
\hline & 15,0 & 30,0 & 60,0 & 90,0 & 120,0 & 15,0 & 30,0 & 60,0 & 90,0 & 120,0 \\
\hline 021 & 121,0 & 197,0 & 241,0 & 247,0 & 247,0 & 134,0 & 197,0 & 235,0 & 235,0 & 235,0 \\
\hline $05 / 01 / 81$ & 209,5 & 316,5 & 241,0 & 247,0 & 247,0 & 215,0 & 323,0 & 241,0 & 235,0 & 235,0 \\
\hline $06 / 01 / 81$ & 234,0 & 341,0 & 241,0 & 247,0 & 247,0 & 247,5 & 360,5 & 247,0 & 241,0 & 235,0 \\
\hline $07 / 01 / 81$ & 272,5 & 404,5 & 260,0 & $247 ; 0$ & 247,0 & 278,5 & 398,5 & 260,0 & 241,0 & 241,0 \\
\hline $13 / 01 / 81$ & 33,0 & 46,0 & 165,5 & 197,0 & 222,0 & 33,0 & 39,5 & 159,0 & 197,0 & 222,0 \\
\hline $16 / 01 / 81$ & 39,5 & 45,5 & 133,5 & 197,0 & 222,0 & 39,5 & 52,0 & 140,0 & 184,5 & 222,0 \\
\hline $17 / 01 / 81$ & 46,0 & 52,0 & 140,0 & 197,0 & 216,0 & 33,0 & 52,0 & 146,0 & 190,0 & 215,0 \\
\hline $18 / 01 / 81$ & 77,0 & 102,5 & 152,5 & 197,0 & 216,0 & 71,0 & 83,5 & 146,0 & 190,0 & 215,0 \\
\hline $19 / 01 / 81$ & 90,0 & 127,5 & 152,5 & 197,0 & 216,0 & 83,0 & 108,5 & 146,0 & 190,0 & 215,0 \\
\hline $22 / 01 / 81$ & 39,5 & 52,0 & 140,0 & 197,0 & 215,0 & 39,5 & 52,0 & 133,5 & 197,0 & 222,0 \\
\hline $26 /$ & 33,0 & & 134,0 & 178,0 & 209,0 & 33,0 & 52,0 & 121,5 & 190,5 & 216,0 \\
\hline $28 / 0$ & 64,5 & 83,0 & 146,5 & 197,5 & 216,0 & 58,5 & 83,5 & 134,0 & 190,5 & 216,0 \\
\hline $30 / 01 / 81$ & 115,0 & 209,0 & 159,0 & 197,0 & 216,0 & 108,5 & 184,5 & 152,5 & 190,5 & 216,0 \\
\hline $31 / 01 / 81$ & 77,0 & 159,0 & 159,0 & 197,0 & 216,0 & 77,0 & 153,0 & 153,0 & 190,5 & 216,0 \\
\hline $01 / 02 / 81$ & 83,5 & 165,5 & 172,0 & 197,0 & 216,0 & & & 159,0 & 197,0 & 222,0 \\
\hline $02 / 0$ & 108,5 & 216,0 & 184,0 & 197,0 & 216,0 & 103,0 & 210,0 & 178,0 & 197,0 & 222,0 \\
\hline $03 / 0$ & 127,5 & 266,0 & 197,0 & 197,0 & 216,0 & 127,5 & 260,0 & 190,0 & 197,0 & 222,0 \\
\hline $04 / 02 / 81$ & 165,5 & 323,0 & 209,0 & 216,0 & 216,0 & 165,5 & 316,5 & 203,0 & 203,0 & 222,0 \\
\hline $05 / 02 / 81$ & 190,5 & 373,0 & 216,0 & 216,0 & 222,0 & 209,0 & 367,0 & 216,0 & 216,0 & 222,0 \\
\hline $06 / 02 / 81$ & 222,0 & 436,0 & 228,0 & 235,0 & 235,0 & 228,0 & 430,0 & 235,0 & 235,0 & 235,0 \\
\hline $10 / 02 / 81$ & 190,5 & 411,0 & 235,0 & 235,0 & 241,0 & 172,0 & 373,0 & 235,0 & 235,0 & 235,0 \\
\hline $12 / 02 / 81$ & 71,0 & 96,0 & 133,5 & 203,0 & 222,0 & 64,5 & 89,5 & 140,0 & 197,0 & 222,0 \\
\hline $13 / 02 / 81$ & 140,0 & 159,0 & 177,5 & 209,5 & 235,0 & 121,0 & 133,5 & 165,5 & 197,0 & 228,0 \\
\hline $14 / 02 / 81$ & 190,5 & 228,5 & 190,5 & 209,5 & 235,0 & 153,0 & 178,0 & 178,0 & 209,0 & 235,0 \\
\hline $15 / 02 / 81$ & 241,0 & 291,5 & 209,5 & 216,0 & 235,0 & 190,0 & 222,0 & 190,5 & 209,0 & 235,0 \\
\hline $16 / 02 / 81$ & 292,0 & 354,0 & 209,0 & 222,0 & 235,0 & 228,5 & 278,5 & 197,0 & 216,0 & 235,0 \\
\hline $17 / 02 / 81$ & 323,0 & 417,5 & 216,0 & 228,0 & 241,0 & 260,0 & 335,0 & 209,0 & 222,0 & 235,0 \\
\hline $18 / 02 / 81$ & 354,0 & 462,0 & 228,0 & 234,0 & 247,0 & 292,0 & 392,0 & 216,0 & 222,0 & 235,0 \\
\hline $19 / 02 / 81$ & 380,0 & 493,0 & 235,0 & 235,0 & 247,0 & 329,0 & 442,0 & 228,0 & 235,0 & 235,0 \\
\hline $21 / 02 / 81$ & 380,0 & 493,0 & 235,0 & 235,0 & 247,0 & 329,0 & 44,20 & 228,0 & 235,0 & 241,0 \\
\hline $22 / 02 / 81$ & 392,0 & 500,0 & 241,0 & 235,0 & 247,0 & 329,0 & 442,0 & 228,0 & 235,0 & 241,0 \\
\hline $23 / 02 / 81$ & 411,0 & 512,0 & 254,0 & 241,0 & 247,0 & 360,0 & 468,0 & 235,0 & 241,0 & 241,0 \\
\hline $24 / 02 / 81$ & 418,0 & 518,0 & 260,0 & 235,0 & 235,0 & 360,0 & 468,0 & 235,0 & 241,0 & 241,0 \\
\hline $25 / 02 / 81$ & 442,5 & 530,5 & 272,0 & 241,0 & 247,0 & 386,0 & 493,0 & 247,0 & 247,0 & 247,0 \\
\hline $26 / 32 / 81$ & 450,0 & 537,0 & 272,0 & 247,0 & 247,0 & 386,0 & 493,0 & 247,0 & 247,0 & 247,0 \\
\hline $27 / 02 / 81$ & 462,0 & 550,0 & 285,0 & 247,0 & 247,0 & 411,0 & 518,0 & 253,0 & 247,0 & 247,0 \\
\hline $28 / 02 / 81$ & 462,0 & 556,0 & 285,0 & 247,0 & 247,0 & 411,0 & 518,0 & 253,5 & 247,0 & 247,0 \\
\hline
\end{tabular}


APENDICE 8 - Valores de umidade do solo $\left(\theta \mathrm{cm}^{3} . \mathrm{cm}^{-3}\right)$, obtidos através das curvas de retenção de ãgua.

\begin{tabular}{|c|c|c|c|c|c|c|c|c|c|c|}
\hline \multirow{2}{*}{ Data } & \multicolumn{5}{|c|}{$\mathrm{T}_{1}$} & \multicolumn{5}{|c|}{$\mathrm{T}_{5}$} \\
\hline & $0-15$ & $15-30$ & $30-60$ & $60-90$ & $90-120$ & $0-15$ & $15-30$ & $30-60$ & $60-90$ & $90-120$ \\
\hline $05 / 11 / 80$ & 0,29 & 0,26 & 0,28 & 0,25 & 0,26 & 0,23 & 0,24 & 0,24 & 0,25 & 0,28 \\
\hline $06 / 11 / 80$ & 0,29 & 0,26 & 0,28 & 0,25 & 0,26 & 0,23 & 0,24 & 0,24 & 0,25 & 0,28 \\
\hline $08 / 11 / 80$ & 0,37 & 0,30 & 0,28 & 0,25 & 0,26 & 0,37 & 0,27 & 0,25 & 0,25 & 0,29 \\
\hline 10/11/80 & 0,41 & 0,36 & 0,28 & 0,25 & 0,27 & 0,39 & 0,31 & 0,25 & 0,25 & 0,29 \\
\hline $11 / 11 / 80$ & 0,37 & 0,35 & 0,28 & 0,26 & 0,27 & 0,36 & 0,31 & 0,25 & 0,25 & 0,29 \\
\hline $13 / 11 / 80$ & 0,33 & 0,35 & 0,28 & 0,26 & 0,27 & 0,32 & 0,31 & 0,25 & 0,25 & 0,29 \\
\hline $14 / 11 / 80$ & 0,31 & 0,30 & 0,28 & 0,26 & 0,27 & 0,26 & 0,26 & 0,25 & 0,25 & 0,29 \\
\hline $16 / 11 / 80$ & 0,29 & 0,27 & 0,28 & 0,26 & 0,27 & 0,24 & 0,25 & 0,25 & 0,25 & 0,29 \\
\hline $17 / 11 / 80$ & 0,29 & 0,26 & 0,28 & 0,25 & 0,27 & 0,23 & 0,25 & 0,25 & 0,25 & 0,29 \\
\hline $18 / 11 / 80$ & 0,29 & 0,26 & 0,28 & 0,25 & 0,27 & 0,23 & 0,24 & 0,25 & 0,25 & 0,29 \\
\hline $20 / 11 / 80^{\circ}$ & 0,35 & 0,27 & 0,28 & 0,25 & 0,27 & 0,31 & 0,26 & 0,25 & 0,25 & 0,29 \\
\hline $21 / 11 / 80$ & 0,37 & 0,36 & 0,28 & 0,25 & 0,27 & 0,36 & 0,30 & 0,25 & 0,25 & 0,29 \\
\hline $26 / 11 / 80$ & 0,30 & 0,28 & 0,28 & 0,25 & 0,27 & 0,25 & 0,25 & 0,25 & 0,25 & 0,28 \\
\hline $27 / 11 / 80$ & 0,29 & 0,27 & 0,28 & 0,25 & 0,27 & 0,24 & 0,28 & 0,25 & 0,25 & 0,28 \\
\hline $28 / 11 / 80$ & 0,29 & 0,26 & 0,28 & 0,25 & 0,26 & 0,24 & 0,25 & 0,25 & 0,25 & 0,28 \\
\hline $29 / 11 / 80$ & 0,29 & 0,26 & 0,28 & 0,25 & 0,26 & 0,23 & 0,25 & 0,24 & 0,25 & 0,28 \\
\hline $03 / 12 / 80$ & 0,37 & 0,35 & 0,29 & 0,26 & 0,27 & 0,39 & 0,31 & 0,25 & 0,25 & 0,28 \\
\hline $06 / 12 / 80$ & 0,39 & 0,38 & 0,28 & 0,26 & 0,27 & 0,37 & 0,33 & 0,25 & 0,25 & 0,28 \\
\hline $07 / 12 / 80$ & 0,34 & 0,30 & 0,28 & 0,26 & 0,27 & 0,31 & 0,27 & 0,25 & 0,25 & 0,28 \\
\hline $08 / 12 / 80$ & 0,35 & 0,30 & 0,28 & 0,26 & 0,27 & 0,31 & 0,27 & 0,25 & 0,25 & 0,28 \\
\hline $09 / 12 / 80$ & 0,33 & 0,29 & 0,28 & 0,26 & 0,27 & 0,29 & 0,27 & 0,25 & 0,25 & 0,28 \\
\hline $11 / 12 / 80$ & 0,32 & 0,27 & 0,28 & 0,25 & 0,26 & 0,28 & 0,26 & 0,25 & 0,25 & 0,28 \\
\hline $14 / 12 / 80$ & 0,35 & 0,33 & 0,28 & 0,25 & 0,26 & 0,33 & 0,28 & 0,25 & 0,25 & 0,28 \\
\hline $15 / 12 / 80$ & 0,34 & 0,28 & 0,25 & 0,25 & 0,27 & 0,31 & 0,26 & 0,25 & 0,25 & 0,28 \\
\hline $16 / 12 / 80$ & 0,33 & 0,27 & 0,28 & 0,25 & 0,27 & 0,30 & 0,26 & 0,25 & 0,25 & 0,28 \\
\hline $17 / 12 / 80$ & 0,32 & 0,27 & 0,28 & 0,25 & 0,27 & 0,28 & 0,25 & 0,25 & 0,25 & 0,28 \\
\hline $18 / 11 / 80$ & 0,31 & 0,26 & 0,28 & 0,25 & 0,26 & 0,25 & 0,25 & 0,25 & 0,25 & 0,28 \\
\hline $19 / 12 / 80$ & 0,30 & 0,26 & 0,28 & 0,25 & 0,26 & 0,25 & 0,25 & $.0,25$ & 0,25 & 0,28 \\
\hline $20 / 12 / 80$ & 0,30 & 0,26 & 0,28 & 0,25 & 0,26 & 0,25 & 0,24 & 0,25 & 0,25 & 0,28 \\
\hline $21 / 12 / 80$ & 0,30 & 0,26 & 0,28 & 0,25 & 0,26 & 0,25 & 0,24 & 0,25 & 0,25 & 0,28 \\
\hline $22 / 12 / 80$ & 0,30 & 0,26 & 0,28 & 0,25 & 0,26 & 0,24 & 0,24 & 0,24 & 0,25 & 0,28 \\
\hline $23 / 12 / 80$ & 0,30 & 0,26 & 0,28 & 0,25 & 0,26 & 0,24 & 0,24 & 0,25 & 0,25 & 0,28 \\
\hline $27 / 12 / 80$ & 0,30 & 0,26 & 0,28 & 0,25 & 0,26 & 0,26 & 0,25 & 0,25 & 0,25 & 0,28 \\
\hline $31 / 12 / 80$ & 0,35 & 0,30 & 0,28 & 0,25 & 0,26 & 0,33 & 0,30 & 0,25 & 0,25 & 0,28 \\
\hline
\end{tabular}


APENDICE 8. - continuação.

\begin{tabular}{|c|c|c|c|c|c|c|c|c|c|c|}
\hline \multirow{2}{*}{ Data } & \multicolumn{5}{|c|}{$\mathrm{T}_{1}$} & \multicolumn{5}{|c|}{$\mathrm{T}_{5}$} \\
\hline & $0-15$ & $15-30$ & $30-60$ & $60-90$ & $90-120$ & $0-15$ & $15-30$ & $30-60$ & $60-90$ & $90-120$ \\
\hline $02 / 01 / 81$ & 0,33 & 0,27 & 0,28 & 0,25 & 0,26 & 0,28 & 0,25 & 0,25 & 0,25 & 0,28 \\
\hline $05 / 01 / 81$ & 0,30 & 0,26 & 0,28 & 0,25 & 0,26 & 0,25 & 0,25 & 0,25 & 0,25 & 0,28 \\
\hline $06 / 01 / 81$ & 0,30 & 0,26 & 0,28 & 0,25 & 0,26 & 0,25 & 0,25 & 0,25 & 0,25 & 0,28 \\
\hline $07 / 01 / 81$ & 0,29 & 0,26 & 0,28 & 0,25 & 0,26 & 0,24 & 0,25 & 0,25 & 0,25 & 0,28 \\
\hline $13 / 01 / 81$ & 0,41 & 0,38 & 0,29 & 0,26 & 0,27 & 0,39 & 0,36 & 0,26 & 0,25 & 0,29 \\
\hline $16 / 01 / 81$ & 0,39 & 0,38 & 0,29 & 0,26 & 0,27 & 0,37 & 0,33 & 0,26 & 0,25 & 0,29 \\
\hline $17 / 01 / 81$ & 0,37 & 0,38 & 0,29 & 0,26 & 0,27 & 0,39 & 0,33 & 0,26 & 0,25 & 0,29 \\
\hline $18 / 01 / 81$ & 0,34 & 0,30 & 0,29 & 0,26 & 0,27 & 0,32 & 0,28 & 0,26 & 0,25 & 0,29 \\
\hline $19 / 01 / 81$ & 0,34 & 0,28 & 0,29 & 0,26 & 0,27 & 0,31 & 0,27 & 0,26 & 0,25 & 0,29 \\
\hline $22 / 01 / 81$ & 0,39 & 0,38 & 0,29 & 0,26 & 0,27 & 0,37 & 0,33 & 0,27 & 0,25 & 0,29 \\
\hline $26 / 01 / 81$ & 0,41 & 0,38 & 0,30 & 0,26 & 0,27 & 0,39 & 0,33 & 0,27 & 0,25 & 0,29 \\
\hline $28 / 01 / 81$ & 0,35 & 0,33 & 0,29 & 0,26 & 0,27 & 0,33 & 0,28 & 0,27 & 0,25 & 0,29 \\
\hline $30 / 01 / 81$ & 0,33 & 0,27 & 0,29 & 0,26 & 0,27 & 0,29 & 0,26 & 0,26 & 0,25 & 0,29 \\
\hline $31 / 01 / 81$ & 0,34 & 0,27 & 0,29 & 0,26 & 0,27 & 0,31 & 0,26 & 0,26 & 0,25 & 0,29 . \\
\hline $01 / 02 / 81$ & 0,34 & 0,27 & 0,29 & 0,26 & 0,27 & 0,31 & 0,26 & 0,26 . & 0,25 & 0,29 \\
\hline $02 / 02 / 81$ & 0,33 & 0,27 & 0,29 & 0,26 & 0,27 & 0,30 & 0,25 & 0,26 & 0,25 & 0,29 \\
\hline $03 / 02 / 81$ & 0,32 & 0,26 & 0,28 & 0,26 & 0,27 & 0,28 & 0,25 & 0,25 & 0,25 & 0,29 \\
\hline $04 / 02 / 81$ & 0,31 & 0,26 & 0,28 & 0,26 & 0,27 & 0,26 & 0,25 & 0,25 & 0,25 & 0,29 \\
\hline $05 / 02 / 81$ & 0,31 & 0,26 & 0,28 & 0,26 & 0,27 & 0,25 & 0,25 & $0,2 j$ & 0,25 & 0,29 \\
\hline $06 / 02 / 81$ & 0,30 & 0,26 & 0,28 & 0,25 & 0,26 & 0,25 & 0,24 & 0,25 & 0,25 & 0,28 \\
\hline $10 / 02 / 81$ & 0,31 & 0,26 & 0,28 & 0,25 & 0,26 & 0,26 & 0,25 & 0,25 & 0,25 & 0,28 \\
\hline $12 / 02 / 81$ & 0,35 & 0,30 & 0,30 & 0,26 & 0,27 & 0,33 & 0,28 & 0,26 & 0,25 & 0,29 \\
\hline $13 / 02 / 81$ & 0,32 & 0,27 & 0,29 & 0,26 & 0,27 & 0,29 & 0,26 & 0,26 & 0,25 & 0,29 \\
\hline $14 / 02 / 81$ & 0,31 & 0,27 & 0,28 & 0,26 & 0,27 & 0,25 & 0,26 & 0,26 & 0,25 & 0,28 \\
\hline $15 / 02 / 81$ & 0,30 & 0,27 & 0,28 & 0,26 & 0,27 & 0,26 & 0,25 & 0,25 & 0,25 & 0,28 \\
\hline $16 / 02 / 81$ & 0,29 & 0,26 & 0,28 & 0,26 & 0,27 & 0,25 & 0,25 & 0,25 & 0,25 & 0,28 \\
\hline $17 / 02 / 81$ & 0,29 & 0,26 & 0,28 & 0,26 & 0,26 & 0,24 & 0,25 & 0,25 & 0,25 & 0,28 \\
\hline $18 / 02 / 81$ & 0,29 & 0,26 & 0,28 & 0,26 & 0,26 & 0,24 & 0,25 & 0,25 & 0,25 & 0,28 \\
\hline $19 / 02 / 81$ & 0,29 & 0,26 & 0,28 & 0,26 & 0,26 & 0,24 & 0,24 & 0,25 & 0,25 & 0,28 \\
\hline $21 / 02 / 81$ & 0,29 & 0,26 & 0,28 & 0,26 & 0,26 & 0,24 & 0,24 & 0,25 & 0,25 & 0,28 \\
\hline $22 / 02 / 81$ & 0,29 & 0,26 & 0,28 & 0,26 & 0,26 & 0,24 & 0,24 & 0,25 & 0,25 & 0,28 \\
\hline $23 / 02 / 81$ & 0,29 & 0,26 & 0,28 & 0,25 & 0,26 & 0,24 & 0,24 & 0,25 & 0,25 & 0,28 \\
\hline $24 / 02 / 81$ & 0,29 & 0,26 & 0,28 & 0,25 & 0,26 & 0,24 & 0,24 & 0,25 & 0,25 & 0,28 \\
\hline $25 / 02 / 81$ & 0,29 & 0,26 & 0,28 & 0,25 & 0,26 & 0,24 & 0,24 & 0,25 & 0,25 & 0,28 \\
\hline $26 / 02 / 81$ & 0,29 & 0,26 & 0,28 & 0,25 & 0,26 & 0,24 & 0,24 & 0,25 & 0,25 & 0,28 \\
\hline $27 / 02 / 81$ & 0,29 & 0,26 & 0,28 & 0,25 & 0,25 & 0,24 & 0,24 & 0,25 & 0,25 & 0,28 \\
\hline $28 / 02 / 81$ & 0,29 & 0,26 & 0,28 & 0,25 & 0,26 & 0,24 & 0,24 & 0,25 & 0,25 & 0,28 \\
\hline
\end{tabular}


APENDICE 9 - Armazenamento de água no solo em milímetros.

\begin{tabular}{|c|c|c|c|c|c|c|c|c|c|c|c|c|}
\hline \multirow{2}{*}{ Data } & \multicolumn{6}{|c|}{$\mathrm{T}_{1}$} & \multicolumn{6}{|c|}{$\mathrm{T}_{5}$} \\
\hline & $0-15$ & $15-30$ & $30-60$ & $60-90$ & $90-120$ & $0-120$ & $0-15$ & $15-30$ & $30-60$ & $60-90$ & $90-120$ & $(2-120$ \\
\hline $05 / 11 / 80$ & 43,5 & 39,0 & 84,0 & 75,0 & 78,0 & 319,5 & 34,5 & 36,0 & 72,0 & 75,0 & 84,0 & 301,5 \\
\hline $06 / 11 / 80$ & 43,5 & 39,0 & 84,0 & 75,0 & 78,0 & 319,5 & 34,5 & 36,0 & 72,0 & 75,0 & 84,0 & 301,5 \\
\hline $08 / 11 / 80$ & 55,5 & 45,0 & 84,0 & 75,0 & 78,0 & 337,5 & 55,5 & 40,5 & 75,0 & 75,0 & 87,0 & 333,0 \\
\hline $10 / 11 / 80$ & 61,5 & 54,0 & 84,0 & 75,0 & 81,0 & 355,5 & 58,5 & 46,5 & 75,0 & 75,0 & 87,0 & 342,0 \\
\hline $12 / 11 / 80$ & 55,5 & 52,5 & 84,0 & 78,0 & 81,0 & 351,0 & 54,0 & 46,5 & 75,0 & 75,0 & 87,0 & 337,5 \\
\hline $13 / 11 / 80$ & 49,5 & 52,5 & 84,0 & 78,0 & 81,0 & 345,0 & 48,0 & 46,5 & 75,0 & 75,0 & 87,0 & 331,5 \\
\hline $14 / 11 / 80$ & 46,5 & 45,0 & 84,0 & 78,0 & 81,0 & 334,5 & 39,0 & 39,0 & 75,0 & 75,0 & 87,0 & 315,0 \\
\hline $16 / 11 / 80$ & 43,5 & 405 & 84,0 & 78,0 & 81,0 & 327,0 & 36,0 & 37,5 & 75,0 & 75,0 & 87,0 & 310,5 \\
\hline $17 / 11 / 80$ & 43,5 & 39,0 & 84,0 & 75,0 & 81,0 & 322,5 & 34,5 & 37,5 & 75,0 & 75,0 & 87,0 & 309,0 \\
\hline $18 / 11 / 80$ & 43,5 & 39,0 & 84,0 & 75,0 & 81,0 & 322,5 & 34,5 & 36,0 & 75,0 & 75,0 & 87,0 & 307,5 \\
\hline $20 / 11 / 80$ & 52,5 & 40,5 & 84,0 & 75,0 & 81,0 & 333,0 & 46,5 & 39,0 & 75,0 & 75,0 & 87,0 & 322,5 \\
\hline $21 / 11 / 80$ & 55,5 & 54,0 & 84,0 & 75,0 & 81,0 & & 54,0 & 45,0 & 75,0 & 75,0 & 87,0 & 336,0 \\
\hline $26 / 11 / 80$ & 45,0 & 42,0 & 84,0 & 75,0 & 81,0 & 327,0 & 37,5 & 37,5 & 75,0 & 75,0 & 84,0 & 309,0 \\
\hline $27 / 11 / 80$ & 43,5 & 40,5 & 84,0 & 75,0 & 81,0 & 324,0 & 36,0 & 42,0 & 75,0 & 75,0 & 84,0 & 312,0 \\
\hline $28 / 11 / 80$ & 43,5 & 39,0 & 84,0 & 75,0 & 78,0 & 319,5 & 36,0 & 3,75 & 75,0 & 75,0 & 84,0 & 307,5 \\
\hline $29 / 11 / 80$ & 43,5 & 39,0 & 84,0 & 75,0 & 78,0 & 319,5 & 34,5 & 37,5 & 72,0 & 75,0 & 84,0 & 303,0 \\
\hline $03 / 12 / 80$ & 55,5 & 52,5 & 87,0 & 78,0 & 81,0 & 354,0 & 58,5 & 45,5 & 75,0 & 75,0 & 84,0 & 339,0 \\
\hline $06 / 12 / 80$ & 58,5 & 57,0 & 84,0 & 78,0 & 81,0 & 358,5 & 55,5 & 4,95 & 75,0 & 75,0 & 84,0 & 339,0 \\
\hline $07 / 12 / 80$ & 51,0 & 45,0 & 84,0 & 78,0 & 81,0 & 339,0 & 46,5 & 40,5 & 75,0 & 75,0 & 84,0 & 321,0 \\
\hline $08 / 12 / 80$ & 52,5 & 45,0 & 84,0 & 78,0 & 81,0 & 340,5 & 46,5 & 40,5 & 75,0 & 75,0 & 84,0 & 321,0 \\
\hline $09 / 12 / 80$ & 4,95 & 43,5 & 84,0 & 78,0 & 81,0 & 336,0 & 43,5 & 40,5 & 75,0 & 75,0 & 84,0 & 318,0 \\
\hline $11 / 12 / 80$ & 48,0 & 40,5 & 84,0 & 75,0 & 78,0 & 325,5 & 42,0 & 39,0 & 75,0 & 75,0 & 84,0 & 315,0 \\
\hline $14 / 12 / 80$ & 5,25 & 49,5 & 84,0 & 75,0 & 78,0 & 339,0 & 49,5 & 42,0 & 75,0 & 75,0 & 84,0 & 325,5 \\
\hline $15 / 12 / 80$ & 51,0 & 42,0 & 84,0 & 75,0 & 81,0 & 333,0 & 46,5 & 39,0 & 75,0 & 75,0 & 84,0 & 319,5 \\
\hline $16 / 12 / 80$ & 49,5 & 40,5 & 84,0 & 75,0 & 81,0 & 330,0 & 45,0 & 39,0 & 75,0 & 75,0 & 84,0 & 318,0 \\
\hline $17 / 12 / 80$ & 48,0 & 40,5 & 84,0 & 75,0 & 81,0 & 328,5 & 42,0 & 37,5 & 75,0 & 75,0 & 84,0 & 313,5 \\
\hline $18 / 12 / 80$ & 46,5 & 39,0 & 84,0 & 75,0 & 78,0 & 322,5 & 37,5 & 37,5 & 75,0 & 75,0 & 84,0 & 309,0 \\
\hline $19 / 12 / 80$ & 45,0 & 39,0 & 84,0 & 75,0 & 78,0 & 321,0 & 37,5 & 37,5 & 75,0 & 75,0 & 84,0 & 309,0 \\
\hline $20 / 12 / 80$ & 45,0 & 39,0 & 84,0 & 75,0 & 78,0 & 321,0 & 37,5 & 36,0 & 75,0 & 75,0 & 84,0 & 307,5 \\
\hline $21 / 12 / 80$ & 45,0 & 39,0 & 84,0 & 75,0 & 78,0 & 321,0 & 37,5 & 36,0 & 75,0 & 75,0 & 84,0 & 307,5 \\
\hline $22 / 12 / 80$ & 45,0 & 39,0 & 84,0 & 75,0 & 78,0 & 321,0 & 36,0 & 36,0 & 75,0 & 75,0 & 84,0 & 305,0 \\
\hline $23 / 12 / 80$ & 45,0 & 39,0 & 84,0 & 75,0 & 78,0 & 321,0 & 36,0 & 36,0 & 75,0 & 75,0 & 84,0 & 305,0 \\
\hline $27 / 12 / 80$ & 45,0 & 39,0 & 84,0 & 75,0 & 78,0 & 321,0 & 39,0 & $37, j$ & 75,0 & 75,0 & 84,0 & 310,5 \\
\hline $31 / 12 / 80$ & 52,5 & 45,0 & 84,0 & $75, C$ & 78,0 & 334,5 & 49,5 & 45,0 & 75,0 & 75,0 & 84,0 & 328,5 \\
\hline
\end{tabular}


APENDICE 9 - continuação.

\begin{tabular}{|c|c|c|c|c|c|c|c|c|c|c|c|c|}
\hline \multirow{2}{*}{ Data } & \multicolumn{6}{|c|}{$\mathrm{T}_{1}$} & \multicolumn{6}{|c|}{$\mathrm{T}_{5}$} \\
\hline & $0-15$ & $15-30$ & $30-60$ & $60-90$ & $90-120$ & $0-120$ & $0-15$ & $15-30$ & $30-60$ & $60-90$ & 9()$-1: 0$ & $0-120$ \\
\hline $02 / 01 / 81$ & 49,5 & 40,5 & 84,0 & 75,0 & 78,0 & 327,0 & 42,0 & 37,5 & 75,0 & 75,0 & 84,0 & 313,5 \\
\hline $05 / 01 / 81$ & 45,0 & 39,0 & 84,0 & 75,0 & 78,0 & 321,0 & 37,5 & 37,5 & 75,0 & 75,0 & 85,0 & 309,0 \\
\hline $06 / 01 / 81$ & 45,0 & 39,0 & 84,0 & 75,0 & 78,0 & 321,0 & 37,5 & 37,5 & 75,0 & 75,0 & 84,0 & 309,0 \\
\hline $07 / 01 / 81$ & 43,5 & 39,0 & 84,0 & 75,0 & 78,0 & 319,5 & 36,0 & 37,5 & 75,0 & 75,0 & 84,0 & 307,5 \\
\hline $13 / 01 / 81$ & 61,5 & 57,0 & 87,0 & 78,0 & 81,0 & 364,5 & 58,5 & 54,0 & 78,0 & 75,0 & 87,0 & 352,5 \\
\hline $16 / 01 / 81$ & 58,5 & 57,0 & 87,0 & 78,0 & 81,0 & 361,5 & 55,5 & 49,5 & 78,0 & 75,0 & 87,0 & 345,0 \\
\hline $17 / 01 / 81$ & 55,5 & 57,0 & 87,0 & 78,0 & 81,0 & 358,5 & 58,5 & 49,5 & 78,0 & 75,0 & 37,0 & 348,0 \\
\hline $18 / 01 / 81$ & 51,0 & 45,0 & 87,0 & 78,0 & 81,0 & 342,0 & 48,0 & 42,0 & 78,0 & 75,0 & 87,0 & 330,0 \\
\hline $19 / 01 / 81$ & 51,0 & 42,0 & 87,0 & 78,0 & 81,0 & 339,0 & 46,5 & 40,5 & 78,0 & 75,0 & 87,0 & 327,0 \\
\hline $22 / 01 / 81$ & 58,5 & 57,0 & 87,0 & 78,0 & 81,0 & 361,5 & 55,5 & 49,5 & 81,0 & 75,0 & 87,0 & 348,0 \\
\hline $26 / 01 / 81$ & 61,5 & 57,0 & 90,0 & 78,0 & 81,0 & 367,5 & 58,5 & 49,5 & 81,0 & 75,0 & 87,0 & 351,0 \\
\hline 28/01/81. & 52,5 & 49,5 & 87,0 & 78,0 & 81,0 & 348,0 & 49,5 & 42,0 & 81,0 & 75,0 & 87,0 & 334,5 \\
\hline $30 / 01 / 81$ & 49,5 & 40,5 & 87,0 & 78,0 & 81,0 & 336,0 & 43,5 & 39,0 & 78,0 & 75,0 & 87,0 & 322,5 \\
\hline $31 / 01 / 81$ & 51,0 & 40,5 & 87,0 & 78,0 & 81,0 & 337,5 & 46,5 & 39,0 & 78,0 & 75,0 & 87,0 & 325,5 \\
\hline $01 / 02 / 81$ & 51,0 & 40,5 & 87,0 & 78,0 & 81,0 & 337,5 & 46,5 & 39,0 & 78,0 & 75,0 & 87,0 & 325,5 \\
\hline $02 / 02 / 81$ & 49,5 & 40,5 & 87,0 & 78,0 & 81,0 & 336,0 & 45,0 & 37,5 & 78,0 & 75,0 & 87,0 & 322,5 \\
\hline $03 / 02 / 81$ & 48,0 & 39,0 & 84,0 & 78,0 & 81,0 & 330,0 & 42,0 & 37,5 & 75,0 & 75,0 & 87,0 & 316,5 \\
\hline $04 / 02 / 81$ & 46,5 & 39,0 & 84,0 & 78,0 & 81,0 & 328,5 & 39,0 & 37,5 & 75,0 & 75,0 & 87,0 & 313,5 \\
\hline $05 / 0$ & 46,5 & 39,0 & 84,0 & 78,0 & 81,0 & 328,5 & 37,5 & 37,5 & 75,0 & 0 & 87,0 & 312,0 \\
\hline $06 / 02 / 81$ & 45,0 & 39,0 & 84,0 & 75,0 & 78,0 & 321,0 & 37,5 & 36,0 & 75,0 & 75,0 & 84,0 & 307,5 \\
\hline $10 / 02 / 81$ & 46,5 & 39,0 & 84,0 & 75,0 & 78,0 & 322,5 & 39,0 & 37,5 & 75,0 & 75,0 & 84,0 & 310,5 \\
\hline $12 / 02 / 81$ & 52,5 & 45,0 & 90,0 & 78,0 & 81,0 & 346,5 & 49,5 & 42,0 & 78,0 & 75,0 & 87,0 & 331,5 \\
\hline $13 / 02 / 81$ & 48,0 & 40,5 & 87,0 & 78,0 & 81,0 & 334,5 & 43,5 & 39,0 & 78,0 & 75,0 & 87,0 & 322,5 \\
\hline $14 / 02 / 81$ & 46,5 & 40,5 & 84,0 & 78,0 & 81,0 & 330,0 & 37,5 & 39,0 & 78,0 & 75,0 & 84,0 & 313,5 \\
\hline $15 / 0$ & & 40,5 & 84,0 & 78,0 & 81,0 & 328,5 & & 37,5 & 75,0 & & 84,0 & 310,5 \\
\hline $16 / 02 / 81$ & 43,5 & 39,0 & 84,0 & 78,0 & $81,0=$ & 325,5 & 37,5 & 37,5 & 75,0 & 75.0 & 84,0 & 309,0 \\
\hline $17 / 02 / 81$ & 43,5 & 39,0 & 84,0 & 78,0 & 78,0 & 322,5 & 36,0 & 37,5 & 75,0 & 75,0 & 84,0 & 307,5 \\
\hline $18 / 02 / 81$ & 43,5 & 39,0 & 84,0 & 78,0 & 78,0 & 322,5 & 36,0 & 37,5 & 75,0 & & 84,0 & 307,5 \\
\hline $19 / 02 / 81$ & 43,5 & 39,0 & 84,0 & 78,0 & 78,0 & 322,5 & 36,0 & 36,0 & 75,0 & 75,0 & 84,0 & 306,0 \\
\hline $21 / 02 / 81$ & 43,5 & 39,0 & 84,0 & 78,0 & 78,0 & 322,5 & 36,0 & 36,0 & 75,0 & 75,0 & 84,0 & 306,0 \\
\hline $22 / 02 / 81$ & 43,5 & 39,0 & 84,0 & 78,0 & 78,0 & 322,5 & 36,0 & 36,0 & 75,0 & 75,0 & 84,0 & 306, 0 \\
\hline $23 / 02 / 81$ & 43,5 & 39,0 & 84,0 & 75,0 & 78,0 & 319,5 & 36,0 & 36,0 & 75,0 & 75,0 & 84,0 & 306,0 \\
\hline $24 / 02 / 81$ & 43,5 & 39,0 & 84,0 & 75,0 & 78,0 & 319,5 & 36,0 & 36,0 & 75,0 & & 84,0 & 306,0 \\
\hline $25 / 02 / 81$ & 43 & 39,0 & 84,0 & 75,0 & 78,0 & 319,5 & 36 & 36,0 & 75,0 & & 84,0 & 306,0 \\
\hline $26 / 02 / 81$ & 43,5 & 39,0 & 84,0 & 75,0 & 78,0 & 319,5 & 36,0 & 36,0 & 75,0 & 75,0 & 84,0 & 306,0 \\
\hline $27 / 62 / 81$ & 43,5 & 39,0 & 84,0 & 75,0 & 78,0 & 319,5 & 36,0 & 36,0 & 75,0 & 75,0 & 84,0 & 306,0 \\
\hline $28 / 02 / 81$ & 43,5 & 39,0 & 84,0 & $75 ; 0$ & 78,0 & 319,5 & 36,0 & 36,0 & 75,0 & 75,0 & 84,0 & 306,0 \\
\hline
\end{tabular}


97

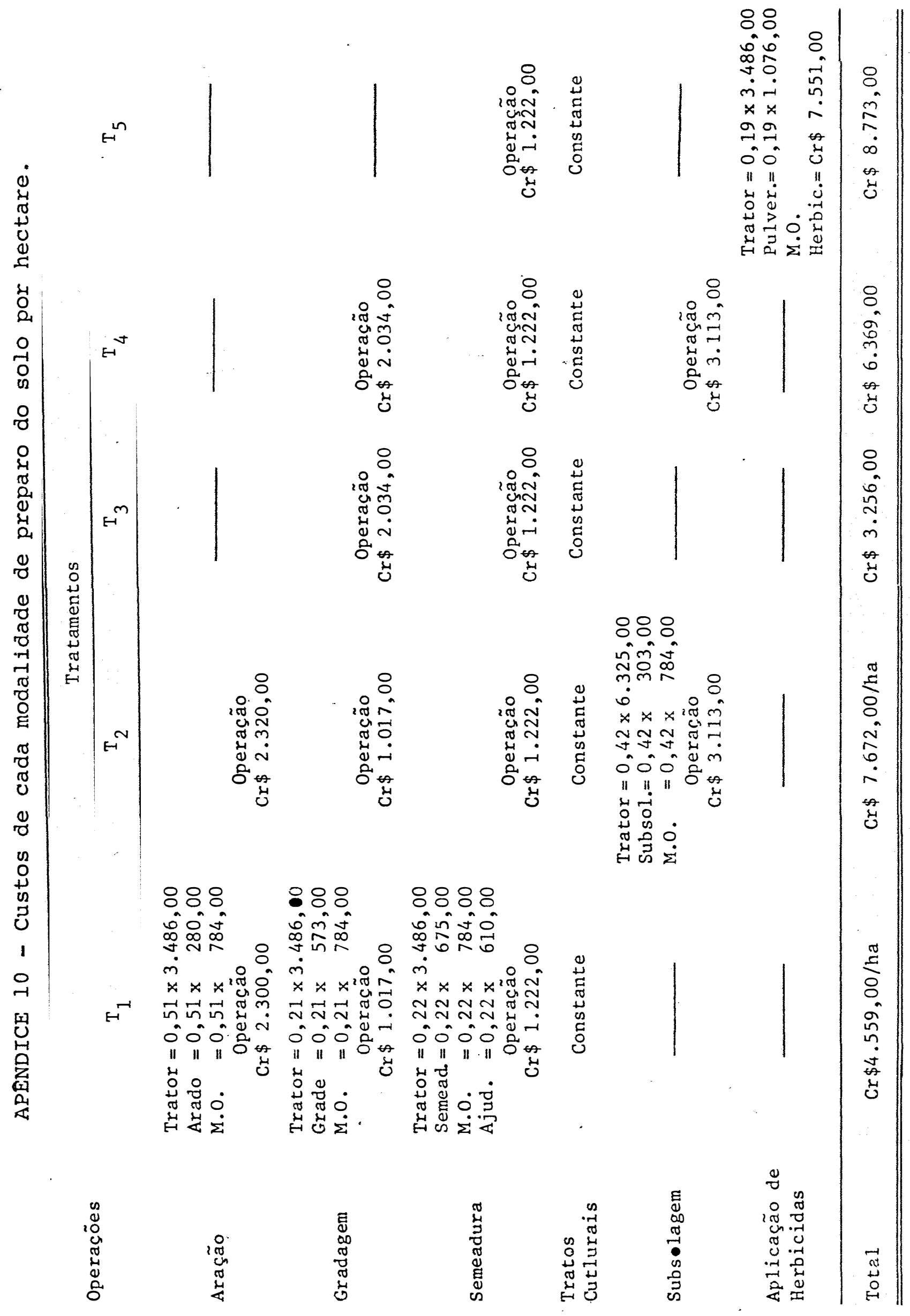

